University of Nebraska - Lincoln

DigitalCommons@University of Nebraska - Lincoln

Papers from the University Studies series (The University of Nebraska)

$6-1972$

\title{
Experiment at Nebraska The First Two Years of a Cluster College
}

Robert E. Knoll

University of Nebraska - Lincoln

Robert D. Brown

University of Nebraska - Lincoln

Follow this and additional works at: https://digitalcommons.unl.edu/univstudiespapers

Part of the Arts and Humanities Commons

Knoll, Robert E. and Brown, Robert D., "Experiment at Nebraska The First Two Years of a Cluster College" (1972). Papers from the University Studies series (The University of Nebraska). 57.

https://digitalcommons.unl.edu/univstudiespapers/57

This Article is brought to you for free and open access by the University Studies of the University of Nebraska at DigitalCommons@University of Nebraska - Lincoln. It has been accepted for inclusion in Papers from the University Studies series (The University of Nebraska) by an authorized administrator of DigitalCommons@University of Nebraska - Lincoln. 


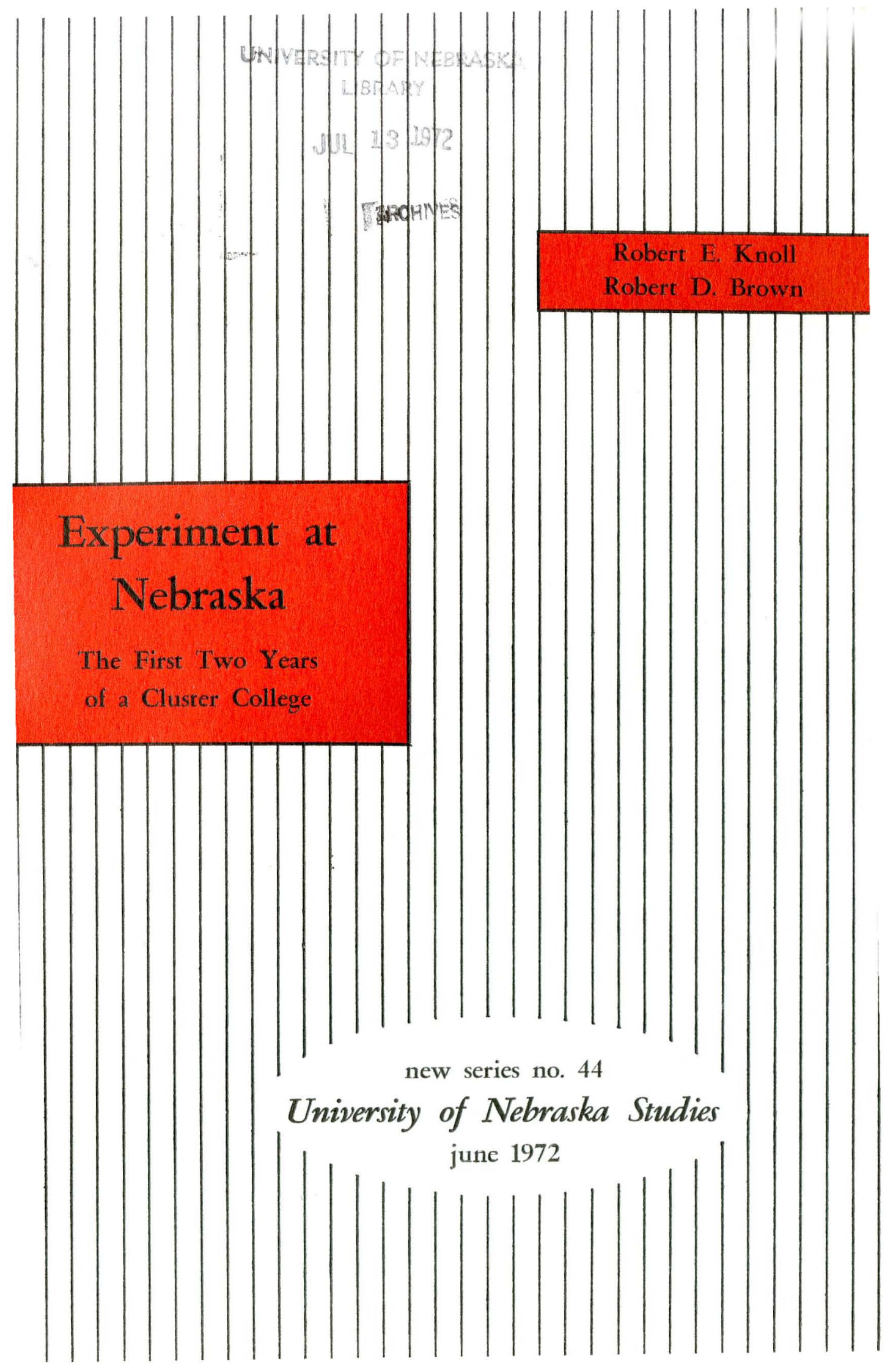




\title{
EXPERIMENT AT NEBRASKA
}

\author{
The First Two Years \\ of a Cluster College
}


Copyright (C) 1972 by the University of Nebraska - Lincoln Library of Congress Catalog Card Number 72-619556 
Robert E. Knoll

Robert D. Brown

\title{
Experiment at Nebraska
}

\author{
The First Two Years \\ of a Cluster College
}

university of nebraska studies : new series no. 44

publisbed by the university

at lincoln : june 1972 


\section{The University of Nebraska}

The Board of Regents

J. G. Elliott

EdWARd SchWARTZKoPf,

Kermit R. Hansen

chairman

ROBERT R. KOEFOOT, M.D.

JAMES H. MOYLAN

Robert J. Prokop, M.D., Ph.D.

Robert L. Raun

KERMit WAGNER

\section{The President}

D. B. VARNER

The Cbancellor, University of Nebraska-Lincoln

James H. Zumberge 


\section{Contents}

Preface By Robert E. Knoll

II. The Preliminary Planning ................................................ 20

By Robert E. Knoll

III. The First Year, 1969-1970 ............................................ 33

By Robert E. Knoll

IV. Student Development: A First Year Look

52

By Robert D. Brown

V. The Second Year, 1970-1971

70

By Robert E. Knoll

VI. Student Development: A Second Year Review.

97 By Robert D. Brown

VII. Warnings, Encouragements, Recommendations 120 By Robert E. Knoll and Robert D. Brown

Appendix

125 


\section{Preface}

$\mathrm{W}$ HEN IN 1966 we planned celebrations for the University of Nebraska's centennial year of 1969 , we looked at the future not the past. We asked, Where next should we build? In what ways can we anticipate the future, and harness it? We did not then feel the full pressure of events at Berkeley, Columbia, Wisconsin, and Kent State; but as the decade wore on, the timeliness of our questions became obvious.

After providing for a history of the University and an assessment of the economic status of the Plains, the Centennial Committee began reexamining the general goals of higher education in America. We were aware that the academic patterns of undergraduate life on our own campus had not been reconstituted in total for better than a generation, not since our enrollment was 6,000 . It was now nearly 20,000 . In order to experiment with educational ventures, we concluded that the University might profitably consider alternatives to the present system. In a new, small college educational schemes might be tried out for the general edification of the total University. And so we recommended that the Chancellor appoint a committee charged with studying the feasibility of an innovating college. This Centennial College Committee, made up of representatives from many areas and including students as well as faculty, deliberated for months. In the fall, 1968, it proposed that an undergraduate residential college be established. This was not to be degree granting; it was to be in only marginal competition with what already existed. Rather it was to operate within the existing framework of the University. We had settled upon a form that is nowadays referred to as a "Cluster College," "a semi-autonomous school on the campus of 


\section{2 / First Years of a Cluster College}

a larger institution which shares, to a significant extent, facilities and services with the other schools." 1

The Centennial College Committee sent its general recommendations to the Chancellor and the Board of Regents, and after minor but significant modifications, the Board directed us to proceed. From January until September 1969 a "Working Committee" consisting of a dozen faculty and students, all of whom were to be directly involved in the new curriculum once it got under way, prepared detailed schemes for what was now called the Centennial Educational Program. It happens that under Nebraska law the state legislature alone can establish colleges; and neither the University administration nor the Committee was prepared to commit us so finally as a state law seemed to indicate. In September 1969 the Centennial Educational Program admitted its first students, 125 freshmen and 40 upperclassmen. In the year that followed, our plans, so carefully worked out in advance, were constantly modified. We responded to the pressures of the time and place. 1969-1971 may have been quieter at the University of Nebraska than at some universities-the Plains has the stable virtues of its conservative limitations-but it too participated in the international ferment of the decade.

This report is an account of what we set out to do in our "cluster college" and what we accomplished in our first two years. Since no experiment by definition is without its failures, we report them, but generally this venture appears to have had considerable success. Others on other campuses may find useful a description of how it evolved, for our experience is not likely to be unique; and others should be able to learn from our mistakes. I have tried to check the judgments in my section of this history with my students and faculty colleagues, but finally $I$ am alone responsible for them. This document must be, at last, rather personal. The sections under Dr. Brown's name are similarly his; and the last section contains our joint conclusions. Dr. Brown judges as a psychologist, $I$ as a professor of English. The Centennial Educational Program is continuing beyond these first years of course; and we can hope that there can be further reports of its growth and change during successive years.

R. E. K.

${ }^{1}$ Jerry G. Gaff and Associates, The Cluster College (San Francisco: JosseyBass, Inc., 1970), p. 3. 


\section{How We Got Started}

By Robert E. Knoll

I

N November 1968 the Board of Regents of the University of

Nebraska was asked to react to a document coming from a

faculty-student committee charged with examining the feasibility of establishing an innovating college on the Lincoln campus. It attempted to spell out the need for such innovation, and it offered a plan for fulfilling the need that it delineated. This is that document:

Within the past generation a new kind of student, a new kind of faculty, and a new kind of university have developed. To meet the challenges which these changes present and to provide for an educational and national future whose nature is unforseeable, many persons have concluded that there is a need for experiments in university curriculum and organization. The purpose of such endeavors should be a graduate who is sharply aware of himself, his society, and his world, able and desirous of continuing his liberal and professional education beyond the classroom.

The New Students

Students who come to the University are different from those who came twenty years ago. ${ }^{1}$ A larger number of high school graduates choose to enroll than before and, of those who come, a larger number graduate. Though the numbers are greater, their quality is not inferior often. Television and other instruments of mass communication have provided them with astonishing funds of miscellaneous information, some of it

${ }^{1}$ A useful general study of the new student and his environment is The College and the Student (American Council on Education, 1966), a collection of essays edited by Lawrence Dennis and Joseph Kauffman. The Student in Higher Education, a Report of the Committee on the Student in Higher Education for The Hazen Foundation (1968) is also valuable. 


\section{4 / First Years of a Cluster College}

inaccurate, much of it irrelevant, and part of it useful. In addition, many have traveled widely. The new students come to us with new formal preparation. High school science programs have been set up by distinguished scientists, the "new math" has become widespread-and public school English has undergone elaborate revision. In the future, advanced placement programs promise to change drastically the relation of entering students to the University.

Perhaps more important, the temper of the undergraduates seems to be changing. The students have learned to react quickly to situations far from home ground, and echoes of Vietnam and Berkeley can be heard in Lincoln. In some universities the students have not hesitated to bite the hand that presumes to feed them, and generally students are becoming increasingly critical of their courses, professors, and colleges. They complain that universities have made them numbers on IBM cards, anonymous to teachers and advisers, and a gray mass to their administrators. They resent a lack of individual attention. For the past two years-at leastresponsible students through their official channels (e.g. ASUN [Associated Students of University of Nebraska]) have undertaken to scrutinize university programs. It is significant that the disgruntled students are not the weakest. The most critical are often the brightest, the most committed socially, and the most responsible morally. The best seem to be the most critical.

\section{The New Faculty}

The new faculty is also different. ${ }^{2}$ The new professor is likely to be a specialist rather than a generalist, to see himself a member of a profession before he is a member of the intelligentsia. Because his loyalties are bound to his discipline more than to his university, the new staff member is highly mobile. He puts down roots slowly and pulls them up quickly. Because departments, colleges, and universities have become so large, many feel anonymous on campus. Some are dissatisfied with the kinds of courses they feel bound to teach and the cut-and-dried nature of the curriculum generally. Significant numbers are bored by the whole enterprise and yet feel inadequate individually to effect a change. If the students feel estranged from the faculty, many professors feel estranged from one another. Departments, colleges, and perhaps the university itself, have outgrown easy human comprehension and the organization as a human institution falters. A good many of the faculty, like a good many of the students, are restive.

\section{The New University}

Part of this restiveness is surely in reaction to the new university. 3 Until this generation educational institutions of 20,000 students have never existed, but now departments have grown into colleges, and colleges into

2 David Brown's The Market for College Teachers (Chapel Hill: University of North Carolina Press, 1965) describes the new professor and many of his motivations and values.

${ }^{8} \mathrm{~A}$ significant and current book on the new University is The College Environment by Alexander Astin (Washington: American Council on Education, 1967). 
complexes. A campus which was once a place of community now has traffic problems, and the right hand hardly knows what the left hand does. One might say that the university has become as impersonal as the city and its occupants subject to similar kinds of alienation. Indeed the problems of the urban community and those of the academic community are strikingly similar: bigness, impersonality, individual irresponsibility.

The university in this generation has changed its nature. Where formerly a university was to a large extent a shelter for reflection and a channel for the dissemination of received wisdom-the ideal was a Hall of Ivy-in our time it has become a Research Center. (The relationship of the College of Agriculture to the state has always been sui generis.) In our time we have increasingly seen a shift from being to doing, from knowing to producing, and universities often justify their existence by prominently listing their explicit research contributions to business and society. The market place and the campus have been joined. Institutional rewards have increasingly gone to researchers rather than to teachers, to analysts rather than synthesizers, and "service" is often thought of less as an aspect of teaching and more as an aspect of institutional or personal advancement.

Ironically as the market and the campus have been linked at the most advanced levels of research, the undergraduate courses of study have been increasingly fragmented by administrative divisions; i.e., departments. Pressures on the student for specialization have come earlier and earlier and interrelationship of study has become unusual. The relation of humane values to the development of technology, for example, has remained outside the standard curriculum in both engineering and arts colleges. Thanks to the present course structure, the student is invited to see the disparity rather than the unity of things, and he often complains that what he studies is "unreal" and irrelevant to the world outside the classroom. The new university in gaining new patronage has sometimes neglected its old responsibilities.

\section{Summary}

Like all institutions the university must be constantly renewed; where it cannot change society, it must modify itself. But departments and disciplines which may have been established as administrative conveniences have hardened into vested interests, and what started as pedagogical experiment has been apotheosized. As a consequence the present fragmentation of intellectual life is frequently assumed to be the natural state of affairs, above revision. It need only be added that the reward system in contemporary universities often discourages intellectual and professional experimentation.

The state of contemporary universities is pretty clear: restive students who think themselves lost in a mass, studying subjects they feel to be irrelevant, in an institution so large it inspires neither affection nor intellectual curiosity.

\section{Experiments Elsewhere}

Within the last decade a number of universities have undertaken educational experiments which they hope will close the widening psychological gap between students and faculty and the intellectual split among the 


\section{6 / First Years of a Cluster College}

academic disciplines. Some large universities have experimented with residential arrangements in order to exploit dormitories for educational purposes. At Florida State and at Michigan State, students are grouped in residential units of manageable size, and classes are held in these dormitories among residential associates. By breaking up the total university into smaller college-type units, these institutions hope to counteract the sense of overwhelming mass. By grouping all students in college-size dormitories, without further curricular adjustments, such places as the University of Kansas hope to bring the impersonal university down to human dimension.

A number of institutions have combined residential and elaborate curricular experimentation. At Justin Morrill College, Michigan State University, not only do the students share coeducational dormitories, but they share a unique program of studies. This special program has an international emphasis calling for independent study both on and off the campus. Many of its courses are "problem centered" as opposed to "subject matter centered" and are interdisciplinary. The experimentation at Montieth College, Wayne State University, is almost exclusively curricular. It seeks to regroup knowledge into three synthetic academic disciplines: Science of Society, Natural Science, and Humanistic Studies. About half the students' three undergraduate years are spent in such integrative studies. The remaining time is spent in the traditional departments. Similar kinds of integrative, synthetic studies are under consideration at Hampshire College, the new institution being sponsored by Smith, Mt. Holyoke, Amherst, and the University of Massachusetts.

On the West Coast both the University of the Pacific and the University of California at Santa Cruz are attempting to break up the great university into small independent colleges clustered together. Each college at each university has its own curriculum, faculty, and dormitory, rather on the model of Oxford and Cambridge. They strive to encourage interdisciplinary cooperation and minimize early specialization. In these experiments efforts are made to combine living and curricular experience, to encourage interdepartmental synthesis, and to involve the faculty and students actively with one another.

\section{The Problems and Goals}

If one judges from the experiences of other institutions, a variety of alternatives are open to any university which, responding to the current scene, wants to experiment in education. The difficult questions seem to be: How can an undergraduate's education be made personal and synthetic, while at the same time professional and specialized? How can curricular and extracurricular experiences be united? How can the various disciplines be integrated without destroying intellectual rigor? How can faculty specialists be made generalists and their enthusiasm for teaching captured?

\section{A Proposed College}

To deal with these questions we propose that a general, experimental College for undergraduates be established as soon as faculty can be assembled and curriculum determined. We assume that anything that can be learned in this experimental College about living arrangements, cur- 
riculum, teacher-student relationships, and even examinations ought to be made available to the larger university. This should be a residential college for about two hundred students in each yearly class. The students should live in coeducational dormitories where commons rooms, class and study rooms are also provided; to minimize isolation from the general university, they should eat in a general dining room with students not in the experimental College. Commuting students should be provided carrels where they can leave coats and books, and receive mail; the carrels will be their homes away from home. By using dormitories in this fashion, we hope that peer groups will educate one another and that their curricular and extra-curricular life will be joined. Several faculty men and women should be invited to live in the College; and we plan that nonresident faculty will lunch with the students regularly and keep extended office hours.

The student body should be a representative, largely random sample of university students-this is not an honors college-and the individual should be admitted upon University invitation. No student would be enrolled against his will but applications would be only selectively entertained. Students anticipating careers in agriculture, engineering, history or education would be equally welcome. We hope that the changes in attitudes during the years in the College might be evaluated so that we can gauge our success and failures rationally. These results should be made generally available. Indeed we would hope that the College would be but one of a number of contemporary experiments which could be judged comparatively.

One such experiment would be the academic liaison between the College and the students in the reorganized honors program in the College of Arts and Sciences. The latter students would be invited to attend special College lectures and colloquiums and perhaps participate in some College classes. The close association between the two groups of students, we hope, would foster an esprit de corps beneficial to both.

\section{Residence}

During the first year in the College, all the students' work should be taken in it, from College faculty, in association with other College students. After the first year the number of College courses the student elects would depend on his interests and the demands of his major-as well as the number of years he can afford to spend as an undergraduate-but he would remain identified with the College throughout his full undergraduate career if he wanted to, irrespective of where he lived or the courses he took; and the commons rooms, study halls, and general associations would continue to be available to him. In short the College would remain his University home. In this first year students would be required to live in the College; in the second year living in the College should be optional though urged. In the third and fourth years, College students should be associated in Houses according to their areas of specialization, i.e. the Lancaster House of Political Thought, the Ferguson House of Technology, the Frye House of Humane Studies, or the Fossler House of Germanic Languages. These Houses would be part of the College and students in them would participate in College activities, even though at this stage much of their course work would be outside the College curriculum. 


\section{8 / First Years of a Cluster College}

Facilities currently existing at the University would lend themselves to this residential plan.

The curriculum of the College should be general; it should be supplemental to professional curricula and it should not be in competition with major (area) requirements. This College should offer the so-called "servicecourses," but as a rule degrees would continue to be granted by the colleges that already exist. Ordinarily the entering student would take all his freshman work in the College, one-third to one-half his sophomore work there; less in his junior or senior years, depending on the changing needs of students as the students and College faculty together might determine. The courses within the College would be generally interdisciplinary, loosely structured, and in so far as subject matter allows, problem oriented.

In the first year the student would divide his time more or less equally among three areas of investigation.

-One third of his time would be devoted to Contemporary Ideas in Historical Perspective. During this time students might investigate Power by reading Machiavelli, Tocqueville, Peter Drucker (The Concept of the Corporation), The New York Times; Religion by reading Levy Strauss, the Book of Job, The Christian Century and Commonwealth, Homer; Liberty and License by reading J. S. Mill, Plato, Hamlet, even contemporary magazines; Realism-Auerbach's Mimesis might give a point of departure-; anti-intellectualism; sexuality, and the like. By the end of the year the student should have learned how to recognize an area that can be investigated, how to define a problem, how to look for evidence, and how to reach a conclusion. In addition he should have been introduced to many of the conventional areas of specialization: anthropology, the arts, philosophy, etc.

-A second third of the first year should be spent on An Introduction to Science in its Historical and Philosophical Contexts. In this investigation the student should learn the kinds of questions that science can and cannot answer, the nature of scientific proof, the scientific methods, and the like. He should get some laboratory experience. This course would probably not be a substitute for beginning chemistry or physics but supplemental to such beginning courses to be taken in the sophomore year.

- The last third of the student's time in the first year should be spent on either a linguistic or mathematical language also in its historical and philosophical contexts. The student electing to study math would have progressed through the calculus by the end of the year; the student of verbal language would be prepared for second year courses by the end of the year. Some students who elect math in the first year may elect language in the second, and vice versa. This language study differs from ordinary courses in that the subject is here studied in its broad cultural context. The student of Russian should not only be able to read a bit, but he should know about families of languages, the history of language and even something about psycholinguistics; the student of math should know not only how to solve problems but the history of math and something of alternate postulates-and their implications. Since the beginning student takes three and only three "courses," he would have time for these additional investigations into meaning and relationship.

In the second year students should have been prepared for early professional courses: math beyond calculus, elementary reading in French or 
Russian; sophomore science; second year social science. Students in programs that are highly structured like engineering might find that they can take no courses in the College in this second year, but most should be able to spend one-third to one-half their sophomore year in further interdisciplinary study of problems that they (and one or two of their professors) have identified.4 The students should do increasing amounts of independent work in this year.

The programs for upper division students should be worked out with major departments and areas, but one would hope that the College student's career would nonetheless differ markedly from the general student's. A number of possibilities suggest themselves. In the first place the student should not attempt to accumulate credits or complete required courses. Rather, departments might consider proficiency examinations set by the department of his specialization as an alternative. These would be taken when the student himself feels ready for them; his major adviser would help him prepare by suggesting courses, books, and independent investigations. During these years one would expect College students in cooperation with their faculty to develop interdepartmental studies of a specialized nature. Senior students of physics and math might construct a colloquiumseminar in Foundations of Modern Science and Math, which presupposes a considerable knowledge of both subjects, for example. Advanced students of Technology might develop a colloquium-seminar in Technology and Public Policy, and students of the social sciences might develop a colloquium on The City. Such investigations would change from semester to semester.

In addition to (1) a number of examinations, the College student would need to prepare (2) a long independent paper of a creative or scholarly nature; and he would need to make (3) a substantial report, either orally or in writing, concerning an extended off-campus application of some aspect of his major study, the definition and nature of which is his own responsibility. A student of anthropology might well spend a summer in an anthropological field excavation, an English major might spend a summer in the Head Start Program or writing poems, a political scientist might work in the State House, a chemist might work in a professional laboratory. The interdisciplinary study in both the freshman and senior years, the report and the undergraduate thesis, and the comprehensive examination, would allow the student in the College to synthesize as well as analyze his experience.

The curriculum of the College should remain extremely flexible, responding at every point to the changing needs and interests of students and faculty as well as to current intellectual climate. One would hope to produce a graduate who was not so much stuffed with information as aware of possibilities, one able to imagine and decide between rational alternatives. He should be an educated man in that he had acquired certain habits of mind, certain abilities to ask and answer questions. He should not be merely the possessor of an established body of doctrine or even information.

4 Where necessary, there would be a system of summer fellowships for students in highly structured programs. These fellowships would allow students to take course work in their majors during the summer if the departments involved deemed such work essential for later sequential classes. 
One would expect to find all kinds of pedagogical experimentation in the College. For example, students by reading and criticizing one another's papers might teach themselves how to organize and write essays. (Note there is no explicit provision for teaching composition in this College.) They might be encouraged to work in groups when they find problems that lend themselves to group work, and they might be expected to leave even the loose organization of the College when they are seized by any interests that take them on uncharted ways. A variety of studentteacher relationships might be considered. Various experiments in how students can teach one another might be tried. Though one would ordinarily expect a student to spend four years at the University, the specially gifted might elect to take his proficiency examinations earlier and so receive his degree in less time; each student would set his own pace.

The faculty for the College should be drawn from the general faculty of the university on evidence of superior teaching. Student opinion in the selection of the faculty should be consulted, and election to this faculty should be analogous to election to the Graduate Faculty with a similar promise of reward in promotion and salary. (Selection should probably be made by the master of the College and a faculty-student committee.) Publication of scholarly monographs would be no necessary qualification for election or for retention-indeed, as envisioned, one of the chief benefits of the College would be the intellectual refreshment and personal development that a faculty member might reap from the stimulus of such an integrative and interdisciplinary curriculum, free from the constant pressures of publication. Ordinarily a teacher in the College should remain for two or at the most three years; he could then return to his department and specialty. Hopefully the returning faculty member would then be a stimulus for change and experiment in the traditional academic program. During his stay in the College, he should devote his full time and energies to it. Ordinarily only full-time permanent staff members would be eligible for election, but occasionally, for special purposes, others might be called on briefly. All members of the College staff would upon occasion be expected to lecture or otherwise instruct the whole College, but most of the time the members of the staff would work with small groups of students in a variety of ways, including experiments in "team teaching." We would hope that the full faculty resources of the University might be available to the College on a temporary basis.

\section{Implementation}

The College should be headed by a Master who is responsible to the Dean of Faculties; he would be a member of the Dean's Council and have the rank of dean. His first responsibility would be to get the approval in principle of a general plan for the College from the necessary University administrators, the Policy Committee, the Liaison Committee, the Student Senate, and finally the Faculty Senate. He should be aided by a College Advisory Board which includes student representation.

Once the College is approved in principle the Master and his Board should select a chairman and staff for each course or area of investigation. On a basis of two hundred students, a College staff of twelve teachers, four for each course, should be sufficient for teaching 500 student credit hours. The Staff who will teach the courses also construct them, but no 
single course would be independent of the others; the staff as a committee of the whole would pass on all courses and implement their interrelation. Once selected the staff of the College would need at last a semester free from other responsibilities to prepare themselves and their courses. Additional staff would be needed in the second year for second year courses. Funds should be available to the Master for visiting lecturers, temporary residents, special programs and the like, and, most important, to support pedagogical experimentation of unforeseen kinds.

2

In November 1968 the Board of Regents approved this document in principle whereupon the Chancellor and the President appointed a "Master"-the title was happily changed later to "Senior Fellow." He was charged with selecting faculty, constructing curriculum, arranging for physical facilities, and nominating participating students. He was aided by a faculty-student committee, the faculty appointed by the President, the students by the Student Senate. Before the Board could take more definite action, they needed more exact information concerning curriculum and costs; and so they called for a second report in which such matters could be spelled out. This second, enabling document was put in their hands in January 1969 and differed from the initial document in a number of important respects.

First, our initial interest in the problems of upperclassmen was laid aside at least temporarily. We had become increasingly preoccupied with the problems of general education for freshmen, on the assumption that we ought to start at the beginning. Our experience, and the evidence available from the educational psychologists, both told us that the most significant changes in undergraduates occurred at the very start of their university careers. We wanted to guide and protect that change. In addition we had become increasingly aware of the curricular complexities of technical education. We did not want to exclude engineers and other pre-professional students with tight schedules, so we set out to reconcile professional and general education. Indeed the reconciliation of professional and general education became one of our primary concerns. We modified our curriculum to provide for it because we wanted to develop a both-and program, not an either-or program.

And so we decided that in his first year every Centennial Scholar ought to spend part of his academic life outside the Centennial Center in the general university, in professional or pre-professional training. This was a modification of our original plans, and an improvement on them. We were eager that our students participate in the best of two worlds: the anonymity of a sophisticated uni- 
versity, and the community of a college. We became convinced that the Centennial Program would best benefit from the resulting variety. To provide time for pre-professional courses, we eliminated our proposed Introduction to Science in its Historical and Philosophical Contexts. This course in science for non-scientist was simply too large a bite for us to chew in this first year. It happened that one of our part-time Fellows, a physicist, was preparing an introductory course in physics for laymen at this very time, but we saw no way to incorporate it immediately. A description of the modified curriculum as it was reported to the Regents in January 1969 follows, somewhat abbreviated:

\section{The Curriculum of the New College}

The curriculum of the New College would be new to this University. A New College Scholar would spend one-third to two-thirds of his time with other New College Scholars and Fellows. They would have specially constructed interdisciplinary, interdepartmental courses. . . . They would be expected to investigate aspects of an assigned problem on their own, and to report their findings to the critical ears and eyes of other students. During the course of the year one would expect self-directed student groups to develop. The Fellows would give direction as it was required, but the instructional manner and relationship would be determined by the needs of the occasion rather than by the "book" form of lecture or class. (The fruitfulness of certain of these encounters should suggest a general applicability for teaching elsewhere in the University.)

In addition to the New College courses, the Scholar would undertake those subjects recommended for his proposed major, i.e. chemistry, applied music, or accounting. He would thus not be cut off from professional interests and friendships. Indeed, what he brought from such courses would enrich his contribution to the College, and his work in them might justify his natural advancement into one of the special upperclass major programs. Scholars undecided on an area of major interest would take University courses recommended by New College Fellows.

We can imagine the following sample schedules-

For the potential engineer or chemist or medical student:

1) New College Course .........................................................ne-third time

2) Mathematics, with other New College Scholars

(Coordinated with New College Course) ………….....one-third time

3) Chemistry, with general University students ...................one-third time

For the potential secondary school teacher:

1) New College Course .......................................................ne-third time

2) Foreign language, with other New College Scholars

(Coordinated with New College Course) ……………....one-third time

3) Laboratory science, with general University students....one-third time For the potential economist:

1) New College Course ……………………………........one-third time 
2) Foreign language, with other New College Scholars

(Coordinated with New College Course) ........................one-third time 3) Mathematics, with general University students ............one-third time For the exceptional, general student:

1) New College Course ..............................................two-thirds time

2) Laboratory science, with general University students....one-third time

The New College Scholar would undertake no more than three areas of study at one time, and $t w o$ of the three would normally be coordinated. This is done in order to encourage the student to see relevances between areas of knowledge.

The "coordinated with New College Course" attached to the foreign language and mathematics options in the New College curriculum would be managed, for the first, by relating the language texts to the New College Course topics; and, for the second, by relating a consideration of the history of mathematics and its nature as "language" to formal instruction in the calculus.

Since no New College Course would or could be repeated, those Scholars who elect to remain in the New College for a second year could participate in the new offerings without duplication. These courses could be substituted in the various undergraduate curricula for General Education Requirements without prejudicing the Scholar's professional advancement. Though the nature and subject matter of these courses remains to be established by the Fellows and Scholars, they will undoubtedly be topical, as opposed to purely historical, in definition. One such course might be an analysis of "The Nature and Limitation of Power," viewed philosophically, historically, scientifically, and socially.

Though the Fellows, and the invited visitors from this and other campuses, would occasionally lecture and provide other formal instruction, the individual Scholars would be given generous opportunity to follow their own bents.

The Board of Regents asked for detailed accounting of prospective costs. The following is the budget which was submitted to them for the first year of operations:

\section{Tentative Budget for the New College}

Educational costs in the New College are not expected to be significantly different from costs throughout the University. Costs of instruction per student, proportion of cost paid by the students, and student-faculty ratios all appear comparable to University norms.

Expenditures required for establishment of the New College have been placed in two categories: planning costs prior to the opening of the College; and, operating costs for the first academic year 1969-1970. Each category is described briefly below.

Planning Costs. Successful performance of any major educational experiment must be preceded by adequate research and development. It is expected that the "core faculty" of the New College (four persons) would devote approximately two-thirds of their time during the spring and summer 1969 to intensive preparation of themselves and of the curriculum for the College. Such a planning program would require approximately 


\section{4 / First Years of a Cluster College}

$\$ 33,000$ in salaries and related benefits. This is the only planning expenditure anticipated. Note that we have no explicit provision for travel and research.

Funds to enable completion of the planning phase of the New College will be requested from the University of Nebraska Foundation.

Academic Year 1969-1970. The New College expects to serve about 150 students for perhaps two-thirds of their time, or 100 full-time equivalent students. The faculty will consist of eleven men, full or part-time, whose total contribution will be that of six full-time equivalent faculty members.

The principal expenditure for the New College in its first year of operation will be faculty salaries and related benefits. This expenditure is expected to be approximately $\$ 85,000$. This is an average compensation of about $\$ 14,000$ per full-time equivalent faculty for a group which will contain three professors, three associate professors, and five assistant professors.

Additional expenditures are anticipated as follows: rent for Centennial Center [offices and meeting rooms] $\$ 10,000 ; 5$ secretary $\$ 5,000$; College library (periodicals, newspapers and small paperback collection) $\$ 3,000$. Other equipment and supplies will be those which are already available to the various faculty members and will involve no additional expense.

Total expenditures are estimated at $\$ 103,000$.

The major source of revenue to the College will be, of course, student tuition. Tuition payments of $\$ 355$ by each of the 100 full-time equivalent students would result in tuition income of $\$ 35,500$. Other indirect benefits to the University would be generated by the fact that New College enrollment would lighten teaching loads for the remainder of the faculty by approximately 1,500 class contact hours.

The implications of the above data, which are summarized in tabular form below, are that the New College would require a subsidy of about $\$ 67,500$ from University funds for the academic year 1969-1970. Students would be paying approximately 35 per cent of instructional costs compared to the University norm of 35 per cent to 40 per cent. The student-faculty ratio would be approximately 17:1 compared with the University 20:1 for freshmen and 15:1 for upperclassmen.

\section{Nebraska New Coliege}

Summary of Estimated Financial Data

A. Planning period, February-August 1969

Expenditures

Faculty compensation $\$ 33,000$

Revenue

Grant, University of Nebraska Foundation

(to be requested) 33,000

Surplus or (Deficit)

- The dormitories at the University of Nebraska were built with money provided by long term bonds, to be paid from student revenues. When we retired a few rooms for faculty offices, seminar rooms, etc., the University had to reimburse the bond holders for lost revenue. 
B. Academic Year 1969-1970

Expenditures

Faculty compensation .....................................\$85,000

Office rent ................................................. 10,000

Secretarial compensation ................................ $\quad \mathbf{5 , 0 0 0}$

Library .................................................... $\quad \mathbf{3 , 0 0 0}$

Total $\$ 103,000$

Revenue

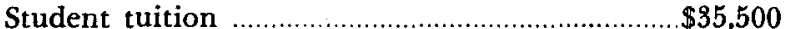

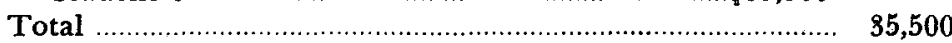

Surplus or (Deficit) ….................................................

Budget Summary. By obvious necessity this budget is tentative and it is modest. The figures describe a cost per undergraduate which is very nearly that of an undergraduate elsewhere in the University.

\section{3}

The planning costs of the Centennial Educational Program were sought by the Fellows from the Woods Charitable Fund, a local foundation. The Woods Foundation generously assumed our total planning costs in the amount of $\$ 38,000$. The officers of the Fund have continued to take an interest in us. When the Fellows approached the Nebraska Book Company it agreed to provide part of our library. Twice during the year we got 600 paperback volumes from them. These volumes were left around on various shelves in various rooms for whatever use our Scholars wanted to put them to. This library was as innovative as our curriculum. We decided that the Centennial Program could not and indeed should not duplicate the general University library; rather, the books which we had should pass freely uncatalogued and unrecorded among the students. It seemed to us that the occasional use of expendable books was the best way to encourage students to read miscellaneously and generally. In the second summer we managed to purchase a small reference library-encyclopedias, almanacs, atlases, and the likefrom the residue of Woods funds at a total cost of less than $\$ 700$. We had missed this collection during the first year.

When we looked around the campus for a location for the Centennial Center, we discovered that no dormitory was ready-made to our purposes. Needing a place where students could both live and have their academic life, we decided two of the older dormitories with modifications could be made to serve our purposes. With the advice of two young architects on the staff who saw possibilities which might have escaped our layman eyes, we removed some walls, set up some half-partitions, put down some carpeting, and thus 
established seminar rooms, faculty offices, and student lounges close to the students' sleeping and dining rooms. This modification was inexpensive as such things go. It came to about $\$ 14,000$. Incidentally these renovated buildings had not been changed since their initial construction more than thirty years earlier.

The furnishings in Love and Heppner Halls, the dormitories we occupied, were originally placed there when the buildings were put up, and they were pretty badly worn. We acquired some good sturdy tables and chairs from University storage and, with the advice of the young architects and an astonished but cooperative housing staff, ordered some additional pieces. The total cost of curtains, rugs, tables, and chairs was something in the order of $\$ 15,000$. It might have been much more expensive but for the humorous assistance of the department of purchasing. These people hunted down all kinds of bargains for us. Thinking that the Scholars should have something to say about the furnishings of the rooms that they were to use, we set aside $\$ 2,000$ to be spent by them for their parlors and Commons Room; but when they arrived in the fall, 1969, and found the Commons Room practically unfurnished, to our amusement they were delighted. The carpeting was thick, the stereo was loud, and the area uncluttered. They insisted that it be left as it was. All year the $\$ 2,000$ fund was unclaimed. Ultimately it was spent, by them, to replace ancient couches and chairs which had given way under their vigorous use. In total the initial costs of the Centennial Program were far from great. This was not an expensive venture.

Once the Centennial Program had been approved in principle by the Board of Regents, we approached the undergraduate colleges for their permission to tinker with undergraduate "group requirements," those courses specified by each college as their minimum for general education. In the winter 1968-1969 the Council of Deans gave us general approval for our innovations. In effect they agreed to accept our six-hour Centennial Course in lieu of six hours per semester in freshman English, political science, sociology, and the like. Subsequently this system of substitutions was taken to the faculty of the College of Arts and Sciences, and in May 1969, after some heated but good humored debate, our requested waiver was approved on a trial basis. Our activities were reported to the general faculty in the Faculty Senate in the spring, 1969, and our plans received wide publicity through both official and unofficial publications during the whole planning period. We were very visible, as President Soshnik said at one point. At no time did we meet serious resistance within the University. Both the 
administration and the faculty cooperated. If we were to fall flat on our faces, we would not do so because we had been tripped. Indeed more than once we rather wished for resistance so that we could share blame for any failures.

During our planning period, and subsequently, we were constantly asked how our Program was to be evaluated. Professor Robert D. Brown of the Counseling Service, our "resident examiner" as we called him, explained:

The goals of the College focus on changes in student behavior that encompass approaches to problem-solving, attitudes toward self and others, interest and participation in intellectual and cultural activities, level of satisfaction with collegiate experiences, and the extent of curiosity and thirst for knowledge and new experiences. In one sentence, the goals narrow down to an increased student awareness of the problems of society and persons, and development of some skill in defining, analyzing and searching for answers to these problems. Perhaps the stated goals are not as unique as the program's commitment to them.

Not to be neglected is the personal and professional growth of faculty members participating in the program.

Assessment and Evaluation Procedures. Because the tactics and the goals are so varied and comprehensive, it is suitable to use evaluation procedures that are equally variable. It is important, for example, that individual opinions of staff and students be gathered as the year progresses. Such personal reactions and insights are invaluable. These, in turn, will be supplemented by questionnaire data on student attitudes and values, and observations and self-reports on student behavior. It is equally important to have some data available on comparable groups of students who were not part of the Centennial College Program.

The planned evaluation might well be pictured schematically as threedimensional with one dimension being the cognitive and affective goals of the Program. The cognitive goals are those usually associated with knowledge of content and development of skills related to a style of inquiry. ${ }^{6}$ Affective goals pertain to those often espoused but seldom assessed objectives, such as attitude change, development of appreciation and growth in intellectual autonomy. 7 The second dimension focuses on the techniques employed to accomplish these goals: the living-learning environment, the Centennial Course, and faculty participation. The third dimension includes the ways in which students are expected to be changed; namely, attitudes and behaviors. We expect them to not only say that they are interested in drama, but to participate in some activity related to drama, such as attending a play or reading one. The evaluation procedures are designed to cut across these dimensions by attending to attitude and behavior change in class and out-of-class.

B See Benjamin S. Bloom, ed., Taxonomy of Educational Objectives: Cognitive Domain (New York: David McKay Company, Inc., 1956).

${ }^{7}$ See David R. Krathwohl, ed., Taxonomy of Educational Objectives: Affective Domain (New York: David McKay Company, Inc., 1964). 
Groups to Be Studied. There will be three basic comparisons: 1) Students in the Centennial Program will be compared to themselves (FallSpring) in order to assess changes that have taken place, 2) Students in the program will be compared to a random sample of students who applied for the program but were not selected in the random selection process, and 3) Students in the program will be compared to a random sample of University freshmen. (The research design is one described as a separate sample pre-test-post-test control group design..$^{8}$ )

Assessment Instruments. Assessment procedures will include the use of standardized questionnaires, locally developed surveys, personal interviews, self-reports, and reactions from participant observers. Three major standardized questionnaires being used are: the Omnibus Personality Inventory, the College Student Questionnaire, and the College and University Environment Scales. All of these have been designed for use in college settings and have been an integral part of the assessment in other experimental colleges. ${ }^{9}$ Randomly selected students in all three comparison groups have already responded to these questionnaires in order to establish a bench mark of where they are now and in the Spring they will respond to many of the same kinds of questions so that changes will be noted.

In summary, some definite objective and subjective evaluation procedures have been outlined and begun. The basic approach at this time is an omnibus one, i.e., find out as much about what happens to students as is possible and in as many different ways as possible. It is expected that meaningful comparisons on a number of important criteria will be possible between students in the program and students not in the program so that the impact of the Centennial College Program can be assessed.

No doubt, just as the program itself evolves, the evaluation procedures will need to be adapted. Hopefully, both will be enhanced. Students and staff have been involved in discussions about evaluation and will be continually involved.

It should be remembered that evaluation is not just an end-of-the-term project. Some of the most beneficial evaluation is that which is part of the on-going process. Although this is not built into the formal evaluation of the program as outlined here, it is an integral part of the Centennial College, as faculty and staff continually critique and revise their on-going efforts.

We were convinced that the University, like all institutions, must be constantly renewed. Where it cannot change society, it must modify itself. We wanted the student's living situation to reinforce his learning situation, and we wanted private interests and common intellectual involvements to become subjects for conversation outside the lecture and seminar rooms. We wanted students to

\footnotetext{
${ }^{8}$ See Donald Campbell and Julian Stanley, Experimental and Quasi-Experimental Design (Chicago: Rand McNally and Company, 1966).

- See Kenneth Feldman and Theodore Newcomb, The Impact of College on Students (San Francisco: Jossey-Bass, Inc., 1969).
} 
educate one another. We wanted a curriculum that emphasized the unity rather than the disparity of ideas, for we hoped to show the inter-relationship of human experience. Practically, we wanted to reconcile professional and general education, and we hoped that our very existence would encourage innovations in teaching generally in the University. We hoped that the result of our endeavors, beyond a faculty renewed in its excitement about teaching, would be a graduate sharply aware of himself, his society and his world; one capable of responsible intelligent judgment; one eager to continue his liberal and professional education. We who were committed to the Centennial Program believed that the present fragmentation of social and intellectual life was not above revision; and we believed that all thoughtful men sought to escape their divided and distinguished worlds. 


\section{The Preliminary Planning \\ By Robert E. Knoll}

B

EGINNING WITH the second semester, 1968-1969, the Working Committee of the Centennial Educational Program met weekly to plan for the following year. ${ }^{1}$ No single member of the Committee attempted to impose his predetermined views on the rest. None of us was doctrinaire. We worked our way to our conclusions from a common belief that the present system of University education deserved reexamination. We did not think that what existed was necessarily bad, only that the new responsibilities to a new generation demanded alternatives. Fundamentally the Centennial Program was a residential experiment. This was the basis of all we discussed. Mass housing of mass students for mass education seemed limiting to us. In addition we questioned accepted pedagogical methods and divisions of subject matter. We wanted to call

'The Working Committee consisted of the four full-time Fellows, five students appointed by the student Senate, and occasional visiting students and faculty. We met regularly at 9:30 on Saturday mornings, the only time all of us were free from other obligations, but we held extra sessions with administrators and advisers.

The full-time Fellows were Professors T. E. Beck, Jr., Jerry Petr, Phillip Scribner, and Robert E. Knoll; the student members designated by the Student Senate were Nancy Ryan, graduate student in English; Georgia Glass, senior in Teachers College; Curt Donaldson and William Mobley, juniors in the College of Arts and Sciences; and Curt Micka, sophomore in Arts and Sciences. Professor Henry Ablin attended the sessions with great regularity and so did Kathy Danker and Carol Jorgensen, sophomore students in Arts and Sciences. The four full-time Fellows were relieved of two-thirds of their normal teaching obligations in order to devote themselves to planning the Centennial Program. One or two of the students received some academic credit for their part in this planning. 
as many conventional academic assumptions into question as we could recognize.

We came to share a number of assumptions. We thought students might logically proceed from an understanding of themselves to an understanding of the greater world outside themselves. We did not expect our students to come to us with a predetermined level of sophistication or of competence; we wanted to start with them at whatever level they had so far reached. In mathematics this might mean high school algebra; in English, science fiction; in politics, Ayn Rand. We were concerned with what they learned, not the standardized level at which they began with us. We assumed further that students, individually and collectively, should participate in planning their educational adventure; but for them to do so they would need considerable self-knowledge. We hoped that no educational plan would restrict a student from following out ideas, materials, and subjects to which he might find himself attracted in the course of his study. Rather we wanted him to be given his head, as it were; we wanted to catch his interests and exploit his natural inclinations. Our students would necessarily engage in much independent study, but we hoped that they would naturally evolve into common interest groups. We assumed that students working on a common problem of common concern would instruct one another. And in teaching one another, they would teach themselves.

We questioned the conventions of semesters, class hours, class periods, and exams. We decided that we would free the student from fifty-minute periods and three-hour courses in order to broaden his study into all hours and all days. We thought they should meet as often as they needed to and for as long as their discussions required. Perhaps, through this, students could learn that all hours are study hours and that all experience is educating. We set out to blur the conventional disciplinary lines of history and sociology and art. Investigations should be topical rather than formal, we thought; and we wanted to ignore the boundaries between academic and non-academic experience. We hoped our students should go off the campus, outside the groves of academe periodically to become involved in the issues of their time. By combining the academic and non-academic, the on-campus and off-campus life, they should see that they lived where the contemplative life and the active life are really one.

Though we wanted our students to be able to give a clear expo- 
sition of information and opinion, we did not want to establish a system of reports and term papers which too frequently seemed to develop an existence of their own. We wanted writing to come naturally out of a student's involvement in his intellectual endeavors, for we were persuaded that training in self-expression independent of subject matter is likely to be wasted. Persons write and talk best when they care about what they are saying. We wanted to establish a community in which students would want to clarify their ideas so they could communicate them to their peers; the community would be both the audience and the critic. In all of this we strove to loosen life-long habits. One must confess that we all found breaking these intellectual habits much more difficult than we had anticipated. Our minds, students as well as faculty, kept returning to the three-hour course and the weekly theme. We frequently reinvented the wheel. Since we were trying to break out of educational conventions, we also tried to avoid conventional hierarchical structures of authority, both academic and residential. (Our experimentations were restricted legally only by the broad policies of the Registrar, the University fiscal office, and the University housing office, all of whom gave us the benefit of every doubt.)

Since we were not an honors program we decided that we would admit our 125 freshmen by lot, from among those students who applied. In this way we would try to get a representative sample of embryo engineers, political scientists, chemists, artists, and accountants. The majority of our students would live in the Centennial Center, but we wanted some representation of those local people who lived in town with their parents. We thus established some "Commuter Rooms"-rooms with desks and book cases where commuters might make their headquarters on campus. In order to get as much variety as possible in our student body, we decided to give some preferential treatment to out-of-state and minority students.

We early determined that we would need some upperclass students in the Program, but we decided to admit them on an individual rather than a random basis. From the number who might apply, we would select about twenty-five. We hoped to find a few who spoke more than one language, some artists and musicians, some "leaders"-we did not mean campus politicos necessarily-and others who might make our community lively and interesting. The University provided and paid one undergraduate student counselor for each floor of the dormitory and one graduate student to whom 
all counselors reported. These we expected to select from among our own Scholars, but we did not plan to provide them with elaborate instructions; we would leave their responsibilities vague.

We decided not to impose a constitution on our students-no "president," no "social chairman," no standing committees-until we discovered the kinds of organization appropriate to our problems. We wanted to allow structure to arise from necessity. We anticipated holding an initial "town meeting" where all students might have opportunity to share opinions about matters of common concern-curricular, administrative, disciplinary, political, or social; and out of this meeting, structure might naturally evolve. We assumed that students and faculty would meet as equals on all governmental units. None of the Fellows had residence in the Centennial Center, there being no accommodations for families in the buildings; but we hoped they would nonetheless be involved in all aspects of life in the community. Clearly we were caught up in the fashionable opinions of the time; it was spring, 1969. We wanted to give "participatory democracy" a chance. Not all the members of the Working Committee were equally sanguine about the success of "total democracy," but the relationship between faculty and students remained good. Only occasionally did the students accuse the Fellows of manipulation or bad faith, but in fact what they took to be high-handedness was only the long habit of authority reasserting itself willy-nilly.

By the end of May the Working Committee had laid out a plan for an interdisciplinary Centennial Course. This would require about one-third of the Scholar's time during the year. The second third would be spent on either language or mathematics within the Centennial Center; and the last third on professional or pre-professional courses outside the Centennial Program in the greater University. We hoped that the Scholars' involvement in the subject matter of the Centennial course would be the primary motive for their labor and that their desire to instruct one another, to communicate what they had learned to their peers, would give focus to their study.

We decided that the Scholars should address themselves to a common theme within which they could find subjects of individual concern. We settled on "The Nature of Change" as the idea for the year, thinking it sufficiently inclusive to allow variety but sufficiently topical to catch the Scholar's interest. The student members of the 
Committee noted that undergraduates do not so much live in the present as they live in anticipation of the future; we would be wise to harness this preoccupation. They were obsessed, the students reminded us, with such questions as What is the world of 1980 to be like? How can we make it the way it ought to be, or at least the way we want it to be? The general contemporary passion for science fiction, a passion not shared by all their professors, was one expression of this adolescent preoccupation with what is to come, they told us. The Nature of Change, and the Nature of the Future seemed to them interrelated. This general topic should give our Scholars something to discuss intelligently, even intellectually, right from the beginning of their academic experience.

Before the Scholar could understand what he and his world might become, we decided that he ought to take stock of what he and his world presently are. The year was to begin, therefore, with a self-assessment which would reach its culmination in the third week with an autobiographical essay. Over the summer the Scholars should have read a number of books to prepare them for this undertaking. We asked them to examine Loren Eiseley, The Immense Journey, because this fundamentally religious book placed them within geological time and incidentally drew its examples from the Great Plains whence the majority of them came; Erik Erikson, Young Man Luther, because this historical study concerns the psychological turmoil of college age persons; Peter Weiss, Marat/Sade, because this play raises questions of political action; and George Orwell, Essays, because it concerns the moral obligations of social experience. During the first three weeks in the fall semester we planned to examine sections from Tocqueville Democracy in America. All these books give rise to queries about the nature of the revolution in our time.

We planned to study two movies. The first was the rather static Martin Luther produced by Lothar Wolff and directed by Irving Pichel in 1953. This movie had an obvious relation to the Erikson book. The second film was to be Orson Welles's Citizen Kane. We hoped the Scholars would see within it examples of social, political, and moral change worthy of discussion. Through Citizen Kane and Martin Luther we wanted to introduce a concern for the art of cinematography, an art we hoped to deal with throughout the year. We hoped the Scholars would learn to look at films critically as we hoped they would learn to read critically.

In the first three weeks of the fall we planned to have the Scholars meet regularly with assigned Fellows in seminar-type 
groups to discuss the books and films. From the beginning the relationship between Fellows and Scholars was to be more informal than our recently graduated high school seniors were accustomed to. We were to meet in lounges, at hours convenient to the students, in an atmosphere self-consciously open. The autobiographical essays were to be ungraded, though elaborately commented on by the Fellows; and they were to be kept on file so they could be reexamined at the end of the year. In the spring, by reexamination of his paper, the Scholar might well be able to judge how he had changed and in what way. Each essay was to be written by one Scholar, edited by another, in order to produce a piece of work of joint labor. The Fellows were to write autobiographical assessments of their own, both as models for the Scholars and to demonstrate that they and the Scholars were engaged in a common enterprise. Both were setting out to explore areas as yet unknown. Although the relationship between them was free, it was not now in September and October as novel as we hoped it was to become later in the year. The Fellows had assigned the readings and proposed the questions, after all, not unlike teachers in other courses. We did not want to break the new students out of their old patterns so quickly as to leave them rudderless. We wanted to loosen their conventional bonds a little at a time until at last they could pose their own questions; discover their own evidence; seek their own answers; and reach their own, considered, conclusions.

The theme then was The Nature of Change. We arbitrarily divided the year into four main sections thinking that a six- or eight-week study period was sufficiently long for beginning undergraduates. After the three-week analysis of self, we planned to devote some six or seven weeks to Project 1: The Nature of Social Change. In this period the Fellows would propose questions which might be investigated; each would be supported by relevant bibliography and study guides. Each topic, which would be posted on a bulletin board, would be followed by certain observations leading students into the heart of it. If Scholars should invent topics relevant to the general thesis, these could be substituted for the Fellows' suggestions. We invited Scholars to consider subjects like The American Negro 1850-1950; The Causes and Uses of Contemporary Poverty; The Impact of Darwinism on 19th Century Religion; The Changing Nature of Business; Religious and Political Witchhunting, and the like. These subjects were often outside the areas of the Fellows' professional expertise, for we were eager to learn with our students in a common endeavor. 
We hoped that the Scholars would naturally group themselves around one or another of these topics; a Fellow would be assigned to each group as chairman, or seminar leader, or "resource person" as present jargon has it. Should more than fifteen students elect a single area of study, the group could be subdivided; we thought none should consist of more than a dozen people. When the group met to become organized, it would itself decide what questions it wanted answered, and then it would divide into smaller investigating teams. Each subdivision would search out its own conclusions and return with them to the total group. This parent group would synthesize the individual results and construct a composite report. This Project report-it might be an essay, a moving picture, a play, a model, a formal debate-would be presented to the whole Centennial Program community, for general edification and criticism. By dividing groups into subgroups and by asking subgroups and groups both to report to peers and colleagues, we hoped the Scholars would learn to teach one another. The final week of the project period would be filled with group reports and criticisms. Though presumably the various study groups would have been conferring with one another for the previous six or eight weeks, in this last week final conclusions would be publicly presented, in some kind of final form. Since all the Scholars were studying varieties of change, the total community should find matters of interest in one another's discoveries, and since presumably students were working on what interested them, curricular and extra-curricular conversation would merge.

Project 2 was called "Stasis," and it, like Project 1, was planned to last six or eight weeks. In this period the student was to be given a choice of ancient or exotic societies, one of which he was to investigate. In Project 1 the Scholar has been helped to the definition of a problem. This time he was to define his own problem as well as gather information with which to come to rational conclusions. Since the Scholars themselves were to lay out the questions they sought to answer, they should know when they had reached a stopping point, we thought. The variety of societies was very wide: the Navajo Indian culture; Pre-Colonial Africa; Ancient Egypt (XVII Dynasty); the France of Louis XIV; Medieval Europe; Pre-Homeric Greece. A Fellow was to be attached to each of these study groups. We hoped that all the groups after this study would question to what degree their own contemporary dynamic society was unique. In Project 1 the Scholar was asked to be concerned primarily with his contemporary, changing world. In Project 2 by way of contrast 
he was asked to view societies sharply unrelated to his own. Perhaps he could develop some sense of historical perspective.

Project 3, again to last for six or eight weeks, was to be concerned with The Nature of Environmental Change. (When we set up this area of study, we did not realize how timely our ecological concerns were to be in the spring of 1970!) Now we did not propose a question as in Project 1 , or a defined area of investigation as in Project 2. Now we asked the Scholars to find their own topics and to define their own problems. The Fellows would of course make suggestions and would volunteer criticism, but we did not post topics or subjects which the students might elect to study. We hoped that the problems of the environment would spark an interest in science, especially biology; and we hoped that the student would see a relationship between pure science and human concerns. We trusted that our Scholars would divide themselves into groups as they had in the first two project periods, and we assumed that each group would want a sponsoring Fellow for the total period. And we assumed the groups would again conclude with general presentations for the edification of the total Centennial community. Again we hoped the students would educate one another.

Project 4 was to be even more open than the three preceding periods. The theme was to be "Utopia." In this project we would attempt to capitalize explicitly on the student interest in the future. This was to be the culmination of all our work during the year. We expected to put in the students' hands a volume containing selections from the classical utopias, from Plato to B. F. Skinner. But by now the Scholars should be able to lay out a project of study independently. Again we expected them to work in groups, but we anticipated that many would work independently. The Fellows would be available for consultation. Their concluding reports, or constitutions, or movies should contain all they had learned during the year of social structure, historical change, and environmental pressure. By now we hoped the Scholars would be well launched on their seas of thought, voyaging in areas of their own interests, to ports they themselves had selected.

In the last two weeks of the year, the Working Committee decided, the Scholars and the Fellows should conduct an extended self-examination. The Scholars should consider in what way they had changed during the year, and the Scholars and Fellows together should assay the merits of the Centennial Program. Plans for correcting limitations could here be made. In these last two weeks we would expect each Scholar to write a second autobiographical paper. 
After much discussion the Working Committee decided that the grading systems to be used throughout this first year should be decided by the Scholars themselves, when they arrived in the fall. We hoped that they would elect to use pass/fail, because this system seemed to us most likely to free them from the whiplash of grade point averages. But we understood the pressures of graduate schools, professional schools, and parents; and we thought this matter too ticklish for us to solve by fiat.

By the end of the year we hoped that many of the Scholars would have discovered subjects which they wanted to investigate in depth. A good number of them should want to go into the greater University for formal instruction in the departments of physics, psychology, and literature. We saw it as our function to prime the pump, not to produce finished scholars; rather we hoped to prepare them to be scholars. And we wanted our students to return to their home towns at the end of this first year knowing that something had happened to them. Our concern was to make them eager for further academic adventure. If in the course of the year we had helped them to learn to define analyzable topics, to gather information, and to come to rational conclusions, all with a degree of pleasure, we would think our work successful. We were concerned less with communicating any single body of knowledge to them than we were with showing them how to think about issues of general concern. We dealt with methods of rational analysis.

\section{3}

In addition to the Centennial Course, the core of the academic experience in the Centennial Program, the Working Committee planned two additional educational experiments. One of these was in mathematics and the other in foreign languages. Our math program, which was worked out in consultation with representatives from the mathematics department, the physics department, and the College of Engineering, was based on the assumption that one must learn mathematics in solitude. Studying math is not a social experience; it is not a group experience, and it does not require community effort. The student must at last find his own way to an understanding of each problem and each concept. He can be shown the road he must travel, but he must finally go the way alone. On the other hand one cannot learn to speak a foreign language in solitude. One must speak to others, and be spoken to. One needs to hear the foreign tongue in various contexts and combinations. One learns languages by saturation and automatic imitation as well as 
by deliberate thought. Where mathematics is individual, language is collective. Math and languages offer contrasting kinds of pedagogical problems.

Our math program was more elaborate than our language program. We decided to divide up the calculus syllabus as provided by the math department (Mathematics 114, 4 credits; 115, 5 credits; 116, 4 credits) into a number of discrete subdivisions. For each of these we provided an outline containing directions for the study of this subdivision, sample problems in sequence, and a bibliography of math books and sections of math books which the student might consult as he needed to. The student could then proceed to competence on his own. If the student was not prepared for the first division of calculus as provided in the syllabus, he could begin studying wherever his diagnostic tests indicated he needed to begin and proceed into the college syllabus from there. If he got stuck, he could go to a Fellow, or one of the designated undergraduate math counselors, or to his friends. We provided a Math Room in which all math students were invited to congregate. There they would find a small reference library of math books, blackboards, colleagues and advisers. We hoped that the students would instruct one another.

When the Scholar thought himself competent in a subdivision, he was to present himself to a counselor for examination. His knowledge of one topic having been demonstrated, he could move on to the next; and upon demonstrating competence in that topic, he could move on to yet another. We hoped in this scheme to provide instruction individualized to the student's need, and we wanted to place the burden of learning fully on the student himself. We thought that students genuinely interested in math should be able to complete more than the standard two semesters of calculus in the first year, and we wanted to see if those studying math only as a requirement or as prerequisite to other courses were as well served by this self-study system as by the standard "lock-step" courses with their built-in disciplines of schedule, lecture, and exams. We hoped that our mathematics could be related to the Centennial Course. A Scholar studying population or pollution, for example, might well make use of math to solve social problems and thus see the interconnection of things. Math was, in our view, necessarily studied alone, but its utility was general. ${ }^{2}$

2 Professor Henry Ablin was in charge of the mathematics program. He, Tom Hawkins, and Dennis Hopkins, senior mathematics majors who served as math counselors, drew up the outlines and supervised the Scholars during the year. The outlines were under constant revision during the year although Professor Ablin and Mr. Hopkins had spent the summer of 1969 preparing them. 
Teaching language offered different kinds of problems. We wanted to establish a community for students studying French, German, and Spanish, where speaking was easy and natural. We thought regular class meetings at regular hours was necessary in order to provide opportunity for drill, but we provided additional aids. The teacher of each language had a room stocked with a record player, posters, foreign language newspapers, and magazines. We hoped that the students would use these office-library-listening rooms in off-hours at their convenience. We found an undergraduate fluent in French and German-the young woman, born in Germany, was married to an American-who came to have scheduled bi- and tri-lingual conversations with the Scholars several hours a week. Among our Centennial Scholars we hoped to discover several who spoke Spanish or French or German as first or second languages. We planned to ask them to be available for foreign language conversation. We hoped that the upperclass students of these languages would practice both on one another and on the beginners, to mutual benefit. Altogether we wanted to provide opportunity for those who wanted to learn a foreign tongue. And again we wanted the students to learn from one another.

We searched for lively materials to use in the classrooms. For beginning French we purchased the series of films, made in France for foreigners, called "En France comme si vous y étiez." We planned to show this series of thirty-nine films, each running about twenty minutes, two or three times a week. Grammar and texts for beginning students were geared to these films, and our tapes and records were correlated to them. These films and tapes would provide opportunity for our students to hear many varied voices and they would give a background in French civilization. The films took the students on a tour of Paris and rural France. We hoped the students would be encouraged through these films to make conversation. We found a bright and enthusiastic young teacher, not a native speaker but one well acquainted with Nebraska undergraduates, who could correlate all these proposed activities. Second year French was to be taught by a native speaker of wide culture and experience.

Both first and second year German were to be taught by native speaking Germans. We provided a film made in Germany, entitled "Guten Tag," which we hoped would work for beginning students of German as the "En France" film would work for the students of French. We hoped it would provide cultural, historical, and linguistic enrichment. Unhappily we could not locate tapes, records, and books to accompany this series of short films, but we had other 
tapes and records for the optional use of the students. Materials for teaching Spanish were most difficult to come by; we could locate no films, and the tapes and records were not so elaborate as those available in French and German. Fortunately we discovered a particularly competent young teacher who taught both beginning and second year Spanish for us. She planned to experiment with tapes and recordings as she could and she prepared some of her own.

Just as we hoped that the subject matter of mathematics could be used in the Centennial Course, we hoped that the languages could be united with it. We planned to ask the teachers of French, German, and Spanish to correlate their readings and discussions to what the students were studying outside their language classes; and we hoped the Fellows could ask the students to use whatever they knew of foreign languages to reinforce their core studies. We wanted the Scholar to feel that he had a whole package, not a series of discrete courses. We wanted him to exist in a single social and intellectual community.

\section{4}

The Working Committee had general faculty cooperation through our whole period of planning. Chairmen of various departments offered help and asserted their good will, and we ran into unexpected support in every corner. We heard rumors of skepticism and, even now and then, malice; but we found no evidence. Our proposals to various faculty groups were treated respectfully, and when put to faculty vote they always won. When we needed aid, we got it. I do not know why we met with such cooperation. The University administration clearly backed our venture, but the faculty at the University of Nebraska has in the past never hesitated to frustrate the administration's academic plans. Indeed over the years this resistance to change has been more usual than exceptional. One can only guess. For one thing experimentation, innovation, was in the air: this was the national mood in 1969. For another, the faculty had been largely renewed with young teachers in the previous decade of astonishing growth-the University more than doubled in size in ten years until now it had nearly 20,000 students. The median age of the staff was well under forty, perhaps even under thirty-five. Finally it may well be that the faculty was so confident of itself that it did not see us as threatening. We were, after all, a small group dealing with a small percentage of the undergraduates. Though we got a good deal of public attention, we were not strong enough to destroy any bailiwicks. For whatever reasons the faculty gave us no trouble-only support. 
The student interest in our undertaking was even higher than the faculty interest. The campus leaders came around to see what 'we were up to, and a significant number sought admission to our Program. The campus newspaper gave us more coverage than we wanted, and we became embarrassingly fashionable.

When we began working on the Centennial Educational Program we kept our eyes on our own problems and sought local solutions. We set out to organize a separate and parallel unit in an existing institution as a means of academic innovation. Though we were attempting to provide an alternative to our standard undergraduate education, we did not seek to disturb what already existed, and made no frontal attacks on anything or anybody. We hoped that our alternate scheme might suit some worthy faculty and students who were discontented with what presently existed, but we did not assume that what we were doing would replace it. We were pluralists, in the great tradition of American education. 


\section{The First Year, 1969-1970}

By Robert E. Knoll

The Centennial Educational Program admitted its first students in the fall of 1969. Early in the spring we had sent out announcements to all high school principals and counselors in the State and to every entering freshman. There were about 3,500 of these. By the first of June we had some 750 applications for admission and by the first of September we had another 100. We thought this a great number.

From these applications we chose 125 students. Our selection was as nearly random as we could make it for we wanted a representative student body, not an honors group. The academic profile of the students we admitted to our program roughly corresponded to that in the general university; we had the same proportion of bright and ordinary students, of engineers and agriculturists, as existed in the student body at large. It is true, we ended with fewer students from the lower half of their high school classes than were to be found in the general university, but few students from the two bottom quartiles had applied to us. It was our guess from the beginning that our scholars, being in part self-selected, would not be as representative as the figures might indicate. We expected them to be a rather more adventuresome group, and, as it turned out, they were. In addition to our 125 freshmen we had originally planned to admit twenty-five upperclassmen, selecting them according to our needs and their usefulness, but so many interested and interesting upperclassmen asked to join us that the Working Committee ended by admitting forty. They were an imaginative, handpicked lot. 


\section{4 / First Years of a Cluster College}

All but about twenty-five of our Scholars had residence in the Centennial Center. The commuters, who lived in town with their parents, were provided desks in Commuter Rooms-made-over shampoo rooms, sewing rooms and the like-and they became as much a part of the community as those who slept here. We found that the freshman and sophomore commuters became generally more active members of the Program than the upperclassmen. The upperclassmen already had friends and commitments on the campus before joining us, but even so they seemed to feel a considerable loyalty to the Program. The seniors had their minds on their own immediate futures and neglected us.

We had, then, about 165 undergraduate Scholars. To direct them in their Centennial Course, which yielded six hours of credit per semester, we had four full-time Fellows and four Fellows who devoted one-third of their academic time to the Centennial Course. The faculty-student ratio with us was roughly what it was in the University generally. In addition one Fellow devoted two-thirds of his time to our mathematics program. These nine Fellows were our staff, but in addition a number of language teachers spent varying amounts of each day in our rooms. Unfortunately they were never fully involved in our Program, largely because the Fellows were so occupied that they could not devote themselves to the languages as they might have liked.

Our evaluation of the year's activities is based on a number of documents and considerable evidence. Several of the Fellows kept detailed notes, recording judgments as the events of the year occurred; and others made evaluations at the end of the year. Several of the Scholars made their critical comments available also. During the year several of them made "surveys" and took opinion polls-they were of varying degrees of sophistication-and they deposited copies of these with us. Altogether by the end of the year we found ourselves with a considerable body of information with which to support our evaluation of the Centennial Program. Dr. Robert D. Brown's professional judgments were reached independently.

1

In the Centennial Program we wanted to create an environment for learning. It had been our experience that within the first six months of a student's life at the University the freshman often found himself turned off. He thought that the University was little more than a larger high school and that the famous life of the intellect 
was grossly overrated. We hoped that our Centennial Scholars would catch some glimmer of the excitement which learning can bring. We wanted to catch the imagination of the students.

From the very beginning we had evidence that in this we succeeded. The Scholars embraced the Program with enthusiasm, and their happiness was sustained throughout the year. It began with euphoria. The students were delighted to find each other and a new educational experience. One morning early in the year we found an unsigned comment on one of the bulletin boards: "I have been here for two weeks and nobody has talked about the weather yet." By the end of the third week a group had made a television film of The Spirit of the Centennial College. It was complete with original music composed and played by some of the students. The result was both funny and shrewd. This initial euphoria did not last, of course, and student attitudes shifted during the course of the year. After the initial somewhat frantic delight, gradually the students settled back into a more regular devotion to study and conversation. In part this was because they became increasingly confident that the Commons Room, and life in the Commons Room, would be there whenever they needed it. They got so they did not feel that they had to rush down every twenty minutes to be sure it was still in place, still going on.

The enthusiasm remained even into the winter doldrums. During a January snowstorm one evening a snowball battle raged outside our windows. The Centennial Scholars closed our doors and turned down our lights in order not to attract attention to themselves. They wanted to protect the Center from becoming involved in the battle; we had become a general object of undergraduate envy, we knew. We saw evidence of group responsibility everywhere. Our Scholars left expensive electric typewriters, books, and even clothing lying about unguarded without danger of stealing. The men's and women's quarters were respected without warning signs. When one of our study groups gave a reading of a Molière comedy, some sixty Scholars turned out to hear it. It seemed to us that the sense of community was admirably sustained all year.

At the end of the first semester, one of our Scholars prepared an opinion poll for a course in education. Although it was not professional, its conclusions reinforced some of the Fellows' judgments concerning the residential aspects of the Program. Jim Schaffer discovered that in the opinions of University students, the Centennial Center was the most desirable living unit on the campus, that it 
provided more cultural experience than any other dormitory or fraternity, that here people talked more about social problemsracism, poverty, and the like-than elsewhere, and that here a significant majority were persuaded their educational experience was valuable. He found that the Centennial Scholars studied in the Center with new friends who had new ideas and attitudes. The Centennial Scholars did not think that the Centennial Program stressed extra-curricular activities, but they thought it encouraged a critical awareness of the educational process. Altogether this questionnaire seemed to show that the environment was accomplishing what we had hoped it would.

The Centennial Center was coeducational and its lounge-study areas remained open always. One might have expected the men and women to take advantage of this freedom; and in light of this, Schaffer's discoveries about the attitudes of the Scholars was informative. He asked persons both in and out of the Centennial Program to comment on their attitudes toward pre-marital intercourse, the pill, and the like. He found that though the dormitory and fraternity people thought their attitudes had undergone significant change since coming to college-they had become more liberal-the Centennial Scholars did not. Perhaps the Centennial Scholars were more liberal when they arrived, but this seems rather unlikely. Rather it seemed to some of the Scholars that the relationship between the men and women in the Centennial Program was not a sexual one and their attitudes had changed much more than they realized but in unexpected ways. The Scholars insisted that a kind of brothersister relationship developed naturally here, that their constant association led to friendship rather than sex. "Since the Centennial people are thrown together in a social atmosphere twenty-four hours a day, [it seems] they are not preoccupied with planning weekend parties, etc.," Shaffer wrote. There was of course considerable romance around, but there was hardly more than could be found in other dormitories. The Centennial house rules were self-imposed and regulated; and "the students are conscious, too, of the dangers to the College's very existence by reports of trouble in this area," Schaffer said. The Scholars rarely turned their freedom into license, and the Fellows and Scholars alike were pleased by the easy friendship they saw developing.

In February students made formal teacher evaluations. The most striking impression which these created was the genuine delight the students had in the Centennial Program. They liked the Fellows, 
they liked the College, they were loyal to everything that was going on in it. Although they were aware of its limitations, they had a singular lack of harsh judgments. Also in February the Scholars responded to a census designed to discover the number wanting to return to the Program in the fall 1970. Nearly all said they expected to continue. Almost nobody was totally disgruntled. One young girl wrote, "I have been asleep for eighteen years and have just awakened. It's wonderful!" The Fellows were reluctant to accept full responsibility for awakening this beautiful girl, but they were pleased to be present at the occasion and to have been of some assistance.

In March and April we began making plans for our second year, and the loyalty of the Scholars became a problem. We could not accommodate everybody who wanted to stay on. The idea of our community differed from others, we all felt. It had an educational rather than a social or political focus. We were confident that our living conditions contributed to our academic ends. Here we were striving for ratiocination, not for social adjustment; for a critical mind, not for a conditioned response. We were achieving a living situation where the students, as one of them wrote, "could seek out new possibilities and potentials as they confronted the world and themselves." One of the Scholars observed in midyear: "a difficult atmosphere, where there was a lack of freedom and a dearth of inspiration, would produce a disheartened listless student, one generally bored with an unexciting education." He wanted, he said, "a vibrant, vital force in the student's social education so that he could exercise his mind." He thought that we were succeeding in establishing such an atmosphere and such a place.

Not only were our Scholars committed to our Program, but they were involved in intellectual matters outside our walls too. Early in the fall the movie, Midnight Cowboy, appeared at one of the downtown theaters. Urged by the students, several of the Fellows held a seminar on the movie, and serious talk about the movie continued thereafter. Later in the year a student group produced the controversial anti-war play "Viet Rock." A significant number of our Scholars participated in the production. When the Fellows went to see it, they found an alert and involved audience sparked in large part by the Centennial Scholars. During the course of the year numerous visiting lecturers appeared in our Commons Room. They uniformly received a critical welcome, and they were generally delighted by the temper of the questions. Some of the visiting faculty felt there was no place else on campus where they could meet an 
alert group of students ready for discussion as these were. In the spring the University presented a series of speakers on "The World in Revolution." Such visiting experts as Saul Alinsky were in residence for a week. In previous years similar conferences had been rather flat, but this time it was a rousing success. Our own Scholars took a prominent part in all the discussions. Indeed they were often the sparkplugs for their groups. They could not be held responsible for the general success of the week-long conference-the subject and milieu were ripe-but they were involved in it. They were involved in other similar kinds of seminars too; and on more than one occasion visitors at the University found their audience made up largely of Centennial Scholars. Our students participated in the spring political activities following the invasion of Cambodia and the killing of students at Kent State. The campus political leaders were not our Scholars-our Scholars were not among the agitatorsbut our people turned up at all the subsequent conferences and participated in all the meetings. One can only conclude that the Centennial Program encouraged a critical awareness of community as we had hoped it might.

From the beginning the Centennial Program aspired to full democracy, with all persons interested in an issue, both social and academic, participating in its resolution. Early in the year we attempted to operate through a Committee of the Whole. We strove for full participatory democracy. At first the meetings were well attended, but as the year went on the Scholars became increasingly bored and then irritated with the mechanics of community decision. They simply did not want to spend the time required to run their own show. As the weeks and months went by, the idea of a Committee of the Whole lost its attractiveness to most of the community. The Scholars and Fellows who were most committed to extreme political positions continued to attempt to make it work. Unwilling to give up a position or compromise on an issue, they sought consensus on all issues. When they could not get a group to come to agreement, they thought it should divide itself into smaller units and talk some more. It seemed to some that the more extreme liberals were unwilling to sacrifice the freedom of individual choice to group decision; they did not seem to understand that the rewards of community and the rewards of individuality are often antithetical, that they could not have individual freedom and community security simultaneously.

As the year went on it became increasingly clear that most Scholars were willing to allow a representative group to make 
decisions. The alert and the critical only wanted opportunity to review them. Very early total participatory democracy ceased to have much general attractiveness. In fact, by the middle of the year, interest in both social and academic government decreased. Once a system of operation was established, most Scholars were willing to leave it alone. From this point of view they became increasingly conservative. They quickly grew accustomed to a way of doing things, even when the accustomed way was anti-conventional as defined by persons outside the Centennial Program. By midyear we had a kind of conventional anti-convention mode of conduct.

The Fellows had perhaps hoped for more intellectual involvement than the Scholars showed themselves ready for. They were politically aware, they had a sharper social consciousness than we might have anticipated, and they were less eager to have parties than many University students were. The political awareness may have been a part of the times. Perhaps it was the result of their Centennial Course; it was certainly related to the fact that they all lived together and learned from one another. In contrast the Scholars did not develop an interest in the cultural affairs of the campusmusic, drama, and art-that the Fellows might have hoped for. This was probably the result of a failure on the part of the Fellows. The Fellows were so involved with the Centennial Course and the general activities of the Centennial Program that we had little energy left over to direct our students to cultural activities.

For some of us who had seen undergraduates come and go for more than a generation, the change in the undergraduates seemed quite natural, even expected. We were not confident that the development we were seeing was completely attributable to our scheming. Some of it, we were sure, was the result of natural maturity. The question remained: Are we changing these students, or are we just accidental midwives, present at the birth of their maturity? A student told me about Christmastime that it seemed to him that in the Centennial Program the Scholars were forced to take stock of their own aspirations and abilities and to decide their futures and their characters earlier than they normally would. We were, in effect, forcing a bloom. A number of the Fellows agreed with this analysis and thought the effort worth the results.

Why was the residential aspect of the Centennial Program successful? A number of explanations suggest themselves. In the first place the Centennial Center was admirably laid out physically. Our Commons Room was in the center of our complex of buildings so that the students had to pass through it on the way to or from 
classes, meals, and their rooms. They were naturally drawn to conversations there. With a minimum of effort, they had opportunity for talk. In the second place our group was so small that everybody could know everybody else. All year long the students warned us not to allow the administration or other faculty to force us to grow. One hundred seventy-five was about right they thought. In the third place we exploited the propensity of the eighteen-year-old to collective action. Undergraduates, especially beginning undergraduates, want to "belong" and we seemed to be providing for this psychological need. The coeducational aspect of our dormitories must have been very significant too. One of the Fellows wrote: "For healthy freshmen from towns, farms, and small cities in the provinces of America, the extraordinary social freedom has been captivating." Perhaps the exciting sense the students acquired that they were at last responsible for their own education, that they at last must assume their own educational burdens, also contributed to the general success of the residential aspect of the Program.

2

The Fellows and the majority of the Scholars were convinced that by the end of the year our students had become unusually open to ideas, unusually aware of themselves and critical of their world and experience, freer of hangups than most students, cheerful and playful and adventuresome. They were more involved in a social and intellectual world than most. We thought that almost none of our freshmen seemed to go away disheartened by their University experience, and we knew that our dropout rate was amazingly low. We retained far more freshmen than the standard university. We thought that we were less successful with upperclassmen. They had already established social and intellectual habits before they came to us, but a significant number of them found a home in the Centennial Program too.

At the same time we were all aware that our students had not gathered any considerable body of organized information during the course of the year. The Centennial Course emphasized process of thought, methods of investigation, rather than the products of the investigation or subject matter. It was impossible to tell how much factual information they had gathered and we periodically regretted this. We were not always confident either that the process which we were trying to teach was fully assimilated. Perhaps they got neither fact nor method. We thought that the Scholars were not working at anything like capacity. If they had worked harder-that 
is, if they wrote more papers, reported on more books, outlined more essays, completed more formal projects-would they then have been as committed, as self-critical, as intellectually playful as they turned out to be? If we had been more rigorous by standard definitions would we have developed the alertness which we were confident we saw around us? Eric Erikson talks of how necessary it is for young people of a certain age to exist for a time, within a moratorium, to lie fallow and take stock. Our students in not laboring over the books night after night, week after week, may have been experiencing some of the rewards of this stock-taking period.

From the beginning we had planned a pedagogical structure rather than a structure of subject matter in the Centennial Course. We cared less what the student studied than the way he went about studying it. In the first project period of six to eight weeks, we planned to provide the student a question which he would then solve. In the second project period we planned to give the student an area of study; within this area he was to find and state a question which he would then solve. In the third project period the student was to consider a certain range of human experience within which he could locate an area of interest to him and define a solvable problem. And in the fourth and last project period the student was to be liberated to discover his own area, state his own problem, and answer his own questions. The student was to be progressively freed from directions so that he could learn to educate himself.

Our failures were the result of our neglect of this pedagogical structure. We did not hold the total group of Scholars and Fellows to a single pattern consistently. As a result the students often floundered because they did not know what they were to do. In Project 1, for example, some Scholars attempted to discover their own areas and pose their own questions before they were prepared, step by step, for this full task. As a result some of them simply gathered information and left it unfocussed and they felt that they were duplicating high school research: the amassing of facts. By Christmas, some of them thought they had not learned anything. They were in fact already discovering by trial and error that investigations are best conducted when oriented to a central question. They were learning by doing, in effect. Unfortunately we had failed to explain to them what we were up to. We should have told them where they were to go, where they stood in the process, and what they had learned when they were finished.

By attempting progressively to make the student discover his area of interest and find his problem, we hoped to place the burden 
of education on the student. Often we had to wait for him to take responsibility and, as a consequence, the Fellows worried that they did not have enough control over what the students were doing. This freedom-or burden of responsibility-was precisely what we had set out to give the students. We wanted to liberate them progressively from the constant direction of their teachers in order to force them to discover their own purposes. A major part of the Fellows' duty was, then, to wait for them to grow into their own initiative. This was not always easy.

We assumed that the Scholars' curiosity would drive them to their investigations. If we could help them find subjects that appealed to them, we thought that they would naturally investigate them. For Project 1, The Nature of Social Change, we prepared syllabuses with suggested bibliographies and courses of study. We hoped to spark some curiosity with leading questions. Apparently we were too explicit, for the students felt themselves trapped into a predigested course. They had been there before. Further, though the range of topics was as wide as we could make it, many of the Scholars were not really taken by any of them. Yet, when we invited them to suggest topics of their own, they had few nominations. They had a limited curiosity about the nature of witchcraft, repressive institutions in America, the spirit of the 1960's, the structure of the city, and even the experience of the American Negro. It may be that we had overestimated our students, that they had too small a stock of information over which their imaginations could work; perhaps they could not really become curious until they had more fact. It may be that we caught them off guard. They had been told what and how to study for so long that their imaginations had simply not developed independently. Later in the year they certainly came up with topics they wished to investigate. It may be that our general theme, The Nature of Change, was too vague, too sophisticated, for them. In attempting to make it inclusive, we may only have succeeded in being disparate. At any rate in this first period many students did not find themselves challenged by the proposed topics sufficiently to carry them through seven or eight weeks of study.

Once the Scholars had willy-nilly committed themselves to one or another topic we sorted them into common interest groups. In these groups of not more than sixteen we thought leadership would naturally emerge and the students would both stimulate and instruct one another. Leaders did emerge and, interestingly enough, they were not always the upperclassmen. Definable and workable prob- 
lems were found and general methods of attack laid out, all in large part by the students themselves. The process was slow, but it worked. The failure came in the general failure of the students to persist in their search for the solutions to their defined problems. They were impatient and did not get deeply into their problems. We had set seven weeks for the completion of the projects, the eighth to be a time of reporting. We hoped that a public summaryreport in this week would focus the group activities. As it turned out, however, the reports were often an unnatural forcing of what had come to be rather divergent interests. Apparently the topics were not sufficiently controlling for inquisitive students, and, at the same time, they allowed the easily wearied and the lazy to discover that in this novel environment inertia was permitted.

Half our troubles were the result of our failure to supply suffcient motivation for study. The other half came in our failure to provide sufficient reward. We had assumed that if we allowed the student to study what he wanted, if we encouraged him to search for answers to questions that he himself posed, he would find the search its own reward. We hoped that he would find that he needed no recompence beyond the pleasure of learning. Further we had hoped that his pleasure would be reinforced by the praise that he earned from his peers when he delivered his report. Neither assumption was sound. The student wanted more rewards than simply knowing, and peer pressure was not rigorous. It was, rather, capricious. We found that grades had been so long the whip and the carrot that students seemed incapable of reacting to other schemes; personal satisfaction and pride of performance did not seem to be enough, at least in this first year. We may have been expecting too rapid change in the students.

The whole matter of grades was a continual difficulty. Though we had encouraged the students to elect pass/fail over standard letter grades, each student could decide his grading system for himself. Initially more than half elected pass/fail. In Project 1, the community of Fellows and Scholars decided that every group should grade every other group's public presentation; through this mutual judgment we hoped to develop cooperation and competition both. Students within each group were also to grade each other. The group grading at times degenerated into hard adversary situations; the individual grading ascended into euphoria. The result was chaos. The grading system as established by the students themselves was unsatisfactory, and the students no less than the Fellows acknowledged this. They quickly learned that grading was a more 


\section{4 / First Years of a Cluster College}

difficult matter than they might have thought. In Project 2 the grading system was changed. The students now elected to have grades allotted within the study groups by the students themselves. This system was considerably less complex and cumbersome than the group evaluations but adversary situations again arose. Nobody was really happy with this system either. The problems of grading remained with us throughout the whole year. As a result of our concern for motivations and rewards we discussed the nature of education, its purposes, and its structure for the whole year. By spring it had become the central topic of controversy throughout the community. This we thought was all to the good.

In Project 1, The Nature of Social Change, we had attempted to direct the students to the examination of certain social questions confronting them in their contemporary world. In Project 2, Stasis, we asked the students to define a question within a limited area, the areas being one or another ancient, exotic society. We asked the Scholars to be concerned with societies not their own, to develop a historical sense. When Project 2 began the students rather quickly formed themselves into study groups of appropriate size and, in many cases, quickly laid out plans of study. By the end of the sevenor eight-week study period, a good many of them reached conclusions and made group reports. The period was not generally regarded as totally successful however for a number of reasons. For one thing some of the students who were studying the ancient Egyptians, say, found themselves decreasingly interested in their area of study. For another, a Fellow's disinterest rubbed off on the students. Many Scholars and some of the Fellows thought the subject matter too restrictive and protested that we had subordinated our general pedagogical method to subject matter. They suggested that we attempted to impose a discipline of subject on a discipline of method. They thought we had lost the idea of change in our particular concern for South Sea Islanders or the Amish communities. On the other hand some of the students found certain aspects of the study of Stasis particularly rewarding. When a group worked with a Fellow who was no expert on a topic, they were freed to raise questions that they were too shy to ask when working with a specialist. They found this freedom exciting. Both they and the Fellow searched out campus experts and learned tomes and they learned together.

By the time Project 2, Stasis, was complete, the students' willingness to substitute pass/fail for standard grades was weakening and a significant number of serious students asked to be returned to 
standard grading. They had come to realize that the rewards within the educational community were geared to grades. They would find themselves at a disadvantage in the competition for scholarships and prizes if they stayed out of step, they thought. They came to realize that an island of pass/fail in a sea of A, B, C, D, F, could only be a place of temporary residence. The Scholars prudently calculated the limits of risk. The Fellows generally sympathized with the dilemma. The Scholars found themselves yearning on the one hand to escape the whiplash of arbitrary grading in order to be free to pursue their education as they themselves could define it, and on the other hand they did not want to count themselves out of the real financial and social rewards of the Establishment.

When we began Project 3, The Nature of Environmental Change, we tried to correct what seemed to be some of the deficiencies in Projects 1 and 2. It had seemed to us that the lack of a common intellectual background within which to select an area and a problem could be corrected. We asked all the students to buy Hardin, Population, Evolution, and Birth Control, A Collage of Contraversial Ideas; ${ }^{1}$ and Shepard and McKinley, The Subversive Science, Essays Toward an Ecology of Man; ${ }^{2}$ and through the study of these various essays find subjects they wished to pursue. We hoped that these volumes would provide our students with a fund of common information and that through them they would become engaged in problems dealing with environment. By now a great many of our students wanted to escape from the books and get into political and social action. They wanted no more theory; they wanted to observe schools, to make surveys, to examine small towns, and to study the jails, firsthand. In some respects the students had become less like their professors than they were initially; professors are by nature speculative rather than activist. The students were off on their own.

In Project 3, The Nature of Environmental Change, at least 25 per cent of our Scholars took full advantage of our open classroom and devoted themselves to the local ghettos, to the nearby Indian reservations, and to other social problems. Some worked very hard in the field. One would guess about another 25 per cent were unengaged and found themselves doing little more than reading a few books or a few articles in a desultory fashion. They were a bit on the defensive among their peers. The bulk of the Scholars in this period gathered information about various environmental prob-

\footnotetext{
' Garrett Hardin, ed. (San Francisco: W. H. Freeman \& Company, 1969).
${ }^{2}$ Paul Shepard and Daniel McKinley (Boston: Houghton Mifflin Company, 1968).
} 
lems and puzzled over its meaning. The Fellows were not confident that they had uniformly posed questions and sought answers in the fashion that we had hoped for. Their attention was engaged but it may not have been fully disciplined. Still, something was going on with them. The students had themselves decided that the public presentation of their results was no longer necessary. The idea of community seemed to be replaced by an admiration for individual actions, and the exact result of the individual action was sometimes hard to estimate.

One of the students told us subsequently that he had at first been upset at seeing that some people gave no appearance of doing anything. He thought that they were goofing off. But, he said, it then occurred to him that if these persons were taking ordinary courses in the standard university, they would be doing less, but there they would be masquerading their inactivity with a shew of busy-ness. They might be grinding out papers to which they gave no thought and preparing for examinations by hasty and temporary cramming. He stopped being disturbed by these inactive persons, he said; in the Centennial Program at least they were honest. It was the Fellows' conviction that there was a minimum of hypocrisy in what was going on, in what was being reported, and in what was being accomplished, and the students were clearly on their own, pursuing their own ends.

The final weeks of the year were disturbed by student activities following the Cambodia venture. Project 4, which was to be devoted to the study of Utopia, began with the general reading of a volume containing some of the more famous utopias from Plato to B. F. Skinner. The students organized seminars on subjects of their own interest, as we had hoped they might. Some Scholars concerned themselves with political utopias, but most were concerned with education and possible reorganization of educational systems. They had no general direction in this project, no "structure." Structure had become an unholy word by now. Some of the natural leaders of the community had persuaded a large group that all imposed order was tyranny. In Project 3 a number of groups had prepared public presentations. In Project 4, Utopia, there were no group presentations. The last six weeks were devoted to independent readings and individual research.

The pattern of the year was clear: from group direction and group study early in the year to increasing individual work until finally, at the end of the year, almost total independent research for independent results. In Project 4 a great many of the students 
read the same books-Walden II, Brave New World, Looking Backward-and carried on informal conversations about them. They neither sought nor willingly accepted directed seminars. Some of the Fellows would have been glad to help them come to a fuller understanding of their reading, but the students did not take up their offers of help.

The problems of motivation and reward which confronted us in the Centennial Course also existed in our experimentations with languages and mathematics. Our Spanish courses turned out to be little more than the standard classes taught in a new setting, the lounge rooms of the Centennial Center. We had no new materialswe could locate no films or striking tapes-and the social opportunities for conversation did not develop, though we had a number of Scholars who spoke fluent Spanish. In fact the students could see little reason for bothering with conversation groups. They did not make great use of the Spanish room either-its books, records, or papers. Apparently they were not sufficiently interested in learning to speak for its own sake. The interest in French was higher. The filmed lessons, which we showed the beginning students, sparked them into talk and carried their commitment. But the informal coffee-hour seminars did not flourish, and the special sessions of conversation which we arranged quickly became little more than other assigned classes. In them they did little more than repeat standard phrases to a pretty young woman rather than to a machine. The human interest which we hoped would buoy them up did not develop, for the most part. Students studying German had similar experiences. The various periods of informal conversation became just more assigned classes. They had no more pleasure and reward from them than from language labs generally.

One of the Fellows, who watched the languages most closely, thought the students' irresponsibility toward learning languages was "symptomatic less of a Centennial Program syndrome than of a malaise just surfacing more widely in this and other universities." It may have been that the freedom we encouraged in the Centennial Course contrasted sharply with the necessary rigor of language study. We rarely succeeded in combining the subject matter of the Centennial Course with the study of languages, and the two areas of work were thus too frequently mutually exclusive, in both manner and content. The progress of our language students was by no means inferior to that of comparable students in the greater 
University, our language teachers told us; but they were not superior either. We concluded that in our second year we needed to arrange a richer context for learning languages and to show the students greater reason for studying them.

The mathematics program was more boldly conceived and it yielded more explicit results. It was essentially an independent study program: each student was to proceed at his own rate to whatever level of mathematical competence he sought. Freed from compulsory lectures and quizzes, at the beginning a great number of students had difficulty assuming responsibility for themselves. By the end of the first semester only half of them had completed the work that students ordinarily finish in that length of time. On the other hand two or three of them completed three times that amount. By the end of the year, more had risen to responsibility, and the number of Centennial Scholars who had completed the standard work was comparable to the number of students in the greater University. The "incomplete-flunk" rate was not higher with us than in the mathematics department, and a significant number had profited enormously.

But though on the whole Centennial math students ended with the same credits that ordinary students ended with, they had had a different experience. Early in the year all the math students agreed that they would work until they had reached an "A" level. They wanted not only competence in solving set problems required of all math students; they wanted to understand the principles of mathematics. They wanted competence in mathematical thought, and it was for this as well as problem solving that they were to be examined It remains to be seen how well the Centennial Scholars do in subsequent math courses, but the math counsellors were confident by the end of the year that the " $A$ " level earned by their students was deserved: they had learned more than how to solve set problems. They had side benefits from this independent study, too. They learned something of their own tenacity, commitment, and seriousness of purpose. After their experience with math, there was no longer any place for them to hide.

Our conclusions about teaching beginning mathematics were made available to the University generally. It seemed clear to us that some students-perhaps as many as 30 per cent-can do well with independent study. They progress at their own rate and develop adequate skills. We estimated that the cost of an independent study program in math would not be greater than ordinary math courses; and we recommended that an independent study program 
be built into the standard mathematics courses for those students who chose to elect it. These would be students with a special interest in mathematics, though not necessarily honor students.

For students who study mathematics for cultural reasons, it seemed to us that a different kind of course ought to be instituted. These students responded no better to independent study than to regular lecture-quiz section classes. They needed a course in the history and philosophy of mathematics which would emphasize ideas rather than problem solving. Such a course, we thought, ought not attempt to prepare a student for the next higher "professional" course; it ought to be its own excuse for existence. Students who want mathematics as a tool only-science, engineering, and other professionally oriented students-need a tightly structured course, we concluded. Their needs are in sharp contrast to the needs of the general student and cannot be filled by either independent study or the cultural course.

Altogether it seemed to the mathematics directors that the central problem in teaching mathematics appeared to be the student's willingness to memorize procedures, proofs, and solutions when he should strive to understand basic principles and processes. $\mathrm{He}$ substituted memory for thought. He clearly needed a different kind of instruction, examination, and grading from what he normally got in secondary schools and elementary courses. To these ends we planned to devote ourselves in the second year of the Centennial Program.

\section{4}

As in many universities around the country, the school year 1969-1970 ended in some upheaval. A number of conclusions can be drawn from our experience with the academic program nevertheless. It seemed to some of us that we had spent a great deal more energy on the matter of grades than the subject deserved. Any grade a student gets is a kind of shorthand, and everybody after a moment's thought recognizes that. In attempting to substitute one system of grading for another, we were attempting to construct a method of evaluation which was independent of a teacher's integrity. If a teacher takes his teaching and his grading seriously, then all the elaborate checks and balances are irrelevant. Those who do not take the system, any system, seriously, who busy themselves with other matters, cannot be reformed by changing systems. The problem was human, not procedural. By the end of the year it seemed to some of us that a conventional grading scheme was as good as 
any other; at least in it the student knew what the teacher thought of the quality of his work, or he could quickly find out. These grades had a conventional core of communication.

For the teacher the conventional system was efficient. By using the standard marks the professor can complete his records quickly. During the year the Fellows tried to write short evaluations, a few sentences, about each of the Scholars they worked with. They found this a considerable task, time consuming and redundant. We asked the Scholars to grade themselves, but in doing so we also asked the Scholar to forego the advantage of a mature judgment of his work. A student deserves to know what his elders think of the quality of his work, even if the elders are sometimes mistaken, being human; so may the student be. When we asked students to grade one another, we too frequently failed to provide them with standards with which they could measure performance. They were adrift. But when we provided standards of measurement, we poisoned the wells. In short, our experimentations with grading made some of us more conservative than we had been at the start.

We reached some other conclusions too. We finally realized that natural curiosity was not sufficient motive to sustain a beginning student coming from a conventional high school through any lengthy period of study. The intellectual pump had to be primed frequently, either by recommended readings or by stimulating people. In our plans we had failed to realize that the range of the students' commitment was not yet determined and that they were eager to try out a variety of things, if for very short periods. We had failed to provide the necessary cafeteria for them to select from.

One of our more thoughtful critics, an engineer, questioned our basic assumptions about problem solving. He said that though he was in the problem solving business himself, being an engineer, he understood that problem solving was only one small aspect of intellectual activity. The arts and the like, he said, are not amenable to this approach. To react to a play or to view a picture did not require him to "solve a problem"-except in a very technical sense; and to see a work of art as a technical problem is not to distinguish it from a steam engine, which it demonstrably is not. His criticism was cogent but incomplete. We oriented our studies toward problem solving not because we thought this the fundamental or exclusive intellectual activity, but because we thought it a useful way of engaging a student's attention. We wanted at the start to show a certain immediate utility for intellectual activity. We hoped to teach him to direct his thinking, not simply to gather wool, to memorize, 
or to collect information. By proposing one method of thought, we hoped to sharpen his reasoning faculties. We agreed with our engineer-critic that to continue this technique throughout an undergraduate career would be misleading, and this we certainly did not propose.

Finally some of us concluded that we in the Centennial Program were attempting to solve structurally what were probably not structural problems. The troubles with contemporary education were not the results of three-hour class schedules, sixteen-week semesters, and heavy reliance on grade point averages. We attacked the letter of educational law rather than its spirit, and the illness was in the spirit. What was needed, we thought, was a synthesis of ideas and facts leading to an understanding of relationships between things, not ceaseless analysis. Our students too frequently got professional answers to human questions. When they asked, What is the Good Life? they were told about the Thirty Years War and cost accounting. When they asked, How can I reconcile my aspiration and my parents'? they were provided with figures about crime in urban America. Even in literature courses they dealt with techniques of drama and types of poetry when they needed to discover how other persons had resolved their human dilemmas. In short, when the students attacked the large, necessary questions, they got partial, specialized answers, if any at all. Asking for bread, they got stones. Our students wanted us to be wise men, not specialists. They wanted us to reach for understanding, not technical competence alone. But, alas, wisdom cannot be programmed, nor its attainment measured. Moreover, as professors we may not feel that we have the competence, or the audacity, to set out on so noble an endeavor as the search for wisdom.

In the Centennial Program our Scholars responded eagerly to our attempts to synthesize what we knew or could find out. They respected our efforts to bring all we learned into their focus. Together we had asked the hard questions: As things change, do they remain the same? What is it to be educated in a changing world? What is it to be a man? And we did not force an answer, for we were not confident that we had one. If we could come to no conclusions, we were not the first. The issues had been raised. Perhaps that was accomplishment enough for the first year. 


\section{Student Development:}

A First Year Look

By Robert D. Brown

I

T Is DIFFICULT to summarize the data and observations gathered from the 150 students of the Centennial Educational Program in the pages that follow, much less in a few hundred word overview. But in briefest summary $I$ conclude that during the first year the Centennial Educational Program (CEP) was most successful in establishing an atmosphere similar to that usually associated with a small college. The students knew each other, were close to the faculty, and had a high degree of college loyalty. Many students were deeply affected by their year's experience and attributed this to their associations with other students and teachers.

The academic accomplishments of the Program were less notable. Students were influenced more by their informal associations than by their studies. Though the Program and the faculty in a number of ways were more attentive to the needs of the vocal upperclassmen than to freshmen who were often shy, it was the freshmen who were affected the most. These 1969-1970 CEP freshmen were significantly brighter and more receptive to new experiences than the typical University of Nebraska freshman. The CEP was not intended to become an honors program, but in effect it was one in its inaugural year. When we compare the Scholars' development with changes occurring in an equally talented group of freshmen not in CEP, however, it becomes clear that the CEP experience had a positive impact unmatched elsewhere in the University.

In the future, if the Program is to have meaning for the rest of 
the University, a clearer delineation of the goals of the Program and a refinement of its unique dimensions need be made. Unless this is accomplished, it may serve the needs of a small group of students but it cannot achieve the fullness of its potential. During the first year it tended to be more an entity unto itself than the experimental proving ground it set out to be.

The purpose of this chapter is to summarize observations and data which relate to the impact that the CEP had on students during its first year. While the sonorous speculations of the CEP Fellows and the arduous responses of CEP students might make more interesting reading, this chapter presents reality from another vantage point, that of verifiable data with conclusions based on that data. Happily, these conclusions largely confirm the independent perceptions of those directly involved with the program. They provide a basis for continued analysis of the direction of this program and of possible goals for future programs. This chapter should provide convenient information for those who wish to know the outcomes of an experimental college venture and to learn from its experience.

The Centennial Educational Program has been referred to as an "experimental college." For the scientist this expression needs exposition. If an experiment necessitates the inclusion of a clear statement of objectives, a description of well-defined treatments, and a random assignment of treatment subjects, then the CEP program cannot be properly called an experiment. However, if a playful and adaptive approach to education, with a constant search for effective and novel ways of stimulating the college freshman to learn is an acceptable definition, the term "experiment" is appropriate. The CEP must be considered such a "humanistic experiment." This is an important distinction, in my mind, for the triumphs of the first year of the CEP rest largely with its success as a humanistic venture. Its design did not permit the collection of hard data to support specific pedagogical suppositions.

Before proceeding with a discussion of the results of this experiment it is important to examine briefly its implied and expressed goals and the nature of its participants.

\section{Goals and Means}

The goals of the CEP have been discussed by those involved in several position papers and publications. These should be examined in detail. (See Chapters I and II.) The program was intended to establish a living-learning environment which would foster aca- 
demic-intellectual and personal-social growth of students. The program included a residential setting, with classes held within the same building as living quarters, a core course of six hours offered on an optional pass/fail basis, and an emphasis on group and independent work on self-selected topics. Students were to play an active role in college decision-making situations, both social and academic. The faculty (Fellows) hoped that such a program would improve the student's problem-solving skills, increase his interest and participation in intellectual and cultural activities, enhance his self-confidence, result in a higher level of satisfaction with collegiate experiences, and move him towards curiosity about and discovery of himself, the world, and others.

The Fellows were convinced there must be better methods to arrive at these goals than the typical university setting provides, but they had no universal agreement among themselves concerning what these methods might be. They hoped to search with the students during the year to find new avenues consistent with their goals. As they continually evaluated their achievements, this diversity provided fertile ground for debate among students and Fellows alike. The vagueness of the goals and the inconstancy of the means, however, made discernment of degrees of success or failure difficult.

\section{Participants}

The CEP was originally intended to be suitable for the typical Nebraska student and it sought to avoid the connotation of being an honors program. But, even though the final selection process was random, there was a good deal of initial screening of applicants. Of the over 800 who applied, approximately 5 per cent were scratched because of low College Board scores and poor high school records. In addition a small number of students, again about 5 per cent, were admitted for special reasons including color and ethnic background. As a result the freshman class of approximately 125 students was indeed a select group, with a near dozen Regents Scholars. Even omitting those specially selected, the average College Board scores of the CEP students were nearly 100 points above those of the typical Nebraska freshman. This initial CEP class represented the top 20 per cent of the total University of Nebraska-Lincoln freshmen and cannot be considered "representative." (See Table 1, page 67 , for comparisons of applicants, accepted CEP freshmen, and nonapplicants.) The CEP freshmen differed in a number of other significant ways from typical Nebraska students. They were not only brighter, but they were more liberal, less vocationally 
oriented, and more interested in literary and dramatic activities than the general UN-L freshmen were.

The forty upperclassmen in the program were carefully selected. On the whole they were brighter and more concerned than their University counterparts. A significant number were active in campus politics, and they tended to be more independent and assertive than other upperclassmen. Their alienation from the regular University was balanced by their intense concern for its improvement. Most were quite effective in communicating with others intellectually, but many were unsure of themselves socially. The Fellows were also a rather select body. All had reputations as outstanding teachers and scholars, and many had received awards as "best teachers."

To say that the program was not an honors program then is somewhat misleading because it contained highly select students and faculty and this combination constitutes the major ingredient of most honors programs. The self-selected titles of "Scholars" and "Fellows" were also hardly egalitarian. The unrepresentativeness of the CEP participants may limit the generalizability of its outcomes and its significance for the total University community. Nonetheless, it was possible to compare changes in CEP students with changes occurring in an equally talented group of regular University freshmen who had applied to the CEP but were not selected. This made it possible to assess with some validity the particular effects of CEP.

\section{Assessment Techniques}

Because the tactics and the goals of CEP were varied and comprehensive, it was appropriate to use an equally variable approach in assessing student growth. Personal interviews, observation, questionnaires, and self-reports formed part of this process.

The focus of the assessment was three fold. We sought: 1) to examine the effectiveness of the living-learning environment, 2) to determine the academic-intellectual growth of the students, and 3) to note personal-social growth. CEP students were compared first to themselves (fall-spring) in order to discover how they had changed. They were then compared to a random sample of students of comparable ability who had applied to the program but were not selected. This control group of students differed only in one known essential-they were not in the CEP.

Comparisons among three groups might have been made: accepted applicants, nonselected applicants, and regular University students. In view of the highly select nature of the accepted students, such comparisons would not only have been inappropriate but 
misleading, so the original intention was dropped. The reader is cautioned to note that continued references to comparisons are between two comparable groups, but both of these groups are distinctly different from typical Nebraska students. In almost all instances, references to differences between the compared groups are to those that were statistically significant.

The questionnaire and interview formats used here were devised specifically for assessing the impact of college experiences on students and they have proved valuable in evaluation of other major experimental colleges. When necessary, they were revised to fit the specific needs of the project. (See page 68.) A highly recommended quasi-experimental research design was employed (Campbell and Stanley, 1966). This is known as a separate sample pre-test-post-test control group design. This procedure permitted assessment of beginning and end-of-year reactions of two groups of students to a wide variety of questions, but no student was required to complete the same questionnaire twice.

\section{Living-Learning Environment}

The term "living-learning environment" has vague connotations comparable to the equally overused and underexplored phrase "community of scholars." Both remain, however, idealized goals for most members of the University, and the establishment of an environment where students could both live and learn was one of the major goals of the CEP. In this setting faculty and students would work together toward mutual understanding of old and new knowledge. Out-of-class and in-class distinctions would fade as intellectual activity, confrontations, and discussion occurred at all times and places. As a result, students would achieve intellectual maturity in their feelings toward themselves, other students, faculty and the College.

Probably no other general goal of the CEP was as fully achieved as this. In many respects the CEP developed the climate usually associated with a small, perhaps elite college. The simple convenience of living where faculty offices were located, where classes were held, where a lounge and congenial companionship were readily accessible had a profound impact upon the participants. At the same time the gulf between the idealized goal and its attainment remained substantial.

A comparison of the expressed attitudes of freshmen within the CEP to those in the total University concerning student-faculty relationships dramatically supports a conclusion that the CEP had 
a singular environment. As compared to freshmen in the total University, by overwhelmingly significant margins CEP students believed their teachers pedagogically superior, more professionally competent, and more tolerant of dissent. They thought that their faculty members were more interested in teaching, provided more opportunities for private talk, and exhibited a more personal interest in them. The almost universal conviction among CEP students was that the College was devoted to their individual concerns as persons. These opinions can be enumerated here, but the fervor with which they were held can be fully felt only after personal discussions with CEP students. Some students in the regular University offered testimony to the warmth of their relationships with faculty members, but their over-all reaction might be summarized in the words of one freshman: "I don't know many of my teachers too well, but the few I do, I get along with." Most CEP students, on the other hand, felt that they could approach at least one Fellow directly with personal questions. Testimony to the effectiveness of this relationship is the fact that the CEP students wanted even more contact with faculty. "I wish they could be around more in the evenings when they and I both feel more relaxed and freer," was a repeated comment of the CEP student. This informal personal contact seemed to meet a profound need among the students.

\section{Student-Student Relationships}

Students spend more time with each other than they do in class or in the lab. How they view and interact with other students is important and often it has the most significant impact upon their views and futures. This was especially true for the CEP students. When asked what proved to be the source of their most satisfying experience on campus during the year, a third indicated "other students." Compared to regular University students, more CEP students saw their peers as honest, more saw their peers directly confronting controversial issues, fewer saw others using "pull," and fewer saw other students as overly concerned about the amenities of social life.

In CEP certain definite patterns of social behavior that might be attributable to the environment could be identified. The common classroom areas provided greater opportunity for informal contacts between men and women than was generally available in the University. As a result, there was less formal dating and more opportunity for informal associations among friends. Significantly fewer CEP students reported themselves engaged or going steady 
at the end of the year than regular University students. The depth of the Centennial friendships, however, was not markedly greater than that elsewhere. In fact, the CEP student might be characterized as being on the loner side of the extrovert-introvert continuum. $\mathrm{He}$ was more independent. Because the CEP student was not forced by his living environment to be dependent upon only a few close friends, his personal relationships for the most part were not as intense. This does not mean, however, that close friendships did not develop.

The upperclassmen proved to be both a hindrance and a help to the freshmen. They served as a major source of assistance to freshmen with personal and educational problems. But in academic group work a significant number of freshmen reported that the challenge of "competing" with upperclassmen was rather frightening. The fact that the upperclassmen were bright and generally verbal intensified this fear. At the same time a number of upperclassmen were concerned with the timidity of the freshmen.

There is little doubt that the upperclassmen became models for the freshmen in some respects. Both freshmen and upperclassmen expressed concern that much of the freshman response was faddish. They saw upperclassmen's notions about politics and education, for example, accepted without much thought.

\section{Activities}

Although the CEP students as a group were more committed to a living-learning environment than their regular University counterparts-they had more contact with faculty, more informal intellectual discussions, and more participation in academic planninga substantial number remained uninvolved. With some deliberate effort, it was possible for a CEP freshman to avoid rubbing physical or intellectual shoulders with other students. Townhall meetings, where academic and social decisions were made, were seldom well attended except when a vital issue arose; and students joining public seminars tended to be repeaters. The same core of upperclassmen with a few freshmen appeared at all announced meetings; others remained "strangers." Efforts to "involve" these strangers were often ineffective, and as a result students and fellows alike tended to ignore them on the assumption that "they exercised their free choice" in the matter. Centennial students seemed to divide into two groups. More CEP students shunned TV and card-playing than other University students, but a greater percentage of them were addicted viewers and card players. Similarly CEP had more 
active student leaders per capita than other University units, but only slightly more students professed any general interest in student government. The atmosphere seemed to stimulate some, to pacify others, and only a relative few were left untouched, in the middle.

Despite this core of uninvolved students, the CEP was clearly a warm, friendly place which added a definite personalized dimension to the collegiate experience not often available to the regular University student. It quickly gained a campus-wide reputation as a place where visitors could be expected to draw an appreciative but critical after-supper audience. A good number of well-known figures appearing at University-wide symposiums appeared there; they acted almost as a secondary faculty and made a valuable contribution to this special environment. They often reported their encounter with CEP as the high point of their University visit. Altogether the over-all morale of the CEP students was substantially higher than the morale of regular University students. Though the CEP had its share of internal critics, it had a pervasive atmosphere of mutual trust.

Image

As a result of the free nature of its curriculum and the degree of student involvement in decisions, the CEP gained a reputation for being more free-wheeling, leftish, even hippy, than other student groups. This reputation was relatively accurate, though exaggerated in many quarters. To this observer, this liberal atmosphere was due more to its particular combination of activist upperclassmen and open, impressionable freshmen than it was to any curricular aspect or policy decision. Given a more widely based student body, this atmosphere would have been tempered or altogether different.

Both planners and participants will have to be concerned about the image of the Program in the future. How the CEP is viewed by parents and advisers will affect the nature of future applicants, and how it is seen by the faculty will influence the reception of recommendations rising from its experimentations. This concern for reputation is therefore more than simply a concern for public relations.

\section{Centennial Course and Academic Achievement}

Since the Centennial Course itself was not designed to accomplish goals directly similar to regular University courses, e.g., English or history, it cannot be directly compared to them. In it students chose the topics that they wished to investigate, irrespective of dis- 
ciplinary limits. They focused on the development of skill in problem-solving, on critical thought rather than on a specific body of knowledge. In an attempt to determine the degree to which this objective was accomplished, a small sample of students in CEP and the regular University completed a test designed to measure ability to think critically (Watson-Glaser Critical Thinking Appraisal, 1964). The results revealed no significant differences between the performances of CEP students and a comparable group of regular University students. Observation and interviews with CEP students suggested that individual performance in the CEP course was extremely variable. More CEP students were deeply involved in their topics than might be expected in regular courses, and more CEP students were less involved and performed at less acceptable levels. The interested student probably worked harder than he would have in a regular class. The critical variable was motivation, not ability; a few quite talented students were seldom stimulated to do much of anything, and a few students of mediocre ability achieved more than would be expected.

The process of establishing a format and expectations for the CEP course was a painful, if not traumatic, experience for the Fellows. Their false starts and ambivalences are better chronicled by them, but it was clear that the students felt a great ambiguity concerning what was expected of them and the level at which they were to perform. With each student working at his own "thing," comparative judgments were difficult. With some notable exceptions, group work leading to group products was only moderately successful, in large part because neither the Fellows nor the students knew how to facilitate group functioning. There were no readily accessible models for them to emulate.

Almost as a last resort rather than by design, the program shifted gears at the end of the first semester and became a modified program of independent study. Frustrated students who could not cope with what they characterized as inefficient group work found independent study more rewarding. This was particularly true for the upperclassmen who, some people thought, tended to dominate the group sessions. Rightly or wrongly, many freshmen felt intimidated by the eager upperclassmen. While this independent study permitted an earnest student to work at his own speed, at what he wanted to do, it also provided the less motivated student with an opportunity to get lost. It was not unusual for two Fellows to be under the impression that a particular student was working on an independent project under the supervision of the other. The initial 
excitement associated with the new freedom waned considerably by the end of the year. Numerous projects were abandoned or finished hastily. The students reported that they felt the course was easy, and relatively few felt that the faculty pushed them to hard work.

For the faculty this year provided opportunity to test out various approaches to teaching that they had been considering for some time. Since the educational philosophy of the Fellows varied, the variety of expectations confused a number of students. As a result some of the group and individual projects were exceptionally well done-judged by standard academic criteria-and some were not. Other students showed that their quasi-academic efforts-activities hard to assess within usual patterns-had a significant impact upon them. For a good share of the students, the CEP course proved beneficial by giving them freedom to work on something they wanted to do and a chance to discuss personally meaningful issues with other students. It provided time for them to work out some of their own personal and social goals.

In several ways this free experience had a general impact upon the academic styles of the CEP students. Questionnaires and interviews showed that, compared with regular University students, more CEP students took notes from textbooks while they read, used the library, read unrequired books related to their courses, and felt better prepared for course examinations. There were also clear differences in the type of academic experiences they preferred. CEP students showed a stronger preference for participatory academic activities-independent work, original research, and class discussions. In general they were more satisfied with their grades and courses than general University students. Fewer were bored with their first year experience. CEP students did not differ from other students in their feelings about the relevancy and importance of grades, in their day-to-day study habits, or in their perceptions of their ability to concentrate.

The pass/fail option for the Centennial Course was taken by roughly two-thirds of the freshmen. The grading distinctions between those electing this option and those receiving grades, however, were minimal as no student received an F, and of those graded few received a grade lower than $A$. There were some interesting differences between the students who elected the graded option rather than the pass/fail. The students who asked to be graded were somewhat brighter, earned higher grades in their other course work, received better faculty ratings for academic-intellectual 
growth, and showed more intellectual curiosity and openness than pass/fail students. The adventurous ones seemed to elect grades rather than pass/fail.

This was in actuality a pass/incomplete system. This option provided a number of practical problems, few of them directly related to the rationale of pass/fail grading. For some students there was an inverse relationship between the amount of effort put forth in the ungraded CEP course and the graded exams and papers of standard courses. But students reported a similar ebb and flow of effort even in graded courses. This inconstancy would probably be less evident if all a student's courses were graded pass/fail. Another problem is that related to computation of grade point averages. The "pass" is not counted in the GPA, sometimes to the student's disadvantage. Should a student receive grades of $D$ and $C$ in regular classes and a $P$ in a pass/fail course, his GPA is then recorded as less than a C. His work-perhaps excellent work-in the ungraded course thus goes unacknowledged.

Grades are ubiquitous criteria of academic achievement, and though they have been found intuitively and empirically to have relevance to little else than performance in other graded situations, they remain of interest. A number of comparisons were made between the grades earned by CEP students and their counterparts within the regular University.

The grades of CEP students in the CEP Course who took it under the graded option were first compared with the performance of students in the control group who were enrolled in regular University humanities and social science courses. (These regular University courses came closest to matching the objectives and experiences of the CEP Course.) The regular University students did well in these courses (above a B average), but their over-all average in humanities and social science courses was significantly lower than the grades earned by the few Centennial students who took the CEP Course for grades.

The grades of the CEP students and the matched sample of students in the regular University were also examined to determine whether or not there were any significant differences in first semester averages, second semester averages, and first year cumulative averages, with the CEP Course grade omitted for CEP students and humanities or social science grades omitted from the averages of the regularly enrolled students. These comparisons yielded no significant differences in the grade patterns of these two groups. Students in the Centennial Program had better than a $B$ average for 
the first year, as did students with comparable abilities and past achievements, who were in the regular University program.

Several language and math courses were part of the CEP curriculum and covered standard subject matter as specified by the math and language departments. CEP courses were taught with materials and styles different from those used within the regular University. It was anticipated that both the uniqueness of these methods and proximity of the students to one another and to the materials would enhance the educational benefits. It is difficult to make meaningful comparisons, but the students in the CEP earned significantly lower marks in their language courses than their counterparts did. The teachers of the languages sections, however, reported that students in the CEP sections were more uniformly enthusiastic and performed better than did students in regular University sections. It is difficult, however, to determine whether or not these differences were attributable to differences in ability or the CEP experience.

Grades are an even poorer criteria for judging the effectiveness of the math program. The students elected to operate under an A/incomplete system for math. A student was to continue working until he had reached A level-until then his work was "incomplete." This system seemed reasonably successful, with no more students receiving "incomplete" in the CEP course than ordinarily failed math. Proportionally, twice as many CEP students as regular University students went on to take a more advanced math course. Approximately one-half of those obtained A, the rest $I$. Among the regular University students who took the advanced math course, the grade average was $\mathrm{C}+$ with one-fourth of those enrolled receiving a D or F. Roughly the same pattern held for the lower division math courses. These results for both math and language seem inconclusive. More observations over a longer period of time need to be made.

\section{Intellectual Orientation}

There were significant changes in the CEP students' intellectual orientation during the academic year that were not matched by students in the regular University. The CEP freshmen at the end of the year showed a profoundly greater interest in reflective thought and a greater breadth of interest in ideas than their counterparts. Their interests grew to include greater concern for the use of reason and for using logic in problem-solving. These changes were accompanied by an increased fondness for novelty and a greater tolerance 
for ambiguity. (See Table 2, page 67.) The typical CEP student was more intellectually curious, more tolerant of new ideas and, in most faculty definitions, more "intellectual" at the end of the year than he was in the fall. These changes were not matched by the regular University student. His intellectual interests were broadened during the year, but not significantly, and in other ways, his intellectual orientation was quite similar in the spring to what it had been in the fall.

We should not be surprised. This lack of growth is similar to that discovered elsewhere. Indeed it is not unusual to find the student's intellectual orientation at the end of the freshman year to be less than at the beginning (Feldman and Newcomb, 1969). This experience was not true with CEP freshmen.

Although the upperclassmen were more generally satisfied with the environment and the Centennial course than the freshmen were, changes in their intellectual orientations were not so great as those of the CEP freshmen. Their intellectual interests at the beginning of the year were already high; they needed only to refine them. It is interesting to note that these upperclassmen were much more visible than freshmen. Better known by the Fellows, they were generally thought by the Fellows to have shown greater academic growth during the year. Though it was intended as a program for freshmen with a heavy seeding of upperclassmen models, the CEP upperclassmen garnered a sizeable share of attention from the Fellows.

Some special efforts were made to enhance the cultural opportunities of students in the CEP. In several ways, however, they were not much more extensive than those that could be found in some residence hall programs. As previously noted the environment supported programs of guest speakers, and CEP students were obviously present at University-wide convocations and discussions. They attended no more plays, concerts, or special artistic exhibits, however, than regular University students. Though the over-all level of cultural sophistication of CEP students increased during the year, the increase was not significantly greater than that shown by other students.

\section{Personal-Social Growth-Values}

During the year social-personal values of the CEP students were influenced by their experiences. The changes were not so much dramatic as they were an accentuation of values already held. Most CEP students were fairly liberal at the beginning of the year and they became more liberal, socially and politically, as the year pro- 
gressed. Concerned about social injustice at the beginning, at the end they directed their concerns to specific issues related to the morality of war. At the end of the year they were less authoritarian and felt a greater need of independence from institutional authority than earlier, but this hostility to authority was directed more toward abstract institutions, usually designated "the establishment," than toward home and peers. At the end of the year the students were as closely united to their parents and to the norms of their peers as they had been in the fall. Their feelings about religion were similar, but as the year progressed the freshmen became rather more skeptical of conventional religious beliefs, especially those of an orthodox or fundamentalistic nature. The greatest change in CEP students came elsewhere. There was a dramatic shift of concern among the students from practical and materialistic needs to the concern for the feelings and welfare of others. The CEP students became more concerned about people than possessions.

Compared with CEP freshmen, the regular University student changed somewhat more in his relationship with his family; and in social concerns-liberalism and desire for independence from authority-he changed as much as the CEP students. Altogether he and the CEP students changed in similar directions but in dissimilar degrees. For example, the regular student became more liberal in his religious beliefs but not so much as the Centennial student. The regular student developed a greater interest in the welfare of man at the end of the year, but his concern for material possessions was just as strong, if not stronger, at the end than it had been at the beginning. In interviews the regular student admitted to little change in his values or his ways of thinking about himself, except for an increased awareness of the values of others and feeling a bit more self-confident. The CEP student, on the other hand, immediately asserted that he had changed, that he sensed a definite movement within himself though he could not state just where he was headed.

Twice as many CEP students (almost half) reported that their greatest problem during the year had been trying to establish a sense of personal identity. It is interesting to note that despite the apparent intensity of this Centennial experience, the CEP students did not change perceptively in their preferred style of relating with people. They did not have a strong interest in being with people at the beginning of the year and at the end of the year they remained social introverts. The regular University student had become somewhat more social but not significantly so. 


\section{Vocational Aspirations}

The future academic aspirations of CEP students did not differ significantly from those of other UN-L students either at the beginning or at the end of the year, but by spring there were clear indications of greater restlessness and uncertainty among the CEP students. At the end of the year a significantly greater proportion were undecided about their majors and their future vocational goals. The girls were uneasy about the relation of marriage to career. More CEP students were considering professional schools and more felt that any future occupation for them should include a chance to be creative and original. These differences had become significant by the end of the year.

Since many college students change their academic and vocational goals during their college years, the experiences of CEP students are not profoundly unique. However, it is very possible that the CEP experience prompted many students to reconsider their aspirations much sooner than the typical student. The developmental crisis is not different but the timing is. Further observation over a longer period of time should indicate whether or not the CEP students resolve this dilemma any differently than do other students.

\section{Faculty and University}

The focus of this chapter has been on the students, which in the assessment of such a program as the CEP can only be incomplete. But if the students changed, so did the faculty. They did not complete a battery of tests, as the students did, but they can offer testimony of how they too have changed. Most have bluntly asserted that they do not believe they can ever teach in the classroom as they did before this past year's experience. Through them the ultimate impact of CEP will be widely felt. The impact the CEP has upon the University as a whole will need to be gauged in the future. As yet there have been relatively few direct effects. More should follow as the program matures and the CEP continues as a gadfly to regular University policies and practices. 
TABLE 1

Mean Scores for Total University Freshmen, Centennial Applicants, Centennial Students, and Control Sample on Scholastic Aptitude Test Scores and High School QuarTiles

\begin{tabular}{|c|c|c|c|c|}
\hline & $\begin{array}{c}\text { Total } \\
\text { University } \\
\text { Freshmen } \\
\mathbf{N}=4324\end{array}$ & $\begin{array}{c}\text { Centennial } \\
\text { Applicants } \\
\mathbf{N}=700\end{array}$ & $\begin{array}{c}\text { Centennial } \\
\text { Students } \\
\mathrm{N}=110\end{array}$ & $\begin{array}{l}\text { Control } \\
\text { Sample } \\
\mathbf{N}=\mathbf{3 0 0}\end{array}$ \\
\hline \multicolumn{5}{|l|}{ SAT-Verbal } \\
\hline Mean & 471 & 498 & 565 & 558 \\
\hline Standard deviation & 96 & 95 & 95 & 90 \\
\hline \multicolumn{5}{|l|}{ SAT-Math } \\
\hline Mean & 520 & 540 & 589 & 579 \\
\hline Standard deviation & 100 & 100 & 101 & 100 \\
\hline \multicolumn{5}{|c|}{ High school quartile average } \\
\hline Mean & 1.76 & 1.55 & 1.21 & 1.28 \\
\hline Standard deviation & .70 & .69 & .53 & .61 \\
\hline
\end{tabular}

1 These were freshmen for the 1969-70 year.

2 These included all students who applied to the CEP for whom complete information was available.

8 These were CEP freshmen randomly selected for admission.

4 These were Centennial Applicants who were not selected and who served as a control group by responding to similar questions.

Nort: There are statistically significant differences between the means of the Total University and CEP Applicants, between Centennial Students and CEP Applicants, and between CEP students and the Total University on SAT scores and HSO TheTe were no significant differences between the CEP Students and the Control Sample.

TABLE 2

Comparison of Intellectual Orientations of a Sample of Beginning-ofTHE-Year Centennial Freshmen and a SA MPLE of END-OF-THE-YEAR FRESHMEN

\begin{tabular}{|c|c|c|c|c|}
\hline & \multicolumn{2}{|c|}{ Fall } & \multicolumn{2}{|c|}{ Spring } \\
\hline & Mean & S.D. & Mean & S.D. \\
\hline $\begin{array}{l}\text { Thinking Introversion } \\
\text { (Preference for reflective } \\
\text { thought) }\end{array}$ & 24.36 & 7.47 & 28.79 & $6.70^{*}$ \\
\hline $\begin{array}{l}\text { Theoretical Orientation } \\
\text { (Preference for scientific } \\
\text { method) }\end{array}$ & 19.27 & 5.16 & 21.47 & $4.61^{*}$ \\
\hline $\begin{array}{l}\text { Complexity } \\
\text { (Tolerance for ambiguity) }\end{array}$ & 16.57 & 5.94 & 19.74 & $5.46^{*}$ \\
\hline $\begin{array}{l}\text { Autonomy } \\
\text { (Non-authoritarianism) }\end{array}$ & 27.89 & 7.70 & 33.17 & $4.80^{*}$ \\
\hline
\end{tabular}

* These differences are all statistically significant. 


\section{INSTRUMENTS USED}

1. College Student Questionnaire, Educational Testing Service, Princeton, New Jersey

This questionnaire was developed for the purpose of gathering a diversity of biographical and attitudinal information about college students. Part 1, administered to entering students, contains questions about educational and vocational plans and expectations; activities, achievements, and perceptions during secondary school; family background; and personal attitudes. Part 2, administered near the close of the academic year, duplicates sections of Part 1, but also asks for college activities, perceptions, and satisfactions.

2. Omnibus Personality Inventory, The Psychological Corporation, New York, New York

This inventory assesses selected attitudes, values, and interests which are relevant to normal students and in particular their intellectual activity. Scales are included which permit assessment of social-emotional maturity, social concern, success in social relations, and confidence. Included under intellectual activity or concerns are scales assessing interest in working with ideas and abstractions, the level of theoretical orientation, and esthetic interests and sensitivities.

3. College and University Environment Scales, Educational Testing Service, Princeton, New Jersey

This instrument is intended for students to describe particular aspects of their immediate college environment. Their answers to individual items and to combinations of items permit a characterization of the environment in terms of student perceptions. The college atmosphere is described by the relative amount of press there is for scholarship, the sense of community, the campus morale, and faculty-student relationships.

4. Watson-Glaser Critical Thinking Appraisal, Harcourt, Brace \& World, New York, New York

This test consists of a series of exercises which require the application of some of the important abilities involved in critical thinking. Some of the abilities assessed are: the ability to discriminate among degrees of truth or falsity of inferences, ability 
to recognize unstated assumptions or presuppositions, ability to reason deductively from given premises, and the ability to distinguish between arguments which are strong and relevant and those which are weak or irrelevant.

5. The Adjective Check List, Consulting Psychologists Press, Palo Alto, California

The ACL consists of 300 adjectives commonly used to describe attributes of a person. It may be administered to an individual to elicit his self-evaluation and serves as a convenient method of recording and tabulating personality attributes of persons being evaluated.

6. Supplementary Questionnaires and Interview Formats

These included open-ended questions designed to elicit reactions to specific aspects of college life and the environment. Special attention was given to expectations, residence hall life, nature of social interactions, and major satisfactions and dissatisfactions. 


\section{The Second Year, 1970-1971}

By Robert E. Knoll

1

7 he second year of the Centennial Educational Program began rather auspiciously. Of the 187 students enrolled in May, nearly 90 per cent had wanted to continue in the second year. Such a large number could not be accommodated, but their enthusiasm was testimony that we were providing something they valued.

In the spring, 1970, we ran into major troubles over what came to be called "de-selection." Since no student seemed to want to be excluded from Centennial, we had to determine who was to decide which ones could not continue, and on what basis. The Fellows were reluctant to invite those back who had not profited from their year, but the students doubted that we could identify the unprofiting ones with accuracy. After much discussion over many weeks, we concluded that the Fellows should confer individually with their advisees and urge those to dissociate themselves who gave little evidence of growth. If a student elected to challenge the advice, he was to make a written appeal to a faculty-student committee. As it turned out, the appeals were few. By May, when the students had to commit themselves to their fall schedule, it became clear that course requirements allowed only 117 to continue. Even this was a larger number than we had planned for; but after surveying the dormitories, we enlarged our enrollment to accommodate them. We did not want simple numbers to dictate to us if we could avoid it. The maximum size of the Centennial Program in its second year was set at 267-117 continuing Centennial people, 125 new freshmen and 25 new upperclassmen admitted upon application. We 
wanted to continue our open door policy-that is, we wanted to make Centennial available to at least a few new upperclassmen each semester. As a result of this decision we occupied part of the second floor of Raymond Hall, a dormitory adjacent to Heppner Hall and Love Hall, the buildings we had used in the first year. We provided for an enlarged commuter contingent by putting desks in a study room in the basement of Love Hall. At the end of the first semester another twenty-five felt the pressure of regular courses and the attractiveness of other programs. We admitted a few new students from our waiting list but our numbers diminished from 243 to 211 . We were not displeased at this student turnover for we did not want our people clinging to Centennial like a security blanket.

The students and Fellows alike were apprehensive of the general increase in size. We feared that our sense of community would be lost. But when the University provided us with one additional Fellow, we were able to keep our student-faculty ratio in the second year roughly what it had been in the first. As the year went on, the consequences of our decisions concerning dormitories became clear. The girls who lived in Raymond Hall, away from the rest, felt left out. They became a kind of enclave and were never really integrated into the community. The physical plan of our Centennial Center-all but the Raymond Hall girls needed to pass through the Commons Rooms several times each day going to and from classes and meals-was of great importance for developing group identity. It may also have been that Centennial provided insufficient general activity during this second year to draw the Raymond girls into the general life. If we had devoted ourselves to them, we might have gathered them in. The commuters too represented a departure. In the fall nearly 20 per cent of our student body were commuting. This was up only by 5 per cent; but since our totals were greater now, they seemed an appreciable body. By spring students and Fellows alike had become convinced that the number was too great. The Commuter Rooms themselves were much less used in this second year, in part because second-year students did not need this home base. In any case second-year commuters were infrequently about the Centennial Center.

When the students arrived in September 1970 the returning upperclassmen greeted one another with almost prodigal enthusiasm. We asked them to arrive one day early so they could be prepared to greet the new students. In the courtyard, that first Thursday, we discussed their responsibilities, and afterward they adjourned to a pizza party where they compared summer notes and 
laid winter plans. When the new students moved in on Friday the old students were very much around, but it seemed to some of the Fellows and student assistants that they did not assume full responsibility for the welfare of the newcomers. Cliques began to develop early, and neither the Fellows nor the student assistants asserted themselves against them. We had six student assistants, three upperclass men and three upperclass women, all experienced in Centennial, and one graduate resident who had been with us through the planning stages of Centennial. The student assistants were not aggressively social. They were scholarly and reliable, but none of them exhibited the kind of rah-rah-magnetism which might have welded the group into a unit. The Fellows were similarly scholarly.

Our new students were as attractive as the old. We had had only half the applications for admission in 1970 which we had had in 1969; in 1969, 750 had applied, and in 1970, 360. Of the 360 , we invited 168 to join us. After rejections, second thoughts, and normal attrition, 116 appeared in the fall-68 women and 48 men. Our attrition rate among freshmen was about what it had been in 1969. When this number was added to our upperclassmen our proportion of men to women in 1970 became equal. Earlier we had 20 per cent more men than women. The quality of applications was also similar. The same percentage of Regents Scholars applied to us as before, and the SAT scores and high school rankings were roughly similar. In this second year we made a conscious effort to avoid turning ourselves into an honors program and tried to make our student body representative of those who had applied to us. We made special arrangements for some nine minority students; we actively recruited five of them.

We of course asked ourselves why we had fewer applications in the second year than in the first. For one thing, in the second year Centennial was no longer a novelty, and thus it did not have the attraction of the untried. In the second place, our publicity during the year had been uneven. The Nebraska Alumnus, a widely distributed monthly magazine from the University, had carried a picture story of Centennial during the winter which showed our students at home in bare feet, sitting on the floor, talking to janitors, in a general state of extreme informality. Some knowledgeable public relations officials thought this very adverse publicity and were convinced that it gave us an unhappy reputation across the state. In 1970 many persons associated innovative educational ventures with the disruptive activities of May; and it may have been that reaction against student activism brought a reaction against Cen- 
tennial. Finally our recruiting efforts were off. In the year 19691970 we had not made any effort to represent ourselves to the high school counselors and principals. We found news stories about ourselves in print regularly, but they appeared independent of our own efforts. If we were to reach the students who could profit from our kind of activity, we thought we had best increase our public efforts. We had never assumed that our undertaking would appeal to everybody. We wanted rather that it should be available to those persons who wanted a new attack, a new way, those who were impatient with the conventional ways of doing things.

In September 1970 then, when the year began and our population was finally stabilized, we had 116 freshmen, 91 sophomores, 21 juniors, and 15 seniors. Half of these students were new to the program and more than half were upperclassmen. In 1969-1970 when all the students had been new, the Program itself being new, about one-third had been upperclassmen. The student mix was thus sharply different in the second year from the first year. Because we had so many continuing students, it was no wonder that some of the problems of the first year were carried over into the second year; but the temper of the students in the fall was much more cooperative than it had been in the spring. Even our noisy minority did not seem so belligerent in September as they had earlier. The Fellows found the students ready to take some advice at least; and they were thus easier to work with.

\section{9}

As in the previous year, the heart of the academic experience in Centennial was, in the view of the Fellows, the Centennial Course. The students did not seem to be so committed to the Course as they; the students thought the social interaction as important and as rewarding. In the second year we attempted to profit from the experiences of the first and not simply duplicate the previous year's method or subject matter. In the first year we set out to study The Nature of Change; its organization was essentially pedagogical. The subject matter was subordinated to methodology. We were less committed to investigating the ancient Egyptians or the contemporary ghettos than we were to encouraging students to learn to lay out solvable problems and to come to rational conclusions. Our catch phrase was: Process not product.

But students did not find this pedagogical organization either stimulating or rewarding. They did not discern its logic, perhaps because the Fellows did not explain what we were up to; indeed 
they may not have been fully committed to it. Further, the students found the divisions of the year into four time periods, each one devoted to a specific topic and pedagogical method, a kind of lockstep. They thought these divisions did not allow for the natural rhythms of learning which differed from man to man and from month to month. These division periods did not seem to them to be essentially different from the semester-final examination pattern of standard education: we were substituting one straitjacket for another. The central theme itself-The Nature of Change-was not compelling either. Perhaps it was too high flown, too sophisticated. The students thus questioned both subject and method.

And so the second year we changed the organization of the Centennial Course. We announced early that we would concern ourselves with The Crisis in Modern Values during this year; but on the decision of the Fellows, we did not deliberately orient our studies around this theme. Students, groups, and Fellows could refer to it as they needed to, for guidance and suggestions. In point of fact it was only irregularly used during the year. We discarded the four formal calendar divisions to allow for more "natural" development. In removing the specified time periods, we removed the pedagogical structure. (Structure had become a dirty word.) We decided that the students would learn from the Fellows and from the upperclassmen who had been with us for a year what they needed to know about gathering and shaping information as they worked on their topics. We hoped the students would arrive at the ability to set and solve problems without the explicit ordering of their development. In this second year we did not compel students to work within groups either, as we had in the first year. The advisers and the Fellows urged their students to work together in order to get group interaction, but group organization was optional, not mandatory. Public presentation of group results also became optional. We urged that conclusions be brought to the attention of the general community. In effect in the second year we allowed even greater individual selection and individual choice than before. We became a collection of individual study projects, and the relationship between the individuals was tenuous.

We set up a new organization for the Course. We assigned each student to an adviser-Fellow and required that he present a report to the Fellow every other week, usually in writing, concerning his activities of the previous two-week period. At the beginning of the semester each student drew up a contract which he deposited with the adviser-Fellow. In it he committed himself to a topic of investi- 
gation, a method of procedure, and a tentative timetable. This contract had to be approved by one Fellow-either the adviser or another-who would guide the student's progress. If a student was working in a group, his contract would indicate its nature. The student was bound by this contract, but if during his study he discovered himself interested in an allied or in a totally different subject he could, with the approval of his adviser, renegotiate it. When a project was completed, a student brought to his adviser a written estimate of what he had accomplished as compared to what he expected to accomplish. This written estimate was the product of a conference between the student and the Fellow overseeing the project.

The adviser kept on file the contracts, the bi-weekly progress reports, completion reports and any record of activity, including notes, bibliographies, journals, and papers. Each student thus had a folder which contained a full account of the year's accomplishments and by checking through it the student and the Fellows could trace the student's achievements. This scheme of bi-weekly meetings and of contracts was drawn up by a student-Fellow Curriculum Committee, and this Curriculum Committee kept a record of all the projects undertaken during the year. It published regularly a list of topics presently being studied so that persons working in parallel areas might consult one another. The organization was flexible enough to allow persons to move about as their interests shifted. During the year there was much shifting from project to project.

After the first two weeks of general orientation in September 1970, the students sorted themselves out into a variety of study groups. Many set out on individual investigations. During the orientation, numerous suggestions for studies had been made; movies and lectures were offered and possibilities were explored. Some of the Fellows suggested explicit subjects which they would themselves like to work on, and in some cases Fellows even invited individuals together and assisted in organizing them around a proposed theme. In the third week of the semester, when all the students had committed themselves to one project or another, the Curriculum Committee published a list of thirty-nine subjects undertaken. They were extremely various and some of them worked out very successfully.

One group of eight or ten students worked on Coming of Age and for eight weeks read books by Erik Erikson, James Joyce, Ivan Sergeyevich Turgenev, Margaret Mead, and others. They published 
their intermediate conclusions in a group paper; and at the end of their studies they wrote a group report containing their conclusions as well as individual estimations of books they had read. Another group was concerned with The Crisis in German Values since 1870 , and after voluminous reading for the whole semester each wrote a long account of one aspect of German culture. Yet another group studied some contemporary plays and completed their work by presenting cuttings from six of these. They were presented complete with lighting, costuming, and staging in the basement of a neighboring church. For varying lengths of time other groups studied Science Fiction, the Renaissance in Italy, Black Oppression in the United States, Politics at the Grass Roots-these students hung around the Statehouse where the legislature was in session-and the Education of Underprivileged Children. This last group went into local grade schools where they devoted hours each week to working with small children. One group studied pottery and dug their own clay, threw their pots, built their own kilns, and exhibited their results-some of it handsome. In a few cases students engaged in two projects at once. Several of those students engaged in pottery were engaged in book projects as well.

Most students during the course of the year completed three and sometimes four contracts. They would work on one topic until they had reached some kind of conclusions or until their interest flagged-usually six or eight weeks, sometimes a bit longer. Then, in consultation with their adviser, they would lay out a new project, the new project sometimes being the proposal of the adviser, sometimes of their own devising. The projects were completed in a variety of ways. Occasionally they ended with summary papers; sometimes with public presentations; frequently they ended without public statement. Sometimes they concluded negatively. One young man, for example, after voluminous reading on experimental education found himself so at sea that he could come to no conclusions whatever. Almost in desperation he decided to leave his body of reading undigested and to start something new. He laid out his next project with care and brought it to remarkable conclusions: a bill which he proposed presenting to the legislature dealing with the taxing of private ponds and lakes. Some students resisted help from anybody and wilfully asserted their own individuality. When they insisted, we let them go their own way. Often they ended with nothing at all but occasionally they flourished under almost total freedom. The choice was their own.

Each of the Fellows found himself supervising four or five groups 
plus a good number of individual research efforts. Originally we planned to allow seniors and upperclassmen to serve as subordinate supervisory Fellows, but for the most part this did not work out very sucessfully. The upperclassmen lacked all but moral authority and though willing often, they did not know how to use that. Some of the Fellows thought that in the early projects many students were rather self-deluded in their estimate of their accomplishment. They thought the students should accept more direction. Perhaps they were wrong, but one perceptive student wrote at the end of the year: "In all my projects the effort put in was much less than the benefits I gained from having the experience of teaching myself. Others tell me that they don't think it is important to write reports and papers showing what they have done. One side of this resulted in the tendency of persons to suppress self-incriminating evidence. There is no way for me to say how often it happens but I think that very often people who do not want to write papers and who can't give good reasons to support themselves are fooling themselves. In the back of their minds they know they have done nothing to write about. The Fellows are subsequently blamed for requiring papers which are described as intruding useless busy work and unfairly mandatory."

Several of the Fellows wanted more public presentations of project results, and they attempted to encourage them. By January the Renaissance seminar produced "Mandragola" by Machiavelli, for the amusement and edification of the community. It was presented in costume with music, and slides of paintings and architecture appropriate to Machiavelli's generation. They interrupted the action of the play to make historical and aesthetic comment intended to illuminate the play and its times. Some of the comments were very perceptive. Other groups were not so successful in public presentation as this, and often the interaction between students was disappointing. One of the second-year students wrote: "Most noticeable about the academic year was the drop in the amount learned by students from students. Nobody told anybody else what they were working on or discovering, nor was there any curiosity to find out what somebody else was doing. Projects were treated like private possessions that belonged to those working on them and no one else had any right to trespass."

Some of the students and some of the Fellows complained early about this loss of community, but the majority of the Fellows throughout the year did not feel it serious enough to demand action. Even so, at the beginning of the second semester, when most stu- 
dents were completing one project and preparing to initiate another, we held a series of seminar-discussions on a variety of topics. For two weeks every day we offered one or two and sometimes three formal discussions-we called them "floating seminars" because they were unattached to any particular group or Fellow. We hoped that these talks would spark interest and encourage persons to gather together. The seminars were well attended and much talked about. One of the freshmen said later on: "I feel the most important thing Centennial did for me was open my mind to different ideas and opinions that I had not encountered before. I don't think these changed my life style but they made me think about my own values and evaluate them. I know that in Centennial the students had a chance to "rap" about topics other than girls and football. This encourages them to form opinions on subjects such as politics, education, and current literature."

This system of projects placed the burden of education squarely on the student himself. It required that he take responsibility for himself. The Fellow stood ready to help him as he was needed and required; indeed, he often searched out students whom he thought might need assistance. The system assumed that the student would be motivated by his own curiosity and be rewarded by learning, by the satisfaction of finding out what he wanted to know. Both assumptions were excessively sanguine. The majority of the students did not possess compelling curiosity. Most of them were not much interested in anything or had interests so heterogenous as to be unfocused. They needed to have their curiosities awakened and directed. Not being committed to any subject or area, for most of them learning was not sufficient reward in and of itself. But unfortunately most of the students in their youth would not sit still long enough to give us a chance to interest them. When they were not required to give us a hearing, and we did not catch their interest with initial presentations, they gave us no second chance.

By spring more students were engaged in regular seminar-type discussions than had been in the fall. Perhaps half were meeting regularly with Fellows to talk about agreed-upon topics and books. Throughout the year a great many worked at individual projects. In this second year the community did not play such a vital role in their lives as it had in the first year, for the community did not receive the reports nor did it support the investigations. Discussions were informal and information was passed from student to student and group to group without plan. When we attempted to organize some opportunity for interaction, the students reacted negatively; 
they prized what they regarded as their freedom, and interpreted all discipline as "coercions." With very few exceptions, however, they went to their bi-weekly meetings, filed their bi-weekly reports, completed their contracts, and moved from project to project. Some of our sheep may have strayed periodically, but none were lost.

Since we were bound by University rules, we had to turn in grade reports on our students at the end of each semester. We encouraged them to take the Centennial Course on a pass/incomplete basis. We wanted to encourage them to work for the pleasure of learning, on topics of importance to them, not for a grade. We wanted to break the old habit of examination and mark. A pass, we decided, would be awarded when the student had accomplished within reasonable expectations what he on his contract had said he was setting out to accomplish; the contract had of course been drawn up with the approval of at least one of the Fellows. The student and his adviser-Fellow in consultation determined whether this promise had been kept. Two hundred and three elected to take this option, and at the end of the first semester forty-six of them were incomplete. Twenty-nine of these incompletes were quickly worked off, so by the end of the year only seventeen remained. Though we were not pleased that 8 per cent remained in limbo, we were not alarmed at this proportion. Indeed we might have been alarmed if it had been lower, for a lower percentage might have indicated a lack of seriousness in gauging accomplishment. In the second semester the grading record was similar. Of the 148 enrolled on a pass/incomplete basis, twenty-two were incomplete in June. On the basis of previous experience, we could expect fifteen of them to be removed by fall.

The problem of standard grades gave us much difficulty all year. In nearly every Town Meeting one or another aspect of it came up. As with the pass mark, the grade was to be determined by the student and his adviser-Fellow in consultation, but we were all at a loss to know how to discriminate among levels of accomplishment. Since each student was largely on his own, we had no chance of comparative achievement. On the basis of conversation, the bi-weekly reports, the completed contracts, and the general content of the student's file, we could determine whether he was engaged in educating himself or merely drifting; but we could distinguish only with great inexactness whether he was educating himself "exceptionally well"-that is, worthy of an A-or only "satisfactorily"-that is, worthy of a C. Neither the Fellow nor the student had a standard against which to measure the kind of things our students were 
attempting to do. When we turned to standard grades, we found ourselves attempting to marry a conventional scheme of judgment to an unconventional effort. We were driven back to standard expectations when we introduced standard grade point averages; we got involved in assignments, deadlines, conclusions, expectations, bibliographies, and footnotes. In concerning ourselves with standard grades, we attempted to reconcile the irreconcilable, and the old bottles contaminated the new wine.

The Fellows consulted the students individually about the grades; and in the confusion the grades were usually resolved to the student's benefit. A number of students may have been using us cynically in order to improve their grade point averages; and several of the Fellows may have been using the grades as an attack on what they regarded as a generally corrupt grading system. But we did not think this cynicism was general. Fellows and students alike were attempting the impossible: we searched for an alternative to standard course patterns and marks. As it turned out the grades for the first semester ran embarrassingly high. The average mark for the twenty-one freshmen in the first semester was 3.81 as compared to 2.7 earned in other courses; the average mark for upperclassmen was 3.84 as compared to 2.97 elsewhere. (4.0 is the top of the scale.) By the end of the second semester we were feeling our way to some adjustment. The grade point average of those enrolled for grades in the second semester was 3.2 as compared to an estimated 2.8 in their other courses. The margin of difference was decreasing but it was still too great. In a letter to all the students in April, one of the Fellows wrote: "I should be ecstatic, I know, that the Centennial Course spurred students to efforts dramatically superior to their work in other courses, but I think people [outside CEP] might read it as indicating the flippancy with which letter grades are treated by a few people in the CEP. Perhaps we should examine our sense of our efforts and of the standards we have chosen. It may be that students on letter grades and the Fellows counselling with them should decide this time with a novel honesty, noting the larger issues. Many more such 'brilliant' semesters and we'll have to fold up the tent."

\section{Language Study}

In Centennial we offered first and second year Spanish, French, and German just as we had previously; and again we provided language rooms, equipped with tapes, books, and records for the 
student's individual and optional use. Our classes were never larger than twenty students, and all contained some non-Centennial as well as our own students. Except for beginning French, in which we used the films made in France "En France comme si vous y étiez," we had been unable to secure classroom materials different from what was used in ordinary classes. The German films corresponding to the "En France" series failed to show up, and supplementary German tapes did not arrive as scheduled. We had books and magazines in all three languages as before. We were fortunate in having experienced teachers, two of them native speakers; none taught full time with us and they could thus view our activities from a settled perspective. They had great flexibility in how they introduced grammar, how they selected readings, and how they grouped students for conversation and discussion, and they used it. In fourth-semester German, for example, the teacher's full attention was given to literature; the grammar had been fully presented earlier. This was a great success from every point of view, student and teacher alike. In the fourth-semester Spanish, the students were divided into small independent study groups, some of which worked on various aspects of Spanish culture. One group worked with high school students; they learned by teaching. Grammar sessions were informal. The results of this experiment did not please either the students or the teacher, and she discontinued it. In the first semester we offered a special section of third-year French, an inquiry into the nature of French Civilization, which made use of slides and tapes especially purchased for it. We hoped this course would spark an interest in the study of language and culture, but we got little evidence one way or another.

By the end of the year, the teachers had come to some agreement about the part languages played in Centennial. For themselves Centennial had given opportunity to try new methods and materials; they had considerable freedom of movement. In addition it had given them a chance to observe reactions closely, their students being clearly identifiable here. This teaching they found was somewhat more demanding, but the atmosphere was stimulating. They thought the tapes and records in the language rooms were used irregularly, in some cases less than those assigned in standard language labs. The special films and lecturers imported to supplement class sessions were also irregularly attended, in part because they could not be integrated into general study plans. They and their students alike had not been made to feel that language study was a necessary part of the Centennial Program; they felt a bit like 
step-children much of the time. They concluded, altogether, that the quality of accomplishment among first-year students was not markedly different from what it was in students elsewhere; secondyear Centennial students were often somewhat better than ordinary second-year students.

The teachers alike agreed that the advantage of the language courses was of a kind difficult to measure and impossible to determine by comparing grade point averages. One of the teachers noted at the end of the year that he had never had students make positive suggestions about methods and subject matter as he had in this year. They seemed critically aware of what they were doing. Another instructor observed that her students taking French for their second Centennial year were more involved in their subject than they had been earlier or than non-Centennial students were. It seemed to the Fellows, observing but taking no part directly, that by spring many students were beginning, finally, to understand how they themselves were responsible for learning a language. One young man reported in May that next year he was going to organize conversation groups; he had accidentally found that practice conversation was extremely helpful-and fun. He said he wanted to exploit the talent he found about him. He seemed unaware that conversation groups, organized by "outsiders," language committeemen among others, had been tried earlier and had failed. The point was, he now was ready to take some initiative. Clearly the residential possibilities of Centennial could not be fully used until the students themselves undertook to use them, and now they seemed ready to do so.

The languages have a general utility for the whole of Centennial. Freshmen said that they often found that the regularity of language classes gave their days an order which the unstructured Centennial Course deliberately removed. The 8:30 German class got them out of bed and going every day. Since the kind of daily discipline needed for learning a language is different at least superficially from the kind of self-imposed discipline we sought to encourage elsewhere, the contrast between the two required the student again to consider first principles. At first some language students neglected their daily work, overwhelmed by their new, general freedom; strong students by the end of the year learned from the contrast and were the better for it. We became convinced that our language instruction contributed to a total critical attitude. By the end of the year we were not discouraged, but we thought it too early to rush to any but temporary judgment. 


\section{Mathematics}

Our program in mathematics was different in the second from what it had been in the first year. Before we had set up a self-study system which allowed each student to proceed at his own rate. By the end of the year the teachers of math had reached some conclusions and had announced them; they are summarized in Chapter III. In the second year we had two one-third-time Fellows in mathematics, two sophomore math majors-one of them simply volunteered his services without payment so that he could learn mathematics by teaching it-and one experienced graduate student. Our student credit-hour production in mathematics was 405 credit hours for the year, easily within the general University allowance. Our only extra cost was the volunteer undergraduate whom we could not pay. We made a greater use of our undergraduates, and we gave them much greater responsibility with the students than they would ordinarily be asked to assume. As a result they not only taught; they learned and knew that they had learned.

In the second year we offered our students a number of options. Anyone who wanted a simple working competence in calculus was urged to take the regular course; we provided him with students and tutors with whom he could study. Students less interested in acquiring skills for their own sake were offered a number of alternatives. In a problem oriented course allowing much opportunity for independent study, a student was asked to consider principles from which the various skills of manipulation were derived. This was identified as Math 114q. He was regularly asked to discover his own methods of solving given problems, the mathematical philosophy having been made clear to him. Students in small groups met several times a week to discuss problems either with undergraduate tutors or with one of the Fellows. Those who successfully completed the problems were assumed to be prepared to move into higher math; but the syllabus of the Centennial Course was not totally parallel to that of the standard course. In the first semester thirty-three students elected to participate. They agreed to work until they reached "A" level of competence, the competence to be measured by examination. Twenty-two of these reached this level by the end of the semester; seven reached " $B$ " level, and the work of four remained incomplete. In the second semester eight persons studied Math $114 \mathrm{q}$ and six of them achieved " $A$ " level competence, one " $B$ " level, and one was incomplete. Students, tutors, and math Fellows were generally pleased with this course.

In the fall, in addition to Math 114q, five students studied Math 
$115 q$ and six Math $116 q$, both in a tutorial self-study system. Our undergraduates supervised this study, and by January eight had achieved an " $A$ " level of competence. One more made it shortly thereafter, and one left his work incomplete. In the second semester the same pattern of instruction continued. Many students simply continued with established tutors. Of the thirty enrolled in these three courses in the spring, twenty-five achieved " $A$ " level by May. The teachers and tutors reported that, if a tutor spent an average of an hour a week with each student in a kind of tutorial conference, the student could work his way through an understanding of mathematical principles superior to what he ordinarily got in a large lecture course. They insisted that this method of learning and teaching-they were directly involved both as teachers and as students-was efficient. The ultimate validity of their assertions can only be tested when the students undertake subsequent courses in mathematics.

In addition to these we offered a different kind of course altogether. It was identified as Math 14q. It was a historical and philosophical study of math, and students enrolled in it were not assured that they could proceed into subsequent skills courses. It was designed for general students who wanted to fulfill their requirements in general education but had no need for manipulative skills. One group approached the theory of math philosophically and another approached it through narrative problems. At first there was great enthusiasm for this, but the students reported that the original promise was not maintained; both the interest and the rigor slacked off half way through the semester. Even so they generally agreed that this had given them a general appreciation of math that they had never had before. Though it needed a good deal more work before it could be successful, its purposes met their total endorsement. It was a first step in a long road. ${ }^{1}$

\section{3}

Our difficulties concerning grading reflected our difficulties generally. These were of a kind we had had from the beginning. The Fellows and students alike felt a need for a clear definition of goals: To what end was the Centennial Program devoted? What exactly did we want our students to accomplish? If we could get this clear, then grading and other problems of academic responsibility could be resolved.

I The information for this account of the mathematics program comes from Professor Henry Ablin and his associates. 
In our original statements of purpose, we had assumed that Centennial would strive to find new ways of arriving at old values. We did not reject what was commonly understood as academic excellence. Our innovations were to be in the means, not the end, of education. In order to encourage profitable intellectual conflict, we divided our students into groups, and we encouraged controversy by asking the groups to engage in discussion. The students were to criticize and monitor one another. We placed our emphasis on the way they came to conclusions more than on the conclusions themselves. We committed ourselves to process not product; process not product came to be our slogan. We thought academia had traditionally concentrated on the products of intellectual effort-papers and reports and the like; it had assumed that the product would ipso facto introduce the student into the process of rational analysis. By concentrating on the end, the mean was assumed to take care of itself. We set out to reverse this procedure. We rejected salvation by works and asserted salvation by intellectual commitment; works would follow. The spirit not the object was our concern. But our initial assumptions of the value of the rationally examined life were those standard since Aristotle.

And yet repeatedly the students asked us to "define our goals." In point of fact our goals had been rather explicitly set forth on a number of occasions. In August 1970, before the second year began, we wrote to all the Centennial students: "During the course of their study scholars will determine the area and topic which they want to investigate. We hope they will learn how to define a problem, how to gather rational data and how to come to rational conclusions." In September when the student arrived, we handed him a Pink Pamphlet-several sheets of paper bound in pink-which contained a detailed calendar of activities for the first two weeks and, on its cover page, a general statement of goals:

\section{The Centennial Education Program Goals-1970-1971}

In the Centennial Educational Program we try to combine the residential experience with the academic experience so that they reinforce each other. We assume that students who study together can learn from and teach one another if they also live together. As curricular and extracurricular interests and commitments merge, the interests and commitments become clarified, become personally more forceful, become generative of new and wider interests and commitments. We want to combine experience, not divide it into competing parts. 
With the help of the Fellows, Scholars should learn in Centennial

1. How to define and limit debatable issues so that they can be analyzed and argued rationally;

2. How to gather data which will be relevant to the defined issues; and

3. How to come to workable, or defensible, conclusions based on the data.

We hope that Scholars will help one another in their definitions, their searching, their summary conclusions. The particular subject of the inquiry may be as various as the interests of the Scholars. We are more concerned with the process of learning than with the particular subject matter. We urge the Scholars to exploit their inclinations. They should move from their immediate concerns to the wider world that surrounds and has preceded them. As a result they should come to an understanding of their place in the intellectual, aesthetic, and social communities of which they are a part.

The burden and direction of such a journey are the individual Scholar's responsibility. But the Scholar moves within an immediate community that supports and participates in the journey.

In the fourth week of the semester one of the student committees sought to discover opinions of the community concerning our goals. Their relatively sophisticated questionnaire, which was returned by approximately 60 per cent of the total community, produced some interesting results. The students wrote: "A consensus appears both in the highest priorities and in the lowest. Generally it is agreed that the burden of responsibility for academic inquiry is upon the individual student. Also it is believed that a Centennial student should become a self-confident, independent, actively learning, creative individual, and that this should continue well into his postgraduate years. There is also a desirability to develop a sense of community and the students must be self-governing and actively verbal concerning planning and change within the College."

The students continued the summary of their results. What importance did the students attach to "coming to valid conclusions at the end of a project period? A low rating seems to indicate that process is more important in projects than product." There seemed to be "a firm rejection [of] creating an honors college through selection" of entering students. One concludes from this questionnaire that the students had heard the words and could repeat them; but they may not have understood what they meant.

In November we provided another statement, which they could take to their high school counselors and principals at Christmas 
when they visited their home towns. ${ }^{2}$ At the beginning of the new semester they got yet another brief statement. ${ }^{3}$ Various individuals and student groups set forth our goals during the year, too. The Brochure Committee, which was charged with the preparation of the pamphlet to be sent to entering college students, produced one such statement. The Listening Committee, which was set up to hear complaints, very early turned itself into a goals committee and by spring produced a lengthy document. The Fellows every Thursday morning hashed over their differences and put their thoughts on paper repeatedly. In short we had no lack of rhetoric concerning our purposes.

But in all this rhetoric the students detected a basic lack of unity. They recognized that the Fellows were not agreed. They did not try to hide their differences, as a matter of fact; they maintained

2 How does CEP differ from the University generally?

-We try to make the student responsible for his own education. He is not a vessel to be filled. Rather, he is an active explorer in the fields of learning. To this end we ask the student to select a topic he wishes to study, to lay out certain plans and determine his own goals-all with the aid and supervision of teachers.

-We are of course interested in subject matter and the gathering of infor. mation, but in this initial course we subordinate the particular subject to methods of investigation. We want the student to learn to separate fact from opinion, evidence from hearsay. We want him to learn how to use books, men, ideas, libraries-the resources around him.

-For academic reasons we want students who study together to take advantage of their living associations here at Centennial. Students can teach each other how to find materials and how to distinguish between the significant and the non-significant. The community exists for educational purposes.

- Teachers are available to students many hours of each week. It is their responsibility to give their estimate of a student's accomplishments because work which is uncriticized does not provide for growth. Feedback from a teacher is essential for a student's evaluation of himself. Because of the special advantages in Centennial our students have an opportunity to excel in academia.

Because we are concerned with the student's education of himself we try to make provisions for individual differences. The varieties of our projects and efforts are thus great but the ends are surely common: we are an educational program.

${ }^{3}$ Telling it like it is at Centennial ...

Here at Centennial we ask the students to start with their own experience, examine topics of immediate concern to them, in order that they may come to a critical awareness of themselves and the world they live in. To put it another way, we start with the students' experience in order to arrive at generalizations, at the abstractions with which the various disciplines deal. Centennial is thus essentially inductive, attempting to take the student from the examined facts of his life into some cohesive linking of these facts. We continue to be interested in helping students to learn to identify problems, to gather information necessary to their solution, and to arrive at rational conclusions. We think this problem-solving ability leads to a critical awareness of one's self and one's world. To these ends we hope to establish a community in which students and Fellows may educate one another. 
them publicly and in good humor. It may be that our central disagreement encouraged a critical atmosphere and forced the students to consider educational alternatives squarely.

From the very beginning the implied basic assumption concerning the importance of standard academic excellence was challenged. The doubters-the New Men, you might say-said that students should strive "to find themselves"; they should seek "personal development" and we should help them "grow into maturity." The Fellows in their view were doctors to the whole man, not teachers of the ancient dialectic. In October the Town Meeting voted to drop the name "Scholar" which had been used in the first year. Henceforth Centennial people were to be Centennial students only. They thought that the term Scholar was elitist and caused resentment across the campus. Some thought that this decision to be simply students indicated their lack of commitment to traditional academic values. Some of the Fellows and at first a good number of the students wanted, not simply to neglect, but to deny the necessity of traditional ratiocinative values. The contemporary enthusiasms for Zen Buddhism and non-western mystical experience contributed to this rebellion. What had started out to be a straightforward assertion of the importance of the ratiocinative process and a search for new ways of reaching it was now under attack. Under the rubric process not product both the product- rationality-and process-the dialectic-were changed. The "product" came to be something like "the complete human being" rather than the rationality; and the "process" was psychic, not logical. We found ourselves hung up on the very issue that disturbed much of contemporary education. Our controversies were real and they were pertinent in the extreme.

We had invited some of this controversy. Before the students came to the campus in the fall of 1970, we had asked them to read George B. Leonard, Education and Ecstatsy (1968). This polemic is an attack on traditional educational methods and values. Leonard thinks that "to learn is to change. Education is a process that changes the learner." And he says that "Learning [is] anything that changes the learner's behavior" (pp. 18-19). He hopes to make students free from restrictions, confident that they will then discover the ecstasy of learning. In addition to this book we asked the students to read The Student in Higher Education (1968) published by The Hazen Foundation as a Report of the Committee on the Student in Higher Education. It too questions traditional assumptions and asks that the college "assume more conscious responsibility for the human development of its students" (p. 5). It proposes all kinds 
of student involvement in the direction of educational institutions. Finally we asked the students to read John Knowles's novel, $A$ Separate Peace (1959). This book too raises questions about the ends and nature of education.

The division between the rationalists and the behaviorists was very clear by fall, 1970. The Fellows did not agree on what we should regard as standards of accomplishment. Early on, we had assumed that the Fellows could talk out their disagreements and come to some kind of modus vivendi; we assumed that the differences could be compromised. In this faith we had deliberately recruited for the Program Fellows of varying conviction-as wide a spectrum as we could find. We may have made a mistake in the beginning by providing such a wide range of faculty opinion. If we had stacked the deck, the Fellows could have provided a united front. Or the Senior Fellow could, at least theoretically, have forced by fiat a unity he did not find. Compromise turned out not to be possible. The differences were fundamental and, apparently, irreconcilable. Some of the Fellows regarded education as a discipline of the reason from which social and personal equilibrium would follow; the reason was the means to necessary order. Other Fellows felt that education should provide for personal growth; they assumed that introspection and psychological analysis could bring equilibrium. Growth through reason was too limited. As one student put it, "We ought to have an alternate way to measure achievement and accomplishment. Standard academic judgments aren't true enough." But how were we to measure psychic growth? Indeed, how were we to recognize it when we saw it?

Since the Fellows could not come to agreement on basic principle, they had little agreement on policy matters. We haggled over such questions as, How long should we allow a student to exist in an academic moratorium? At what point should we coerce him into standard academic activity? How much external pressure should we bring to bear on him? How do we distinguish between coercion and discipline? Coercion became another of our catchwords, like process; coercion was a dirty word. As a result of differences, what one Fellow expected from his students and what another expected were often sharply different. One might well ask for extended papers and full reports, while another would accept journals and oral accounts of illuminating experiences. Another catch phrase appeared: "Nothing is not something." It referred to a certain self-indulgent self contemplation which some Fellows thought they observed about them.

Almost immediately the students began seeking out the Fellows 
who could provide what individually they thought they wanted. It was instructive that not all the students sought out the most permissive, the most undirective, of the Fellows. On the contrary. The weight of labor divided itself rather equally across the spectrum which the Fellows represented. The Fellows agreed on certain basic matters. They all felt that the student was responsible for figuring out what he wanted from his education and they thought that he was responsible for achieving it. The student had to educate himself. The Fellows were agreed that it was their business to be near, offering help and direction, but it was not their business to impose themselves arbitrarily. During the year some of the students changed their views rather markedly. Some who had felt that education was basically self-development came to respect traditional discipline. Very few if any moved in the opposite direction. The Fellows had similar experiences. One or two of the most liberal were by spring surprising themselves by their conservatism. One of those most committed to interdisciplinary study began to have second thoughts. Another who had been sympathetic to free form began to ask for regular meetings and set hours. In this atmosphere the Fellows and students were forced to examine, and reexamine, their basic educational assumptions.

For all their disagreement on basic principle, the Fellows were alike in their concern for the welfare of their students. We met several hours every week to consider how we might help them. At the end of each semester we discussed in detail the progress of every student individually, and at the end of the year each of the Fellows filed a written estimate of the growth and achievement of every student with whom he had dealt, an estimate which was to be kept permanently within the student's file. This record was of course available to the student should he choose to see what the Fellows thought of him and his work. The estimate-students repeatedly ask for a narrative estimate of themselves in lieu of grades-was timeconsuming to compose; and not everyone ended believing it worth the effort. Some of us thought a standard grade a very convenient shorthand, perfectly comprehensible to teacher and student alike; in those few cases in which its meaning was obscure or ambiguous, its meaning could easily enough be explained face to face.

Our general conclusions in January and again in May were similar. We thought few if any of our students had been injured by the responsibility we had given them. Some did not take advantage 
of it, and they did nothing at all. They simply sat. After a lifetime of directives they were paralyzed by freedom. But a really significant number flourished. They became aware of a wide world; they became critical of themselves and their total experience. They were touched but not changed, one of the Fellows said, and seemed ready for independent academic work at the end of the year as ordinary students were not. After careful consideration, the Fellows finally concluded that about half of the Centennial students showed a decided benefit in critical awareness of themselves and their enlarged experience, that about a quarter simply drifted through our hands, perhaps using us for an easy mark, perhaps indulging themselves in laziness. The rest we were undecided about. They seemed tentative; we could not make out to what degree we had reached them, if indeed we had reached them at all. When we compared the kinds of involvement we saw in Centennial with the kind of involvement we had seen in our regular classes, we concluded that the 50 per cent figure was decidedly higher than what we had experienced with groups of students under ordinary circumstances.

We were able to make some other observations, with some confidence. Those students who flourished under our freedom were not always the brightest-that is, the scholarship winners and the high testers. In fact the high testers not infrequently collapsed into apathy when hurdles were not set out for them. On the other hand, many students found themselves playing over their heads, writing papers and reading books, and involving themselves in a way that six months earlier would have been impossible for them. In total we thought that our students did less formal work than they did in their other courses; they had more elbow room because they did little busy work. One of our brightest girls wrote in her final estimate of the year: "The gift of Centennial is time-a very precious and elusive thing, but vital if one is to learn the art of educating oneself." Another student, less gifted but at least as promising, wrote: "This year I polished a few diamonds and went looking for some others. I have developed confidence socially and intellectually, and my ability to analyze myself and others has grown in proportion to my increased ability to focus on a given problem, develop a tentative solution, and then work toward that solution. The test of this year is not how much I have learned but how much I will retain and be able to augment. First returns say that it will be much." One of the girls whom we watched closely and left alone because she seemed to want to be independent said: "To evaluate the Centennial Program is basically to evaluate myself. In compari- 
son with my regular university courses I sense a great feeling of joy in learning. I was really excited about the subjects I was studying. I was learning how to put my academic interest into some kind of a program, an educating operation, through which I could learn. The responsibility, which is both frightening and exhilarating, of educating me was my own."

In balance, when we made a formal assessment of the achievement of the students, we could only conclude that for most of these students freedom had not been wasted. We concurred with one of our students who wrote: "I have spent a year and a half in the regular University. The greatest advantage of Centennial to me was as a supplement rather than as an entire end in itself. I do not believe that I would find it either enjoyable or useful to have CEP as my only form of education. There are some areas that need to be attacked with a more organized battle plan than is often used here." Initially we had set out to encourage the students to be interested in educating themselves. In that we thought we had been successful. In the middle of May one of our teachers of French, a sophisticated and devoted woman, told us that she had questioned her classes about the influence of Centennial on their work. In the group she had both Centennial and non-Centennial students. She asked if they had found that their experiences in Centennial had contributed to their general educational accomplishments. To a man they said that they thought it had. But, alas, the students in other dormitories reported that they had found the University disappointing, a dreary duplication of high school. The French professor concluded that the atmosphere at Centennial was one in which students could flourish.

But we did not trust our own judgments alone in coming to final conclusions about Centennial. Our students had provided public evidence of accomplishment both individually and as groups. In the fall we asked one of the consulting psychologists in the Department of Student Health to come talk to our students about human sexuality. A week or so later we got an unsolicited testimonial from her. She told us that she got a more serious response to her remarks, more penetrating questions, and more alert interest at Centennial than in any other group she visited on campus. She looked forward to future visits with Centennial students. In midwinter a group studying the opera invited the director of University opera to visit us. We got no written response from him, but for the next two weeks he talked about our Centennial students to everybody on the campus. He said he found more interest in the 
opera and more knowledgeable commitment to it among the Centennial students than he had found even among music majors. $\mathrm{He}$ subsequently volunteered to come see us more often.

In the spring we asked one of the Governor's assistants to come talk to us about the legislature and the University budget. He was somewhat reluctant to do so because on earlier campus appearances he had met only apathy. He and other members of the Governor's office felt that they were wasting their time with University students. He came nonetheless. With Centennial students he met such questioning and such discussion that he sent over the Governor's chief fiscal analyst a few weeks later. These meetings with the Governor's associates were unlike some of our other meetings with "visiting firemen" because for them the students had boned up; they had looked up facts and figures. Generally our visitors met more enthusiasm than intellectual rigor. Our students were not generally shrewder than others-they were just more interested.

Our students carried their new interests outside Centennial. By the end of the second year, a number had decided to spend their junior year in Europe. Four set up their own program and made their own arrangements to study in Germany; two others joined an established program that took them to Bordeaux, France; two more located themselves at the University of Valencia, Spain; one announced that he was going to Vienna, on his own. Half a dozen students spent the summer 1971 in various European summer schools, and more than twenty traveled abroad independently. The proportion of our students who set out to expand their horizons in this fashion was unmatched on the campus. The Fellows hoped that this general exodus abroad might serve as a pump primer for the general University.

As compared to the previous year, 1970-1971 students were much involved in cultural events. They were ubiquitous at lectures, plays, and musical events; and they turned themselves into a corps of ushers for the May Festival of Music so they could participate in more events than they could afford. In the middle of the winter two busloads went to Omaha to see a production of Aïda-we made a party of it, with formal clothing and full regalia. In the spring several of them went to Minneapolis for a week with the Metropolitan. On several occasions during the year one of our students, a blind girl, presented evening recitals of her own musical settings for poems by Catullus, Shakespeare, Yeats and her Centennial contemporaries. These musical evenings drew considerable crowds.

One of the high points of the year was the building of a harpsi- 
chord. In the middle of the winter a group of students, supported with Centennial funds, constructed it from raw lumber and purchased parts. For the rest of the year students were at the keyboard late into the evening; we had Couperin and Bach at one end of our corridor and Joan Baez and the Rolling Stones at the other. A professor of piano came over regularly to play our harpsichord, both for his own pleasure and ours; and by spring another group had established a workroom in our basement where they built a second harpsichord, this one for sale.

But our interests were more than musical. Our students were prominent at the University Theatre, both on and off the stage. Frequently during the year one or another of our people posted their photographs and paintings on our bulletin boards, for mutual pleasure; one girl left us some of her paintings on semi-permanent loan. In the spring a group produced a television program for the Nebraska Educational Network. Though they consulted the Fellows and took advice from the professionals, they wrote the continuity and determined the contents of the half-hour program themselves. Nearly seventy-five of the Centennial people were involved as writers and actors before the program was complete. The result was of professional calibre and we had a right to be proud of it. It was shown on the statewide network.

Our students were active outside the confines of Centennial itself. During the year the Association of Students at the University of Nebraska (ASUN) appointed a committee to make recommendations for the improvement of higher education. By May their reports which ran to many pages were published. They contained analyses of the University in total, of the colleges, departments, and courses. They made recommendations for possible improvement. These position papers were superior to many similar position papers prepared by faculty committees, for they identified major issues, gave evidence of wide reading, and made thoughtful suggestions, some of which can be adopted quickly. The excellent report does Centennial credit, because more than half the committeemen responsible for it were Centennial people. They had had the time, the interest, the initiative, the information, and perhaps most important, the commitment to education and the University to devote themselves to this positive accomplishment.

If our successes were real, the areas in which we needed improvement were also real. The students generally agreed by springtime they had a greater need for help, for advice-for teaching-than they had acknowledged in the fall. Many asserted that though in the 
fall they had been unwilling to tailor their interests to group interests, they now saw that such group effort was necessary. Though they still wanted to be able to select a topic and an area to investigate, they thought all students needed the experience and discipline of community effort. They thought the academic work this year needed "tightening up." They meant that it needed regulations, that it needed deadlines and specified goals; and if students could not impose them on themselves, they needed to be externally determined. They continued to hate the words "coercion" and "structure," but this is in effect what they were asking for. One of the students wrote at the end of the year: "Students at the University want to learn, but learning is not their highest priority. They want to do wellthere is often a difference." The students were asking that we show them what we meant by doing well and they wanted us to urge them into doing it.

Some of the Fellows thought it important the students come to this understanding of a need for discipline on their own. They needed to develop their own sense of purpose, and they needed to see that they had to have deadlines if they were to accomplish much. One of the more thoughtful freshmen spoke for many: "By the end of the first semester I felt a change in myself as a person and as a member of a community. Centennial was a place flexible enough to give me time to think about myself as an individual and time enough to play a role as a member of a community. This was something that hadn't happened in all my previous years of institutional educational experience ... now at the end of the second semester I feel a change has taken place within me pertaining to education. Centennial helps my attitude toward education in the outside university. It gives me a way to think that can be applied. It makes me question things more. It helps me get more out of other courses." Another student, saying much the same thing, concluded, ". . . maybe I could have done this on the outside. I'd hate to try though."

Quite clearly in the next year we needed to strengthen academic standards and help the students teach one another. As one of the Fellows said, "It is a shame to box different kinds of persons together arbitrarily. My forty advisees are forty different individuals and must be treated like individuals." Our biggest continuing problem remained how to accommodate ourselves to the varying needs of numerous students at varying levels of achievement and aspiration.

Another of the Fellows wrote: "Centennial does appear to beckon invitingly to 'passivity, self-indulgence, purposelessness.' Yes, some students succumb, kick their feet, and scream 'sick so- 
ciety' or 'screwed system.' But many students-perhaps most students-see their own weakness, their own intellectual transgressions, and they are disgusted by them, and they grow in wisdom and justice. They demand a sympathetic understanding of their weaknesses and they demand assistance toward a new strength.... Simply stated, the truth is we ask our students to confront their personal demon. We hope that in such confrontation they will discover the internal strength which will replace the hickory stick. We do not indulge the weakness; we cause the student to be aware of it as the enemy he must conquer. To do less-to allow a student to substitute our will, our institutional will, for the development of his own intellectual drive-is to fail to meet our responsibility to him."

Nobody questions the necessity of discipline both in learning and in living. The question is, whence comes this discipline? If from outside, we remain children. Only when the rod is within us do we grow up. In Centennial we strove to turn children into adults, and it is to our credit that occasionally, even often, we succeeded. 


\section{Student Development: A Second Year Review \\ By Robert D. Brown}

An Overview

7 HIS REview of the second year of Centennial College and its impact on students parallels that of the first year. It raises some of the same questions. Chief among these is the purpose of the program. What is the relationship between intellectual and psychological development here? Progress has been made in defining goals, but these now need to be related to the methods of the program. The select nature of the student participants is a second major concern. CEP students continue to be above average even before they enter the University, and this does not appear to be a result of self-selection alone. If CEP continues to serve a rather special population, its lessons for the rest of the University will be minimized. Finally, the balance between student freedom and responsibility needs continual reexamination. The current shift toward independent study has had a negative impact on the sense of community within CEP. A number of specific suggestions are made in this report for resolving these concerns.

\section{Introduction}

The purpose of this review of the second year of the Centennial Educational Program is somewhat different from the evaluation report issued after its inaugural year (see Chapter IV). The earlier report took an omnibus look at what happened to students during the first year, commented descriptively about the Program, and high- 
lighted several issues which needed attention. This year we reexamine some of the same key issues in the context of two years of student and faculty reactions and make suggestions about where the Program might go from here.

It is not the purpose of this evaluation to describe in detail the accomplishments of all of the students in CEP, which have been many. That task can, and will be, performed best by those identified more closely with the Program, namely the Fellows. Rather, it is my hope that this review places these accomplishments in their proper perspective. The ideas presented about what decisions lie ahead or what direction the Program should take as it matures are, of course, debatable.

Last year's report served to provide a general description of the Program and a summary of what happened. This year's comments are addressed more directly to those involved intimately with the CEP. In a number of ways, it is a more personal statement. Nevertheless, because the Centennial Educational Program is an experimental program within a public institution, its development is of interest to many. Its failures and successes and its deliberations present lessons for the entire University community. For that reason this report is also a public statement.

There are three major issues or concerns which I would like to attend to in this report. First, what is the proper balance between intellectual and personal development within CEP? This issue needs to be resolved as the Program's goals are further defined and clarified. Second, how selective should the student body be in CEP? Should it depend upon self-selection, random assignment, or should its student body be representative of the rest of the University on key factors such as ability and past achievement? Finally, there is the question of the decision-making powers within the program. Should the CEP operate on the principles of a participatory democracy, much as do free schools, or should an elected group be empowered to rule? In one fashion or another, all three of these issues were raised last year and most certainly they are all highly interrelated. Discussion of these questions will make up the major portion of the report. In separate sections the living-learning environment and faculty development will be examined. Some suggestions and viewpoints will be presented in the narrative body. These and others will be summarized in a final section.

\section{Methodology}

This year's study of the Program did not involve examination of outcomes among a comparable group of students-a control group- 
as it did last year. The primary reason for this lack was the decrease in the number of new applications and the relatively select nature of the accepted applicants. It was impossible to set up a control group large enough to be statistically reliable and comparable on all pertinent variables. Thus, we cannot make comparisons between the accomplishments of CEP students and a group of regular University students equal in ability, interest, and motivation. This is a major loss. Program participants will rightfully wish to point with pride to the accomplishments of CEP students in the total University, but without a control group it is not possible to assert unequivocally that these achievements would not have occurred in another academic environment.

For those reasons it was necessary to limit the focus of the evaluation efforts on happenings within CEP itself. Students, primarily freshmen, completed a number of surveys, were interviewed, and observed in various settings. Included in this process were the American Council on Education Survey (completed by almost all University freshmen), the Adjective Check List, and a specially constructed questionnaire designed to assess level of participation and attitudes toward the Program. Faculty members completed an openended questionnaire and were interviewed.

Outcomes: The Precarious Balance Between Intellectual and Personal Development

The summary evaluation report on the first year of the CEP made pointed references to the need for continuing delineation of the objectives of the Program. At the risk of being shrill and redundant this need must be reiterated at the end of the second year of the Program. As individuals and as a group, the Fellows and a group of CEP students spent many hours throughout the second school year working on goal statements. Some very fine individual statements of goals were developed, but to my knowledge there has never been a formal adoption of a particular set of objectives nor have these goals been related to specific aspects of the Program. From an evaluator's viewpoint, Program objectives should be clearly stated, preferably in behavioral terms, before a program is begun. An evaluator's task is difficult if there is no standard or criterion by which to judge or compare a program's outcomes. Clearly stated objectives provide a formidable bulwark against slipshod, wishfulfilling and impressionistic evaluation. Nevertheless, arriving at program objectives, especially for an experimental college, can be viewed as a process, not an event, and as such can also be seen as 
developmental. The development of objectives can be concurrent with the development of the program. This can be not only a truer picture of reality, but also a more productive one. Such has been the Centennial Educational Program.

The Program started with vaguely stated objectives similar to those that might be found in the catalog of any liberal arts college. However loosely they were stated, it was still possible to sort out some broad objectives, particularly those related to attitudinal change and the establishment of the living-learning environment, which made it possible to attach some handles to the evaluation efforts made during the first year of the Program. Yet, this effort was an exercise almost exclusively of the evaluator. Suitable behaviors and attitudes were derived from implicit, rather than from explicit, statements. While a behavioral scientist may be uncomfortable with this process, if he is a realist he will be satisfied with this as a major accomplishment for the first year of a program.

During the second year the Program moved on to the next step, which was to attempt to further delineate objectives and perhaps even to modify the original ones. The Fellows engaged in a lengthy and painful process of developing position papers on goal statements. These exercises were more than that-they were intense personal attempts to arrive at a coherent statement of what higher education is about or should be about. Differences of opinion on key issues became apparent. Hassles over means sometimes interfered with efforts to arrive at consensus on purposes.

Much of the disagreement among all educators centers on how students should learn or be taught. The same could be said about the differences among members of the CEP community, Fellows and students. Nevertheless, these differences find their eventual roots in basic philosophical viewpoints on the nature of man and how he learns. The philosophical becomes psychological when it can be put to an empirical test. Many of the differences about means and constructs in CEP can be subject to that kind of test. This is what the CEP is all about.

Eventually the task of defining goals was taken on by a joint faculty-student goals committee. After several approximations the group arrived at statements that came close to defining what the CEP is operationally attempting to do. To this observer the goals as stated in this "working paper" place more emphasis on the personal-social development of students than did initial Program goal statements.

Viewed developmentally, the process in CEP seems to be on 
schedule, even if we might wish it to move more rapidly. Certainly the process has been educational for faculty and students, even if excruciatingly slow at times. There appear to be several remaining steps left in this process. First of all, some consensus has to be reached on the goal statements. This consensus should include the Fellows and the University administration, as well as the students. The critical issue for all concerned might well be the relative emphasis given personal-social and intellectual development. Both should be included, but to what degree? Intellectual development can also be compartmentalized into cognitive skills such as writing and critical analysis, and attitudinal orientation such as rational approaches to problem solving. Obviously, CEP wishes to develop both. But again the critical question is one of priority and balance. Hopefully this step, further delineation and consensus, will not be too time consuming. It is apparent, however, that the wishes of all individual participants cannot be met in such a statement.

The final step in this process is relating specific dimensions of the Program to the goal statements. This should give a coherence to the Program. Decisions and judgments could then be made with some relationship to delineated program goals, as well as to immediate problems of student morale or campus political moods. How do the day-to-day decisions fit in with the over-all goal statements? Right now these immediate decisions are sometimes made out of context, but the daily decisions definitely have an impact on the goals of the Program. These decisions loop back to change the objectives of the Program.

Suppose a group of students decides to organize and participate in an encounter group. Should these students be given academic credit under the umbrella of the CEP course? This question should be answered within the framework of stated goals of the Program. If personal-social development is a major goal, and if it is reasonable to assume that positive growth would be an outcome of such an experience, then it would seem that such an experience would be legitimate. On the other hand, if personal-social development is a goal subordinate to academic achievement, then credit might not be granted in the CEP Course. If program decisions are made arbitrarily or without consensus of all those properly involved in the decision-making process, day-to-day decisions may warp the total objectives of the Program.

A clearly stated set of goals serves a number of purposes. It can provide a framework to use in making those day-to-day decisions and it can help program planners look at questions of balance and 
omissions. It can also help all involved evaluate their efforts. Instead of just being able to say, "We did this and that well," they will be able to say, "We set out to do this and we did it well." The first statement relies solely on serendipity, the second permits both public accountability and serendipity. To accomplish this final step will take patience. Those responsible may need some outside help and consultation.

It is possible to commend the Program for where it has gone so far in this process and yet at the same time stress the importance of continued follow-up on this endeavor. Unless this process is completed, the Program runs the risk of being judged a success or failure on the basis of criteria completely unrelated to its goals. Or it might catch itself shadow boxing with its critics-countering a criticism with an unrelated accomplishment. Perhaps a more immediate danger, already felt, is the frustration that develops when we fail to understand why something did not work and have few means to discover why it did not work. Most of us in academia have lived through such situations, but with deeper wrinkles as a result.

If these steps: 1) further delineation of goals, 2) consensus agreement of participants and administrators, and 3) relating Program dimensions to Program objectives can be accomplished during the third year of the CEP, this would be a major achievement.

\section{Nature of Participants-The Question of Selectivity}

The second-year freshman CEP class, like the first, differed in significant ways from regular University students even before the school year began. Clearly, the CEP student was a unique student. On the important dimension of ability, the CEP freshmen were significantly superior as indicated by their Scholastic Aptitude Test scores. On the average they were 80 points higher than the regular University students, and 100 points higher than the applicants who were not admitted, on the Verbal scale of the Scholastic Aptitude Test (see Table 3 on p. 119). The average CEP freshman ranked in the top 19 per cent of the University freshmen on a measure of verbal skills and knowledge. The differences were less profound on mathematic competencies, but the CEP freshmen surpassed about two-thirds of the regular students.

Past academic achievement is always the best indicator of future achievement as it includes an index of motivation as well as ability. The same pattern of differences was apparent when the high school records of these students were examined. The average class rank for the CEP student was at the 83rd percentile, whereas for the non- 
selected applicant it was at the 64 th percentile, and for the regular University student at the 70 th percentile. Approximately 85 per cent of the CEP freshmen ranked in the top quarter of their high school classes compared with 60 per cent of the rest of the freshman class. About 6 per cent of the CEP freshmen had less than a B- average in high school whereas nearly 25 per cent of the non-CEP students had performed at that level in high school.

As might be expected, the CEP students were involved in a greater number of activities in high school than their NU counterparts. About half again as many were involved in music, speech, journalism, and similar ventures. The only exception was varsity athletics. Slightly fewer CEP freshmen had earned letters in varsity sports.

The CEP freshmen also tended to come from a different socioeconomic background from other students and to have distinct goals, expectations, and political views. Fewer farm kids were represented in the CEP student body, and more students had fathers who had gone to college and earned high incomes. Whereas about one-half of the other NU students intended to enter graduate school or professional school, some two-thirds of the CEP freshmen aspired higher than the B.A. Almost all of the academic majors were represented in the freshman CEP class, but engineering, physical sciences, and business fields were underrepresented; the social sciences and humanities were overrepresented.

As a group the entering CEP freshmen were significantly more liberal than their regular University counterparts. One-half classified themselves as liberal compared to less than a third of the regular University students. Thirteen per cent said they were politically conservative compared with 21 per cent of the other NU students. This liberalism was apparent in their responses to specific issues. Whether it was firearms control, school desegregation, or the Southeast Asia war, the CEP students were more likely to respond with the liberal viewpoint than were the more conservative regular University students.

Among the CEP students there were more liberal views toward education quite early in the fall term. Over 88 per cent of the CEP freshmen, for example, felt that college grades should be abolished but only half of the regular University freshmen agreed. Over half of the CEP freshmen felt that they would not be satisfied with college, but more expected to hold a student office than did regular NU students.

Two things should be very clear from this evidence. First of all, 


\section{4 / First Years of a Cluster College}

it is apparent that the CEP freshman was brighter, more liberal, and better motivated before he started college. Second, these differences cannot be attributed to self-selection alone. The evidence suggests that a sizeable proportion of the CEP applicants for last year had ability and motivation profiles similar to those of other NU freshmen. Some of these students may not have been selected because they did not want to take the math or language part of the Program, but if this did dramatically affect the profile, the program planners should duly note this and resist further references to the student participants as "representative" or "typical" of NU freshmen. They were not.

This concern raises basic philosophical questions about the purpose of CEP. If the Program skims off the top cream of the freshman class, its lessons will have little relevance for the rest of the University. David $P$. Campbell speaks to this point in a recent issue of American Psychologist.

The irony is that this [selective admissions] is usually done in the name of academic nobility and intellectual challenge. What is so noble about surrounding yourself with appealing students who are already so motivated that they have been straight A students all of their lives? And what is so challenging about picking students who already hold many of the same viewpoints as the faculty? I call that fun-and as a matter of fact, one of the most closely guarded secrets of academic admissions policies is that most of these policies are little more than formal methods to surround the faculty with people they feel comfortable with. ${ }^{1}$

Though the selection of students has been a subject of continued debate within the college since last year's review raised the issue, I am concerned that it is still not regarded seriously enough. A new admissions policy has been announced for the third year's class, but it remains a question as to how it will be implemented.

What alternatives remain? The Program can continue to serve the exceptional Nebraska student, providing this student with an enriching educational experience that will hopefully keep him interested in learning. A conscious effort to go in this direction would accentuate, but not dramatically change, the profile CEP now has. Or the Program could go the middle route of randomly selecting from its applicants. The differences then would be attributable to self-selection alone. Depending upon publicity and public relations, the student profile would more closely approximate that of the regular NU freshman class. Another course would be to consciously

${ }^{1}$ David P. Campbell, "Admissions Policies: Side Effects and Their Implications," American Psychologist, 26 (July, 1971), 646. 
decide to replicate the $\mathrm{NU}$ freshman class in miniature through a process of random stratified sampling and/or publicity that would attract a broader spectrum of students.

I would strongly recommend the last course if the Program is to have relevance for the rest of NU's undergraduates and fulfill its full potential and be more than a showcase. This is the tough, hard direction to go. Right now the Fellows are finding it difficult enough to motivate the relatively highly motivated. It will be even more of a strain to motivate the less interested. But the rewards are greater.

Given the characteristics of the CEP freshmen upon entrance, development psychologists would predict that in almost any collegiate environment the students would attain the level of achievement and type of accomplishments that they did. The Program might well become an enclave of students who are liberal, bright, and upper-middle-class. That this situation is arising is apparent from the comments of one freshman, "I am leaving the Program this year. I had a good year, but I can't say I was satisfied. I got the impression that if a person wasn't one of the Commons Room group he tended to be somewhat isolated. There just wasn't any place for the conservative, average student in CEP." My bias is clearly to ask what we can accomplish with the typical student, not the exceptional.

\section{LIVING ENVIRONMENT}

\section{Student-Student Relationships}

The informal relationships among students in the established casual atmosphere of CEP remained for the second year one of its most successful accomplishments. The CEP and the Commons Room became a new home for students. The impact was probably felt most by freshmen who viewed the setting in marked contrast to life in other residence halls. Being part of a special entity augments identification, closeness, and a sense of pride, even if it is partially derived from a feeling of exclusiveness.

Despite this relatively positive picture, it is my impression that the pervasiveness of the warmth associated with being part of a grand venture deteriorated somewhat from the first year. Two ready but incomplete explanations are: first, the novelty was gone for the returning students, and second, the College had increased in size, not dramatically, but a numerical increase had taken place. Counter to these arguments is the fact that though the experience was old hat for the upperclassmen there was still the fresh input of 
eager and new freshmen. The numerical increase in enrollment was balanced by the increased number of commuters; the number of live-in students remained fairly constant.

When asked to compare the current year with the previous year, many upperclassmen mentioned the lessening in the community spirit and the increasing number of cliques. They complained of there being less group spirit, less closeness as an academic community, and less excitement. Over a third complained of being hemmed in.

All of the reasons given thus far and others may have been causal factors in this diminishing sense of community. A major component in my mind was the changing focus of the program from group to independent work. Apparently the shift was perceptible enough to have an impact on the community spirit within the College. Poor communication within the College about what other people were doing was also a frequent complaint. Isolates were more in abundance. While half of the students said the Commons Room was their favorite gathering place, a third indicated that they hardly ever spent time there. Instead of moving toward programming that would get the isolate out of his or her room, the move toward independent study and the fewer public presentations of projects made it possible for the isolate to remain one. I am suggesting that there were students spending lonely hours in their rooms when they would really like to have been somewhere else with people.

Despite this lessened community spirit, a phenomena one perhaps would have to expect during the second year of any new program, the CEP remained a uniquely close knit community, unmatched on campus outside of the Greek system. Almost 90 per cent of the upperclassmen indicated that they had helped a freshman with some academic work and two-thirds of the freshmen reported being helped by an upperclassman. Nearly all of the students admitted that they had shared a problem or concern with another CEP student this semester. Rivalries among students were reportedly rare.

Neither did the CEP experience isolate students from the rest of the University or their peers in the larger community. During the second semester over two-thirds of the freshmen dated someone outside of CEP and over 90 per cent met a new student outside CEP and ate at least one meal with a student from outside CEP.

Student Reaction to the Fellows and General Morale

The pattern of student-Fellow interactions did not vary significantly from that of the first year of the Program. Students had more 
personal contact with their Fellows than any comparable group of students had with other faculty members. Over half said they had talked to a Fellow about a personal problem and some 85 per cent had visited about a particular issue or just chatted casually with a Fellow. Over 80 per cent felt they could talk to a Fellow confidentially if they so desired and slightly more felt they could call at least one Fellow a "friend."

If anything, however, the craving for more personal contact with the Fellows was more shrill and demanding than it was during the first year of the Program. Over three-fourths indicated they would like to get to know the Fellows better and almost half offered a chorus of unsolicited recommendations regarding Fellows' "moving out of their offices," "being around more in the evenings," and "trying to relate more to the students."

The Fellows' minimal involvement in the evenings led a sizeable number of students to perceive the faculty as unaware of some of the happenings in CEP and some student concerns. A third felt that there were major problems within CEP that the Fellows did not know about and half of the freshmen and two-thirds of the upperclassmen admitted that the Fellows were often criticized by students.

On the whole, student-faculty relationships within CEP must be characterized as excellent. All but a very few students were satisfied with the channels that were open to them for expressing complaints. The student concern for more contact should not be ignored, however. How a student felt about the Program and how fully he participated were highly correlated with the degree of his contact with the Fellows. An unhappy experience with a Fellow was enough to cause a student to wash himself out of the Program.

The over-all morale of the students in regard to both the living and the learning aspects of the Program was quite high. Ninety per cent felt that they had "really learned" something and more felt they had gained some knowledge they did not have before. Three-fourths felt they had grown as persons in a fashion they could attribute directly to CEP. The evidence gained last year, in a more direct approach, lends credence to this self-reported change. However, the students were not uncritical. At least half did not feel they could recommend the Program for all freshmen, and only 10 per cent indicated they were completely satisfied with the Program. Always a key indicator of satisfaction is returning rate. Over 85 per cent of the CEP students indicated they would like to return, if everything else were equal. 
The faculty, in my mind, needs to get more involved with the after dark life of CEP. This may mean scheduling some class meetings in the evening and it should mean joint meetings with student assistants.

\section{LEARNING ENVIRONMENT}

Academic Program

Efforts to put more rigor into the Centennial Course itself appear to have met with modest and variable success. Students were requested to meet bi-weekly with their advisers and to loosely contract for their current group or independent study projects. However, contingencies were unclear and loosely administered. Undoubtedly individual students worked masterfully on some group and independent study projects. As the Program is now structured, the bright and sometimes even the not-so-bright student is permitted to pursue topics he might never have tried without such an opportunity. However, these same students might not have done as well taking an independent study course from one or two professors in the regular University. Over-all quality control remained poor despite efforts to establish deadlines and minimal accountability procedures. As yet the academic program has not reached that precarious balance between freedom of choice, love of learning, and academic accountability.

Student reactions reflect this imbalance. Some students resented the required bi-weekly meeting with their Fellow advisers. To some it seemed perfunctory, to others it represented a vestige of authoritarianism, and to others it did not lead to a profitable learning experience. It is obvious that for many the division between teacher and student roles was never surmounted. For those who were able to work through this division-because of a predisposition or because of particularly satisfactory relationships with their Fellowsthe experience was rewarding and clearly had a profound impact upon both their intellectual and personal development.

When looking at others, less than a third of the freshmen felt that most CEP students worked pretty hard on their projects. Slightly more than half personally found most projects a real intellectual challenge, but less than a fifth felt they were pushed to the limit by work on a CEP project. Almost all indicated they had learned something from their CEP experience, but three-fourths were irritated at themselves or others who did not work hard. Forty per cent admitted to some apprehension about the value of what 
they learned compared with what they might have gained from conventional courses.

These data are subject to various interpretations. Mine are that the students were generally satisfied with the freedom they had in choosing projects and topics. Some believed they had profited as much by their failures as by their successes. Still others, with perhaps inordinately high expectations, were disappointed with themselves and the Program. Some felt the need to be pushed.

Several issues concerning projects over the past two years have evolved. They have tended to be discussed in terms of black and white alternatives: groups or independent study, required papers or no required papers, public presentations or no public presentations, more structure or less structure. The discussions have been much oversimplified and rhetorical. Many of the issues were resolved on the basis of which option provided for more student freedom rather than which made more academic sense.

Actually student opinion on the issue of groups vs. independent study was fairly evenly divided, the critical factor being the effectiveness and worth of previous group experiences. Factors most influential in determining the value of a group enterprise included: 1) clearly defined goals for the group, 2) regular meetings, 3) some clear responsibility for leadership, be it in students or Fellow, 4) little domination by one person-Fellow or student, 5) a group of workable size, and 6) sincere interest and commitment of all participants. Interestingly enough, criticisms of independent projects focused on clearly related concerns-lack of direction and organization.

The question of group and/or independent study needs further examination because it interacts with the whole purpose and being of Centennial. As I indicated last year and what was more true this year, the Program has moved toward more independent study. While this has some justification educationally and philosophically (if one supports the notion of supporting student choice), it also has profound implications that I would frankly view as negative. This movement toward independent study needs to be consciously thought through before group work is abandoned or downplayed. Let me elaborate my concern.

College professors are traditionally lecturers and supervisors of independent research. They prepare lectures and respond to questions. They also, on the basis of their own experience, advise students in one-to-one situations about readings and research. Group processes are not an important or necessary skill in either teaching 
situation. The small group projects in CEP represent different situations entirely. First of all, the faculty member may not have much expertise on the topic. For another, he may have had some experience in leading a discussion, but very little in situations that involve group decision-making. Questions about what is read next, what type of paper should be written, or how the labors are divided are usually made unilaterally. Outcomes are primarily papers written individually by students, not presentations that may involve process decisions.

Examine for a moment the criticism of group projects in CEP. Fifty per cent of the students said they were not satisfied with the functioning of groups of which they had been members. Less than half said the groups were well organized and one-fourth indicated their groups never really got going. One-fifth of the freshmen said they did not speak up in their group. A fourth felt the Fellow dominated the discussion too much and half thought some students dominated too much. These are commentaries on group process. Best liked and most profitable projects included those in which the opposite was true-as spelled out earlier.

I would suggest that the response should not be to have fewer groups or to place greater emphasis on independent study, but to work on group processes more. This would mean training faculty, students, leaders, and eventually the students themselves in task oriented group processes. This could very well be one of the first projects or it could be attended to throughout the year. With outside consultants helping, faculty and students could attend to group functioning as they work on projects, papers, or other creative enterprises.

An issue here is again the one of freedom and coercion. Should a student be required to be a member of a group? My answer would be yes, at various times during his stay in CEP a student should be involved in a group project, perhaps in various roles ranging from observer, to participant, to leader.

Lack of sufficient communication about projects within the College and the lack of a central theme also played roles in lessening student cohesiveness and intellectual give and take. Fragmentation into smaller clusters of students-cliques-occurred partially as a result of more independent study and less emphasis on groups, lack of communication about projects, and minimizing of a central theme. Repeated student complaints focused on the paucity of knowledge about what other students were doing. They could of course find out, but they lacked the special initiative necessary. 
Public presentations in as many forms as possible seem highly recommended. Some very effective musical, dramatic, and artistic presentations were part of the CEP program this past year. More of these might become group enterprises.

The idea of a central theme such as The Nature of Change or The Nature of Values has also received diminishing attention as the first two years of the Program have been completed. There were relatively few, if any, instances during the second year when all CEP students were tackling the same topic from different vantage points. Again, the issue seemed to be one of student freedom. Forcing all students to think about one issue would be an infringement on that freedom. Of course, the real question is one of balance. A program devoted entirely to independent study would be neither efficient nor innovative. Not only are some of both necessary in a program, but I would say that some of both are necessary for every student's full development.

\section{Characteristics of Highly Involved CEP Students}

One special focus of this year's evaluation effort was to take a closer look at the active and inactive CEP student. Are there differences in their ability levels, past achievements, or personality characteristics? What are the correlates of a high degree of involvement? The answers to these questions might well lead to suggestions for alternative ways of getting more students involved. In order to make it possible to examine these questions freshmen were asked to indicate the extent of their participation in the Program and the Fellows were asked to indicate the extent to which they felt that each student had grown academically and personally during the year. Analyses of the data suggest the following descriptions of the High Participator, the Highly Satisfied, and the Highly Ranked Students (those rated highly by the faculty). In most instances, the low participators, the less satisfied, and less highly ranked were the converse of their counterparts.

The student's own picture of his level of involvement with the Program correlated significantly with a number of other dimensions of his relationship with CEP and with some key personality characteristics. Generally speaking, high participation level (regularly attending Town Hall meetings and floating seminars, talking to Fellows, speaking up in groups, etc.) coincides with the student's feeling positive about the Program and satisfied with the functioning of groups within CEP. One of the most important findings was that participation level and contact with Fellows went hand-in-hand. 
The actively involved student had more contact with the Fellows in varying relationships than did the less active student. This student also tended to be more positive in looking at himself and other people. He tended to be more spontaneous and more restless than low participators.

\section{The Highly Satisfied}

The picture of the highly satisfied varies in a number of significant ways from that of the faculty rated high-growth person. In contrast to the faculty favorites the highly satisfied student sees himself as better adjusted and as much more interested in people, less self-centered and less negative. Students who felt most positive about the CEP tended to be those who were active participants, had frequent contact with Fellows and felt a part of the "in" group in the college. Personality characteristics of the highly satisfied paralleled those who were highly rated by the faculty. As might be expected, they were in many cases the same students. The satisfied student was fairly obliging, tactful, competitive, and persistent.

\section{The Highly Rated}

Students rated high by faculty, and students rated low, differed significantly in ability and past achievement. Those rated high by the faculty were superior in ability and past achievement. Their SAT scores and their high school ranks were higher. The high-rated group also had a significantly higher GPA for the current year than did the low-rated student group. In general, the faculty was not able to discriminate between academic and personal growth and the resulting ratings were highly correlated and thus clearly interrelated. Whatever the causal factor might be, it does appear that the faculty tended to see greater growth among the brighter and the high achievers than among other students. Students who were intelligent, hard-working, persistent, and dependable were rated high by the faculty as having grown academically and personally. The highly rated student was also likely to be fairly competitive, assertive, independent, and somewhat self-centered. In certain respects this same student was less socially active, being less affliative, warm, and outgoing. We have here, it appears, the more bookish student, but one who was fairly assertive and self-confident.

Further analysis and discussion of the findings should suggest a number of implications for the program. 


\section{Group Problem Solving Tactics ${ }^{2}$}

One of the early goals of CEP was to enhance problem-solving and analytic skills associated with critical thinking. Last year a test of critical thinking yielded no differences between GEP students and a group of equally bright regular University students. A modest attempt was made this year to assess the group problem-solving talents of CEP students. The results were incomplete, but provide helpful suggestions if the Program wishes to continue group projects and problem solving skills. The assessment tactic employed holds promise for other similar evaluation enterprises.

Two of a planned series of three or four group interview sessions were held with students who had previously been ranked on the basis of their faculty ratings of academic growth and program involvement. One group consisted of students rated high by the faculty, one group was made up of students, half of whom were rated high and half who were not. A planned third group of students, relatively unknown to the faculty, did not meet.

The task given to the group was to evaluate CEP. The students were given a four-point agenda relating to describing an ideal livinglearning community, matching up CEP with this ideal and making suggestions for improving CEP. Suggestions were to be made in writing; a piece of paper was provided. A forty-five minute time limit was announced. The sessions were tape recorded and four observers categorized student statements. It was apparent, from both the directions and the procedures established, that group process was being observed as well as content.

The students' verbal responses were categorized by the observers into five categories: 1) responsive-entailing a simple response to another member of the group, 2) conventional-these included casual and general noncommittal observations, 3) assertive-relatively vigorous expressions and expectations of being understood, 4) speculative-a posing of ideas as hypotheses requiring further work or confirmation, and 5) confrontive-a form of challenge to others or to the environment. The target of the communication, to whom it was directed, was also recorded.

On the basis of theories of group process and previous research three possible outcomes were predicted. If a group has been functioning in an environment which values group participation in problem solving, we would expect the conversation to be highly speculative and confrontative. There would be little effort needed

\footnotetext{
${ }^{2}$ This study was designed and carried out jointly with Ezra Kohn, Assistant
} Professor, Graduate School of Social Work. 
to establish a working relationship, and the members should feel free and comfortable in group interaction, getting right to the task. If, on the other hand, the group is composed of people who are accustomed to living in a group environment but not engaging in group problem-solving behavior, we would predict their conversation to be more responsive and assertive. There would be a sharing of ideas, but no real confrontation with the issues. If the group is not accustomed to a group environment or to group problem solving, their conversation would be responsive and conventional because of discomfort in the group setting. There would also be variations in the target of their conversation.

\section{Results}

Neither of the groups engaged in group problem-solving activity. Their pattern of responses matched those of groups who live together, but do not solve problems together, more than those of groups who do both. It is interesting that despite directions to respond as a group with suggestions, each group member reached for paper and individually submitted suggestions. While this pattern held for both groups, the high participators showed a greater inclination to share efforts, while the low participators were more concerned with individual and personal concerns. The failure of the planned third group of low participators to convene speaks for itself.

\section{Limitations}

The incompleteness of the study and the relatively small sample taken must make the interpretations applicable for the groups studied but only tentatively suggestive of what may apply to other students in CEP. Nevertheless, the results and the technique seem important. The results suggest that not only does the CEP environment not reinforce a group problem-solving set, but it may in fact be encouraging individual responsiveness to the exclusion of group responsiveness. Again, the program planners must consider balance between the two.

\section{Fellows and Change}

Some efforts were made to assess what the impact of the experience of being a Fellow had on a faculty member and what the implications are for the future of the Program and the rest of the University. Because a number of Fellows were leaving CEP after two years, including the Senior Fellow, this appeared to be an 
opportune time to gather their reactions. Each Fellow completed an open-ended questionnaire and most were interviewed.

How have their views about education been affected? Several themes recur. All admit to being influenced by their experience, though some suggest that the influence was more dramatic than others. The amount of change is undoubtedly related to their starting points. One of the shifts appears to have been in the relative importance of the personal-social development of students. Most all would still give primary allegiance to the importance of cognitive development but the non-cognitive looms more prominently now, some suggesting that the one cannot occur without the other. Attitudes and values have become more important.

Some have lost faith in sole reliance on student interest and "self-motivation" as the basis on which to establish a program. Several refer to the need for a framework, a set of expectancies, or guidelines. Hopefully, learning would still start from where the student's desire and interests are, and coercion is still anathema. But freedom without accountability is unworkable, according to the Fellows.

That students learn by doing is the most frequent theme of how the Fellows now look on the learning process. Books and lectures are seen as having definite limitation-the tools of learning, but not the meat. An individualized personalized approach is also important.

Most of the Fellows believe they will teach differently when they return to a regular classroom. The responses are as varied as the Fellows, but again recurring themes such as individualizing instruction, being a facilitator, and placing more emphasis on process than content are discernible. Less lecturing and more student involvement in deciding what is to be taught are tactics that suggested themselves to the Fellows. It was clear that most had a new confidence and determination to try new approaches in their classrooms. Some of the part-time Fellows already have. As one stated, "I am less afraid of failure." This observer has the impression that the Fellows came away from CEP with no bag of teaching tricks but rather with renewed optimism and a revitalized vigor to attempt new techniques with their students. They have acquired or further developed new attitudes towards teaching and students rather than skills.

All felt their experience in CEP has direct relevance to the rest of the University. The two most recurring themes were student housing and curriculum requirements. To them it seemed possible that housing could be humanized at the same time that it was modified for academic purposes. The coed lounge and student 
involvement in decisions relating to housing regulations succeeded in creating a living environment that the Fellows felt was one of the most successful achievements of the Program.

Greater flexibility in the general education requirements of the University also received strong support from the Fellows. On the whole anything that would make the teacher-student relationship closer or improve teaching were seen as high priority among the Fellows. According to the Fellows, teachers should be less concerned with coverage of material and more with students' learning the skills of critical analysis.

These assessments might well be checked in another year or two as the Fellows return to regular classrooms. Are they able to change their teaching tactics in their classrooms? Are they satisfied with changes occurring within their departments? Within the University? Will they find that this new experimental attitude holds up in the classroom with more typical students?

The role of the Fellow within CEP is still evolving. As noted earlier, the Fellows have succeeded in large measure to personalize the educational experience within CEP. More have become aware of the demands that students can make on their time. They recognized this year more than last the need for faculty-adult models to be around CEP in the evenings. But they question who and how. The student cry for more evening contacts was loud and clear this year and was acknowledged by the Fellows but resulted in little noticeable behavioral change. On the whole the Fellows were little involved with the residential aspect of CEP. For a few, there was little desire to be involved.

Few had time to pursue professional or scholarly interests during their years with the Program but few would trade the two-year experience they had with CEP. It is very clear that for many this was a rejuvenating experience. Time will give a truer picture of the full impact.

\section{Program Suggestions}

As this report parallels last year's review, so does the following list of suggestions. The CEP responded to each of last year's concerns with a sincere attempt at resolution, but many of the same issues remain. The suggestions this year are more specific and for that reason more debatable. They may be interpreted as contrary to the emphasis on the freedom of choice and independent study which has tended to become a more pervasive part of CEP. They are not, though they would necessitate establishing limits. The 
intention is to establish a balance rather than a refocus. For that reason, Program participants and those responsible for decisions related to CEP should thoughtfully consider these proposals, work up alternatives, and rationally decide among them.

\section{Objectives}

The following steps should be worked on during the third year of the Program.

A. Further efforts should be made to delineate the objectives of the Program with special attention given to priorities among the goals.

B. Efforts should be made to have the goal statements accepted by those responsible for the decision-making regarding CEP.

C. Program planners should relate specific dimensions of the Program to the objectives.

II. Admissions and Student Body Mix

A. A selection process should be established which guarantees a CEP student profile closely approximating that of the other NU freshmen on ability and achievement measures.

B. Once selection procedures have been established they should be handled by the Dean of Student Academic Services.

\section{Academic Program}

A. One feature of the program should be a central theme for the year or a semester. This theme should be broad enough to include many different approaches and subtopics, but should also be specific enough so that topics, speakers, and programs can be logically related to it.

B. All students should be required each semester to work with at least one group studying a project related to the central theme.

C. Provisions should be made for student involvement in a balanced program of group and independent study. The pattern might be something like this:

1. First semester freshmen would be involved in two groups. One would be working on a topic related to the central theme of the year. The format should be fairly structured at the beginning. The other group would focus on group process: How do groups function, what facilitates group productivity, cooperation, and decision-making? 
2. Second semester freshmen would continue to work in groups on a topic related to the central theme. Perhaps, however, the emphasis might be on the esthetic with groups given special encouragement to write plays, to construct mobiles, and to express themselves in ways other than writing.

D. A select number of mini-courses should be offered which would focus on skill development, e.g., writing skills.

E. Upperclassmen should be encouraged to lead groups themselves. A special seminar experience might be arranged for these students to help facilitate reading, thinking, and practicing the art of working with groups.

F. The program should consider the possibility and the implications of all of a student's course work being on a pass/fail basis, even courses taken in the regular University. This would require approval from various faculty bodies.

G. Everyone in the CEP program should take the CEP credit for grades or $\mathrm{P} / \mathrm{F}$. The current option provides too much opportunity for game-playing among students and Fellows, something the CEP is striving to avoid.

H. CEP course and group offerings should be scheduled for the evening as well as day times.

I. Fellows might consider having students contract for projects with clearcut contingencies being established.

$\mathrm{J}$. Because in one way or another group decision-making and group efforts will probably remain a vital part of the CEP experience, the faculty and key students should be given special training in small group processes.

$\mathrm{K}$. The nature of the Fellows' involvement in the program needs rethinking. Preliminary analysis of data on the characteristics of students who are quite involved in the program and highly satisfied suggests that they are people who are in frequent contact with the Fellows. This contact is not limited to the academic. If a student's intellectual and personal development cannot be separated, then the Fellows can be most effective as change agents if they are involved in both. To accomplish this, these changes should be considered.

1. Put faculty offices on residence hall floors.

2. Schedule classes, group meetings at varying hours-evening, night, daytime. 
3. Have each Fellow stay overnight at least one night a month.

IV. Evaluation and Consultation

A. Evaluation efforts should be continued and expanded.

B. Evaluation should be in regular and smaller doses than has been provided. Monthly feedback sessions would be helpful. Perhaps a subcommittee of the Advisory Board could serve this role to some degree. However, a full-time or at the minimum a half-time evaluator-consultant would be more appropriate. The task is time consuming, necessary, and in the long run rewarding.

TABLE 3

Scholastic Aptitude Test Scores of Rejected Centennial Applicants, Centennial. Freshimen, and Regular University Students

\begin{tabular}{|c|c|c|c|}
\hline & $\begin{array}{c}\text { Rejected CEP } \\
\text { Applicants } \\
\mathrm{N}=150\end{array}$ & $\begin{array}{c}\text { Accepted CEP } \\
\text { Applicants } \\
N=110\end{array}$ & $\begin{array}{c}\text { Regular University } \\
\text { Freshmen } \\
\mathrm{N}=4630\end{array}$ \\
\hline \multicolumn{4}{|l|}{ SAT-Verbal } \\
\hline Mean & 450 & 560 & 475 \\
\hline Standard deviation & 95 & 95 & 95 \\
\hline $\begin{array}{l}\text { Percent surpassing } \\
\text { regular NU freshmen }\end{array}$ & $40 \%$ & $81 \%$ & \\
\hline \multicolumn{4}{|l|}{ SAT-Math } \\
\hline Mean & 501 & 557 & 520 \\
\hline Standard deviation & 110 & 109 & 98 \\
\hline $\begin{array}{l}\text { Percent surpassing } \\
\text { regular NU freshmen }\end{array}$ & $43 \%$ & $63 \%$ & \\
\hline \multicolumn{4}{|l|}{ High school rank } \\
\hline Mean & 64 & 83 & 70 \\
\hline Standard deviation & 22 & 15 & 24 \\
\hline $\begin{array}{l}\text { Percent surpassing } \\
\text { regular NU freshmen }\end{array}$ & $40 \%$ & $80 \%$ & \\
\hline
\end{tabular}




\title{
VII. Warnings, Encouragements, Recommendations
}

By Robert E. Knoll

Robert D. Brown

\begin{abstract}
FTER MORE than three years with a cluster college, we have A come to conclusions which might be of value to persons 1 concerned with innovating educational ventures. Our judgments, and the evidence on which the judgments are based, cannot be calibrated-cannot, as they say, be quantified-but some truth is independent of numbers. We can expect modifications by our successors in the Centennial Educational Program, but at present we hold these opinions:

1. Any innovating educational venture needs to have a single, clearly stated purpose, a purpose that somehow makes it unique from other campus endeavors. Its uniqueness can be social-all its students may be taken up with international society and thus form an International House; or political-all its students may be Socialists or Ayn Rand revisionists; or scholarly-all its students could be prospective teachers or archeologists or painters. The program can be built around learning methods; for example, its students might be involved totally in programmed learning, or they may be engaged in research so independent that they have no teachers at all. Or the innovation could be curricular; all its students could undertake interdisciplinary study of the city or foreign trade. No program can be all things to all people. If the innovating program attempts to experiment with subject matter, teaching method, and living arrangements simultaneously, the consequences can be con-
\end{abstract}


fusing and the innovation self-defeating. Where the innovation has several facets-a pedagogical experiment might involve certain dormitory rearrangements and thus social adjustments-the relationship of these facets to one another must be clearly stated.

2. Before setting forth, the innovators need to decide how they will measure success, both of individual students and of their program in general. If they involve students in curricular or pedagogical experimentation, they should be able to grade their accomplishments. They should be able to determine how much and what each of their students learned as compared to conventional students. If they are concerned with method-"process not product"-a different sort of judgment might be called for; letter grades may not be appropriate. If the innovations are primarily in group living, interpersonal relationships, and the like, yet a different measure will be called for. In all cases a student's accomplishments will need to be judged and communicated; and the standards of judgment should be explicit. A clearly stated method of measuring and recording success should be an early order of business in any innovating program.

3. The faculty must agree on the purposes for which they have come together, and they must agree on the criteria by which accomplishment is to be measured. If some are primarily committed to assisting students "find themselves," and others are concerned with helping students develop intellectual interests, and yet others want to experiment with group living, the results can be chaotic. Each faculty person must play his part in a common venture. We think it a mistake to assume that faculty people can be persuaded to a common view after they become involved in a program. As a committee of the whole, they need to work out means not ends. They should not hesitate to call on campus experts for advice. Specialists in psychology, administration, and subject matter can often bring order out of temporary chaos.

For the faculty, interdisciplinary study offers several particular difficulties. Since professors become restless when they are remote from their professional interests, they must not attempt to be all things to all men. Rather, they should explore the relationship of their professional interests to other disciplines, but they should not stray so far from their own bailiwicks as to lose their expertise. They should be encouraged to try out new areas, within their expertise; and we have found they often do their best, fresh work there. They and the students explore together, as it were. We have found too that teachers often become restless when they move too quickly from 
the pattern of teaching to which they have been long accustomed. If they are used to lecturing, they should be weaned slowly to tutorials; and if they are accustomed to seminars, they may not find one-to-one confrontations easy. In short, as much effort must be spent on plans for the faculty as is spent on plans for the students; and the more experienced the faculty, the more elaborate the planning will need to be. From the beginning, regularly scheduled pedagogical discussions are necessary.

4. The kind of students involved in the program-their intelligence, their aspirations, and their interests-will have as much influence on the nature of the program as the faculty and the planning. Once the students make application and appear, the faculty needs to consult with them. The faculty must get their honest responses. The program will have unanticipated kinks, and students can help materially in ironing them out. Flexibility at this juncture may not guarantee success, but rigidity portends failure. If the goals of the program have been made clear, their proposed changes will deal more with means than ends. If the goals have not been clear to them, their reactions to crises can warp the program.

5. The relationship of faculty to students needs careful assessment before any program gets far underway. Our students are not less interested in their teachers and not less willing to respect them than they have ever been, but we found that they see us in a new way. We appear to them now as human beings, not primarily as professors of chemistry and anthropology. We are examined as much for our total attitudes as for our professional competence. One of our colleagues has recently written, "I don't think what a teacher professes can be easily separated from what he is as a human being. Nor do I believe it should be. The teacher either shows unity to his students or he shows hypocrisy." Our skeptical students are quick to perceive our falseness and they know when we withhold a part of ourselves.

It seems to us that students search for wisdom, and they expect us to be searching too. They come asking, not for an explanation of the second law of thermodynamics or Skinner's theories of behaviorism, primarily; they want us to help them find their way through their lives and this world. They seem to feel that our learning should be not so much of something as for something. No professor should get involved in a cluster college-or any other contemporary educational venture, so far as that is concerned-unless he is willing to expose his moral and political and social assumptions as well as his professional knowledge and skills. Students are cannibals of 
course; they will absorb as much of our time and life as they can reach, and we must learn to protect ourselves from them. But their very cannibalism is evidence of their need.

In spite of their protests, the students continue to see us in locus parentis; but now they want to dictate the kind of parents we are to be. They resist us as father-figures, fathers who hold them to high standards, who criticize their failures and demand achievement. Rather, they want us to be indulgent mothers who embrace them no matter what. They want to be loved, not led. Often they can only be coaxed into learning. The teacher who persists in indulging their softness refuses to help them grow. But the teacher who holds them uncompromisingly to what they feel are arbitrary academic standards turns them off and sends them fleeing from the intellectual life. A teacher in an innovating program must find a relationship which allows him to discipline them academically even as he concerns himself with their total being.

6. A cluster college must be more than a dormitory arrangement. It needs to have a center of shared intellectual experience which can provide a legitimate basis for academic community. This common core of subject matter or theme needs to be general enough to allow for individual interests, but it must have defined limits and its study must have structure. Without an intellectual heart, a cluster college is only a fraternity. In order to exploit the subject matter, students need to be set in study groups. Without these groups, the community is likely to disappear into a collection of anonymous individuals. Though we have found no magic size for a cluster college, we think that a total of more than four hundred will present disruptive problems. Any number can play, however, if the rules are carefully laid out and the faculty are sufficiently aware of their opportunities.

7. The physical facilities are of some importance. The cluster college needs to be close to the parent university. The students profit most from the cluster college when they are also involved in the greater community. They should not have to make a choice between the large and the small; both should be available. The cluster college should be conceived of as a neighborhood, self contained perhaps, within a larger urban-like totality, both requiring attention and devotion.

In adapting dormitories to wider use, university architects, especially students of architecture, should be consulted. The relationship of bedrooms to commons rooms, to dining rooms, to conference rooms influences the nature of community, and students perceive 
possibilities and needs out of their own immediate experience. Institutional style should be avoided, and space where students can be alone with books and thoughts must be protected. The contemporary relaxation of dormitory rules and hours makes this private space especially necessary.

8. The initial planning should provide for a student government through which students may order their own activities. Total participatory democracy is not likely to work, however disposed the students may be toward it. The areas within which the students have responsibility should be clearly set forth, and the faculty needs to be in close agreement concerning these limits.

9. A valuable resource pool is often available among the students themselves. If a sense of community is vital to the venture, and we have found it so for our cluster college, then it makes sense to look within that community for talent. Does a wall need painting, a desk fixed, a poem written? No doubt there is someone nearby aching to be asked to help. Upperclassmen can be helpful in exploiting these resources. Students who have tutored or assisted in classrooms affirm the truism that they learned best when they taught. They learn not only subject matter, but much about themselves and individual interaction as well.

10. In any innovative program faculty and students are likely to find themselves in great fluctuations of temper and enthusiasm. Euphoria is followed closely by something like despair, and for periods everybody is likely to feel confused. We are convinced that this fluctuation is no cause for alarm. Without it the excitement of the new venture would be lost, and the mediocrity of the great world would descend. One must remember that results are not likely to be available quickly, that failure and success can only be gauged years after the fact. As in society generally, the key is faith. 


\section{Appendix}

The following persons composed the staff of the Centennial Educational Program, 1969-1971:

Henry Ablin (Part-time Fellow 1969-1971) teaches courses in electronics and systems and has been an influential participant in interdepartmental study in the College of Engineering. $\mathrm{He}$ was in large part responsible for the development of the CEP math program and is deeply concerned about the understanding of the nature of science and engineering. He has received the University's Distinguished Teaching Award. (Associate Professor of Electrical Engineering)

T. E. Beck, JR. (Fellow 1969-1971, Senior Fellow 1971-) was educated at Princeton University, the Virginia Theological Seminary, and Columbia. He has twice been honored by undergraduates as a Distinguished Teacher. Trained both in literary history and religion, he has a particular interest in the relation of the Classical tradition to the European Renaissance, but a year in CEP reawakened his earlier, broader interests. (Assistant Professor of English)

Robert D. Brown (1969-1971), Associate Director of the Counseling Center and Coordinator of Research in Student Affairs, has had extensive evaluation experience at the University. He acted as Resident Evaluator in Centennial from the beginning and helped establish both principles of operation and definition of goals. (Professor of Educational Psychology)

SAlly Gordon (Executive Secretary 1969-) is a Nebraskan with notable experience in the Statehouse and at the University. She is the CEP's effective ambassador and counselor. 
Thomas Helms (Part-time Fellow 1969-1970) is an entomologist in the College of Agriculture. A native of Arkansas, he has only recently joined the University's staff; but he has already earned a reputation among students for the breadth of his interests. He is particularly concerned with methods of teaching science to nonscientists. (Associate Professor of Entomology)

Edward Homze (Part-time Fellow 1969-1971), educated in Ohio and Pennsylvania, is a student of modern German history. In addition his professional interests include undergraduate teaching and good writing of all kinds. Other interests include people watching, photography, travel, and good conversation. Recently he and his wife saw the publication of their first joint book, a study of contemporary Germany: Germany: A Divided Nation. (Associate Professor of History)

Richard Johnston (Part-time Fellow 1969-1970, Fellow 19701971) is an anthropologist who has specialized in American Indian archeology. Since his graduate student days at Indiana University, he has had a diverse career including museum and government service with the Smithsonian Institution and numerous excavation projects in the United States and Canada. (Visiting Professor of Anthropology)

Theodore Jorgensen, JR. (Part-time Fellow 1969-1971) obtained his degrees from the University of Nebraska and Harvard. He was a member of the Manhattan Project and helped test the first atomic bomb at Alamagordo. After the war he established the Accelerator Laboratory Research Project at the University. Some years ago he received the University's Distinguished Teaching Award, and he has been instrumental in effecting several changes in the physics curriculum. Widely known as an expert in Chinese cooking, he lives in a house designed by himself and built largely with his own hands. (Professor of Physics)

Patricia Knaub (Part-time Fellow 1970-) was raised and educated in Nebraska. With her graduate work in human development and the family and in educational psychology, she has taught nursery school, high school, and adult education. Now at the University, she was elected to appear in the 1970 Outstanding Educators of America. Her interests include her family, teaching and working with people, skiing, and the adventure of travel. (Instructor in Human Development and the Family)

Robert E. KNoll (Senior Fellow 1968-1971) was educated at the University of Nebraska, Yale, and the University of Minnesota. 
Committed to the undergraduate experience in higher education, he has received the Nebraska Foundation Distinguished Teaching Award, and has been a Woods Fellow in England and a Fulbright Lecturer in Austria. A widely published scholar, he combines interests in the Renaissance, especially Shakespeare, and twentieth century America. He has an amateur's interest in painting and music. (Professor of English)

ScotT MoRgan (Fellow 1970-) received specialized training in graduate work at Princeton in Shakespeare and Renaissance poetics. From an undergraduate major in philosophy (Haverford College) comes a continued interest in how people hold their values. This interest is now maintained in studies of educational theory. In the CEP, he is further investigating specific interests in the detailed study of literary style, modes of characterization, and sensitivity groups. (Assistant Professor of English)

Jerry Petr (Fellow 1969-1971) is an economist by training (at Cornell and Indiana University), and an educator by choice. Well known for his educational imagination, he has been honored by students as a Distinguished Teacher. His professional interest is the impact of economic systems upon the human condition; he extends his concern into his private life through active political involvement. (Assistant Professor of Economics)

Nancy Ryan (1969-1971) was Resident Graduate Assistant. After extended service on the Working Committee before opening day, she acted as liaison between faculty and student and worked to combine the living and learning experience of the students. A graduate of Emmanuel College, Boston, she is a Ph.D. candidate in American literature. (NDEA Fellow, Department of English)

Phillip Scribner (Fellow 1969-1970) was educated at the University of Colorado and the Johns Hopkins University. A professional philosopher with interests in the philosophy of science and in political philosophy, he is also a participant in community politics and an adviser to undergraduate groups. He is well known for his rapport with University students. (Assistant Professor of Philosophy)

Paul Wilson (Part-time Fellow 1970-1971) is particularly interested in historical and philosophical approaches to mathematics; he helped develop studies of this kind in Centennial. He received training in advanced algebra at the University of Cincinnati and at Illinois. (Assistant Professor of Mathematics) 